\title{
Regulation of soil-surface respiration in a grazed pasture in New Zealand
}

\author{
A thesis \\ submitted in partial fulfillment \\ of the requirements for the \\ Degree of Master of Science
}

at

Lincoln University

by

Mathew Brown

Lincoln University

2006 


\section{Abstract}

The work in this thesis investigated the regulation of soil-surface respiration $\left(R_{\mathrm{s}}\right)$ in a grazed pasture, located near Oxford, Canterbury, New Zealand. An environmentally controlled laboratory exercise was conducted to investigate how soil temperature $\left(T_{\mathrm{s}}\right)$ and root-zone volumetric water content $(\theta)$ interacted to regulate $R_{\mathrm{s}}$. These data were used to develop a model that described $R_{\mathrm{s}}$ as a function of $T_{\mathrm{s}}$ and normalised $\theta\left(\theta_{n}\right)$. Chamber measurements of $R_{\mathrm{s}}$, carried out in the field approximately twice a month throughout the 2005 - 2006 growing season, were used to validate the $R_{\mathrm{s}}$ model.

A closed gas exchange system was used to measure the individual exchange rates of ecosystem respiration $\left(R_{\mathrm{e}}\right)$ and $R_{\mathrm{s}}$, in order to gain knowledge of the contribution of $R_{\mathrm{s}}$ to $R_{\mathrm{e}}$ in this system. This knowledge was used to partition eddy covariance nighttime measurements of $R_{\mathrm{e}}$ into $R_{\mathrm{s}}$ and above-ground autotrophic respiration ( $\left.R_{\mathrm{aa}}\right)$. Eddy covariance soil-surface respiration $\left(R_{\mathrm{SE}}\right)$ measurements were compared to modelled estimates of $R_{\mathrm{s}}$. Finally, the model of $R_{\mathrm{s}}$ and continuous field measurements of $T_{\mathrm{s}}$ and $\theta$, were used to estimate total growing season $R_{\mathrm{s}}$ at the field site.

The laboratory exercise revealed that the influence of $T_{\mathrm{s}}$ on $R_{\mathrm{s}}$ was best described using an Arrhenius-type function, while the influence of $\theta_{\mathrm{n}}$ on $R_{\mathrm{s}}$ was expressed with a linear function. The model determined that when $\theta_{\mathrm{n}}>0.90, R_{\mathrm{s}}$ remained constant. In the field, $R_{\mathrm{s}}$ measured with a respiration chamber, was strongly influenced by $T_{s}$, which ranged from a low of $12.2^{\circ} \mathrm{C}$ to a high $20.1^{\circ} \mathrm{C}$ throughout the measurement period. Values of $\theta_{\mathrm{n}}$ at the field site, ranged from 1.00 to 0.59 , but were generally $>0.90$, and as such, rarely limited $R_{\mathrm{s}}$. Maximum and minimum rates of $R_{\mathrm{s}}$ in the field were 11 and $6 \mu \mathrm{mol} \mathrm{CO}_{2} \mathrm{~m}^{-2} \mathrm{~s}^{-1}$ respectively. The field soil-surface respiration rate, normalised to $10^{\circ} \mathrm{C}\left(R_{10}\right)$ was $4.7 \mu \mathrm{mol} \mathrm{m} \mathrm{m}^{-2} \mathrm{~s}^{-1}$. The model developed in the laboratory exercise was able to explain half $\left(r^{2}=0.52, P<0.05\right)$ of the variability observed in the field $R_{\mathrm{s}}$ measurements. 
The partitioning exercise revealed that $R_{\mathrm{e}}$ was comprised of $84 \% R_{\mathrm{s}}$ and $16 \%$ $R_{\mathrm{aa}}$. There was a significant relationship between the contribution of $R_{\mathrm{s}}$ to $R_{\mathrm{e}}$ and leaf area index $(L)$.

There were 62 nights of valid eddy covariance $R_{\mathrm{e}}$ data from the field site. Maximum and minimum nightly averaged $R_{\mathrm{e}}$ were 12 and $2 \mu \mathrm{mol} \mathrm{m} \mathrm{m}^{-2} \mathrm{~s}^{-1}$, repetitively. Eddy covariance soil-surface respiration $\left(R_{\mathrm{sE}}\right)$ was determined by multiplying nocturnal eddy covariance $R_{e}$ measurements by the fraction 0.84 , as determined in the partitioning exercise. The eddy covariance soil-surface respiration measurements were generally lower than modelled $R_{\mathrm{s}}$ estimates. For nights of valid eddy covariance data, the model total $R_{\mathrm{S}}\left(44 \mathrm{~mol} \mathrm{CO}_{2} \mathrm{~m}^{-2}\right)$, was $57 \%$ greater than the total $R_{\mathrm{SE}}\left(28 \mathrm{~mol} \mathrm{~m}^{-2}\right)$. Total growing season $R_{\mathrm{s}}$, as estimated by the chamber based model was $162 \mathrm{~mol} \mathrm{~m}^{-2}\left(1.94 \mathrm{~kg} \mathrm{C} \mathrm{m}^{-2}\right)$.

This study has shown that $R_{\mathrm{s}}$ in this temperate grazed pasture is a function of both $T_{\mathrm{s}}$ and $\theta_{\mathrm{n}}$, however, during the measurement period, $\theta_{\mathrm{n}}$ rarely reached low enough levels to limit $R_{\mathrm{s}}$.

Keywords: Carbon dioxide, carbon cycle, soil-surface respiration, pasture 


\section{Acknowledgements}

First, I would like to express my gratitude and thanks to my supervisor, David Whitehead of Landcare Research, for his enthusiastic support and friendship throughout this thesis. Throughout this entire year, he provided encouragement, sound advice, and lots of good ideas. Also at Landcare Research, I would also like to thank John Hunt, for all of his technical assistance and helpful discussions throughout the year, as well as Greg Arnold and Troy Baisden for their extensive help with the modelling. Special thanks are also due to Tony McSeveny and Graeme Rogers who contributed to this project in many ways, from making sure the growth cabinets behaved, to providing valuable biomass data, and an endless supply of cookies.

I would also like to thank my Lincoln University supervisors Tim Clough and Rob Sherlock for their friendship and extremely helpful comments, especially during the thesis-writing stage.

I would like to thank Landcare Research for providing facilities and Lincoln University for providing a Graduate Research Scholarship.

Finally, I would like to thank Wan Tzu and my family for their support and allowing me to bum around in New Zealand for a year. 


\section{Table of Contents}

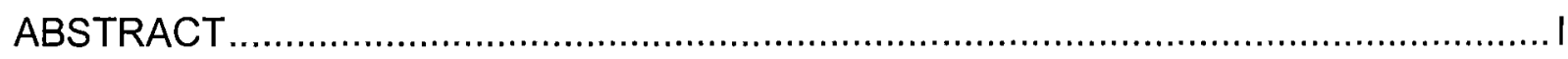

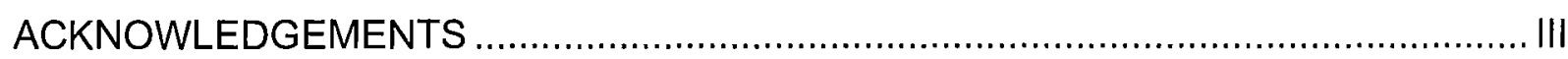

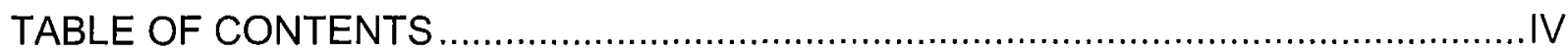

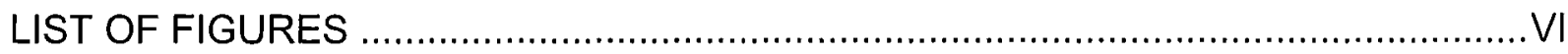

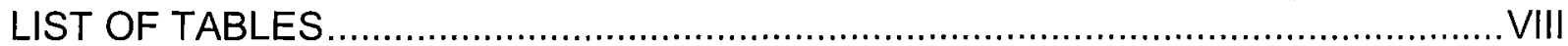

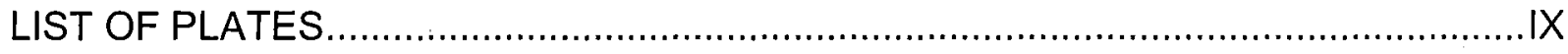

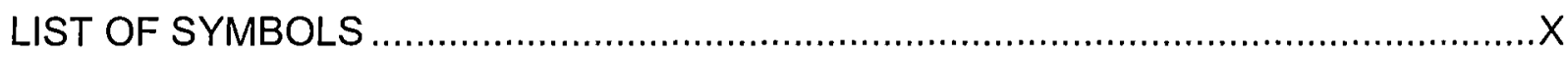

1 INTRODUCTION .......................................................................

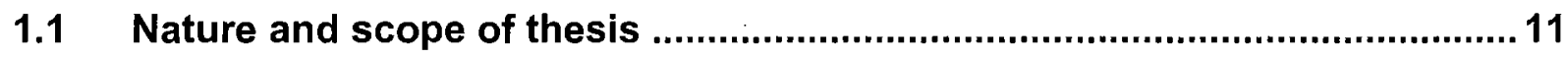

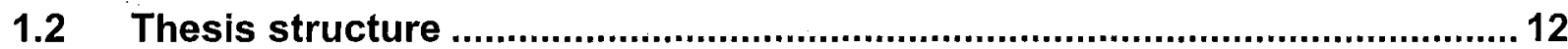

2 SOIL TEMPERATURE AND ROOT-ZONE WATER CONTENT REGULATION OF SOIL-SURFACE RESPIRATION IN A NEW ZEALAND

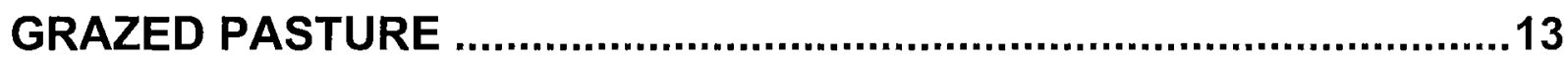

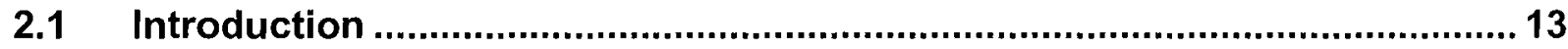

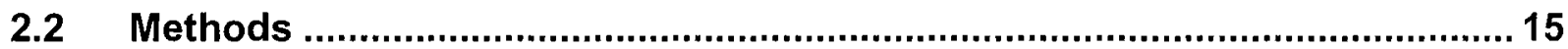

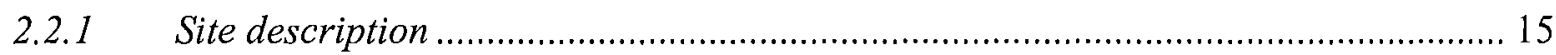

2.2.2 Soil-surface respiration measurements made in the field ....................................... 16

2.2.3 Laboratory measurements of soil-surface respiration ……...................................... 17

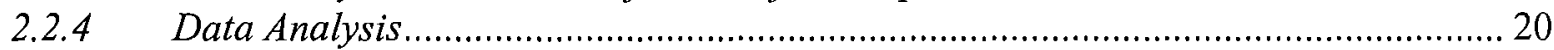

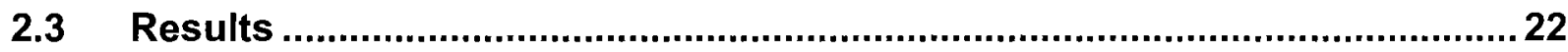

2.3.1 Laboratory measurements of soil-surface respiration ........................................... 22

2.3.2 Modelling of laboratory measurements ............................................................ 24

2.3.3 Field measurements of soil-surface respiration ................................................... 25

2.3.4 Modelling soil-surface respiration in the field ....................................................... 26

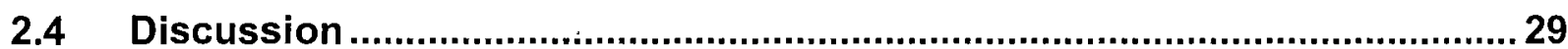

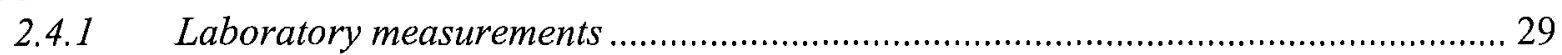

2.4.2 Field measurements of soil-surface respiration ........................................................ 29

2.4.3 Comparison of modelled and measured soil-surface respiration in the field ........... 30

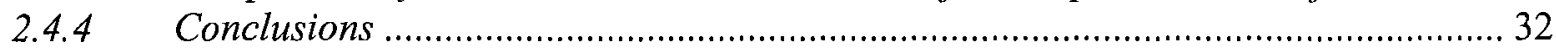




\section{MEASUREMENT AND MODELLING OF SOIL-SURFACE RESPIRATION FROM A GRAZED TEMPERATE PASTURE DURING THE

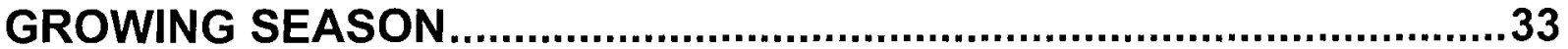

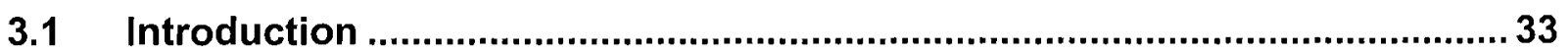

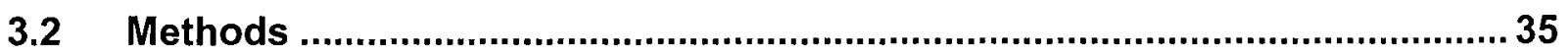

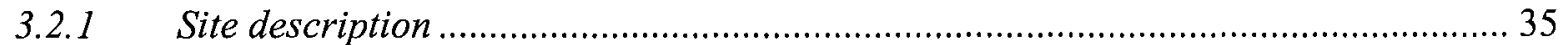

3.2.2 Determining the contribution of soil-surface respiration to ecosystem respiration . 36

3.2.3 Eddy covariance ecosystem respiration measurements .......................................... 38

3.2.4 Measurements of root-zone water content and soil temperature .............................. 40

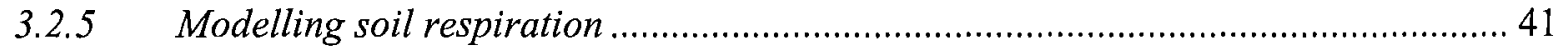

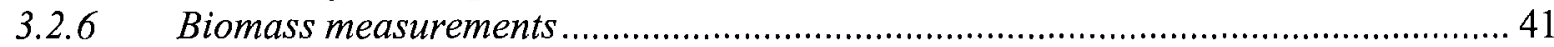

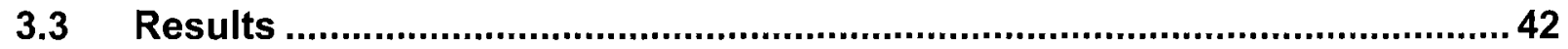

3.3.1 Determination of the contribution of soil-surface respiration to ecosystem

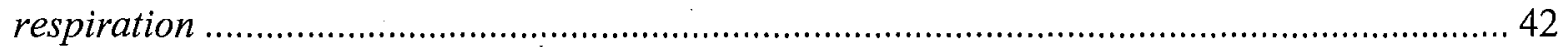

3.3.2 . Eddy covariance nighttime respiration measurements ........................................... 44

3.3.3 Modelling soil-surface respiration measurements .................................................. 47

3.3.4 Estimating total growing season soil-surface respiration at the field site ................ 50

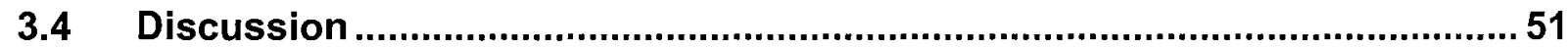

3.4.1 Partitioning sources of respiration …………...................................................... 51

3.4.2 Measured and modelled soil-surface respiration ……......................................... 52

3.4.3 Estimating total growing season soil-surface respiration......................................... 53

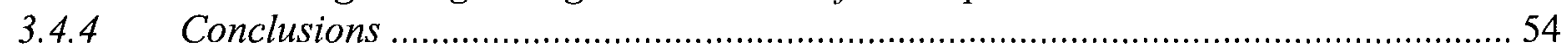

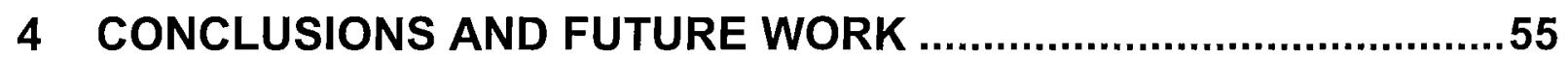

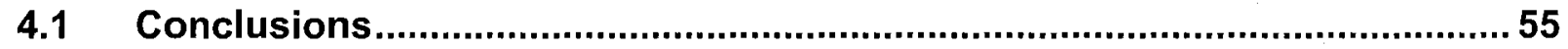

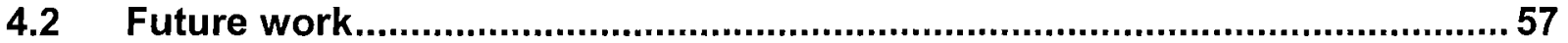

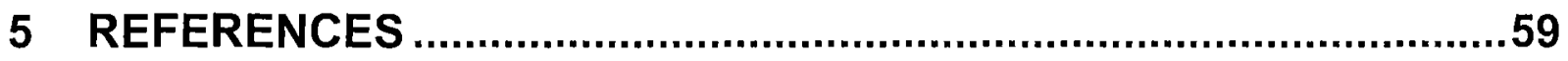

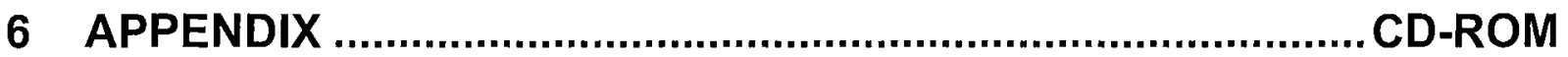




\section{List of Figures}

Figure 1-1 The biogeochemical carbon (C) cycle in simplified form. Shown are the $C$ reservoirs $(\mathrm{PgC})$ and the annual fluxes of $\mathrm{C}\left(\mathrm{PgC} y r^{-1}\right)$ between these reservoirs. $R_{\mathrm{e}}$ is ecosystem respiration and GPP is gross primary productivity. The terrestrial biosphere is shown to be currently acting as a $\mathrm{C}$ sink. An annual atmospheric $\mathrm{CO}_{2}$ concentration increase of approximately $3.2 \mathrm{Pg} \mathrm{C}$ is observed (Grace 2004) ........................................

Figure 1-2 Carbon (C) exchange between the Earth's terrestrial biosphere and the atmosphere in simplified form. Shown are the $\mathrm{C}$ reservoirs $(\mathrm{Pg} \mathrm{C})$ and the annual fluxes of $\mathrm{C}$ between these reservoirs $\left(P g C \mathrm{yr}^{-1}\right)$. $R_{\mathrm{aa}}$ is aboveground autotrophic-respiration, $R_{\mathrm{ab}}$ is below-ground autotrophic respiration, $R_{\mathrm{h}}$ is heterotrophic respiration and GPP is gross primary productivity (Houghton 2003).

Figure 1-3 The net change in terrestrial carbon (C) storage (including changes in land-use) (thick grey line), the flux of $\mathrm{C}$ from changes in land-use (black line), and the difference between the net flux and the flux from change in land-use (thin grey line). Positive values indicate a terrestrial $\mathrm{C}$ source and negative values indicate a terrestrial C sink. From: Houghton (2003) pp.485.

Figure 2-1 Laboratory measurements of $R_{\mathrm{s}}$ (soil-surface respiration) of all soil cores in relation to soil temperature at a depth of $50 \mathrm{~mm}$, at six different classes of $\theta_{\mathrm{n}}$ (normalised root-zone water content) (numbers in brackets represent the range of $\theta_{n}$ in each class). The line is fitted using the model (equations

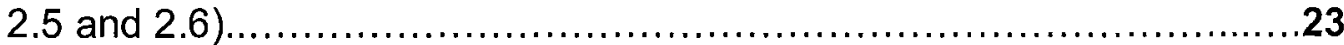

Figure 2-2 Soil-surface respiration normalised to $10^{\circ} \mathrm{C}\left(R_{10}\right)$ and $\theta_{n}$ (normalised rootzone volumetric water content) when $\theta_{\mathrm{n}}$ is $<0.90\left(\theta_{\mathrm{c}}\right) . R_{10}$ values are normalised to the maximum $R_{10}$ value. $R_{10}$ values were determined by fitting equation 2.5 to respiration measurements in $\theta_{n}$ classes of $0.80-$ $0.90,0.70-0.79,0.60-0.69,0.50-0.59,0.40-0.49,0.30-0.39$ and $<0.30$, in each of the thirteen soil cores. $r^{2}=0.84 ; y=0.1141+0.9891^{*} x$

Figure 2-3 (a) Field measurements of soil temperature at $50 \mathrm{~mm}$ (square points connected with solid line) and $\theta_{\mathrm{n}}$ (normalised root-zone water content) (diamond points connected with dashed line) and, (b) $R_{\mathrm{s}}$ (soil-surface respiration) measurements from September 2005 to March 2006. Individual points represent averages of measurements made at 24 collars and bars represent standard errors 
Figure 2-4 (a) Field measured soil-surface respiration $\left(R_{s}\right)$ (dashed line, $n=24$ ) and modelled soil-surface respiration $\left(R_{\mathrm{s}}\right)$ (solid line) throughout the year and standard error bars. Modelled values are slightly offset measured values of $R_{\mathrm{s}}$ to avoid overlap. (b) Field measured and modelled rates of soil-surface respiration $\left(R_{\mathrm{s}}\right) r^{2}=0.52 ; P<0.05$. Dashed line represents the line of unity. The concordance correlation coefficient was 0.66 , indicating agreement

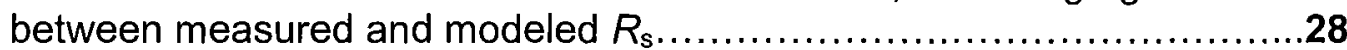

Figure 3-1 The relationship between the ratio of $R_{\mathrm{s}}$ to $R_{\mathrm{e}}$ and leaf area index $(L)$ for each of the nine replicates in the $\mathrm{CO}_{2}$ exchange partitioning exercise. $r^{2}=$ $0.557 ; y=0.672+0.051^{*} x$

Figure 3-2 Field site soil temperature $\left(T_{\mathrm{s}}\right)$ (solid line) at $50 \mathrm{~mm}$ depth and normalised root-zone water content $\left(\theta_{n}\right)$ (dashed line) over the measurement period.

Figure 3-3 Ecosystem respiration $\left(R_{\mathrm{e}}\right)$ (solid line) and eddy covariance soil-surface respiration $\left(R_{\mathrm{SE}}\right)$ (dashed line) over the measurement period. $R_{\mathrm{SE}}$ was calculated by multiplying $R_{\mathrm{e}}$ by the fraction 0.84 , as determined in the partitioning exercise.

Figure 3-4 Eddy covariance estimates of soil-surface respiration $\left(R_{\mathrm{SE}}\right)$ normalised to $10^{\circ} \mathrm{C}$ and total above-ground live biomass. $R_{10}$ values are averages of acceptable nights of $R_{\mathrm{SE}}$ data occurring within a week of biomass measurements (providing cattle were not grazing within that week). Biomass measurements represent the average of twenty replicate measurements. Bars show the standard errors on both axes

Figure 3-5 Eddy covariance soil-surface respiration $\left(R_{\mathrm{SE}}\right)$ (solid line) and modelled soil-surface respiration $\left(R_{\mathrm{s}}\right)$ (dashed line). $r^{2}=0.1481$

Figure 3-6 Growing season soil temperature $\left({ }^{\circ} \mathrm{C}\right)$ at $50 \mathrm{~mm}$ (dashed line) and modelled soil-surface respiration (black line) on the left axis, and normalised root-zone water content $\left(\theta_{n}\right)$ (dotted line) on the right axis. The gap in the data from days $259-268$ is due to equipment malfunction.......50 


\section{List of Tables}

Table 2-1 Fitted parameters ( \pm standard errors) derived from the soil-surface respiration model. $R_{10}$ is the soil-surface respiration rate at $10^{\circ} \mathrm{C}$. $E_{\mathrm{o}}$ is related to the energy of activation, and $\theta_{c}$ is the threshold point at which a further increase in normalised root-zone water content no longer has an influence on soil-surface respiration.

Table 3-1 Leaf and soil temperatures, and normalised root-zone water content (0$300 \mathrm{~mm}$ ) during the days of the partitioning experiment

Table 3-2 Direct measurements of NEE (net ecosystem exchange), $R_{\mathrm{e}}$ (ecosystem respiration) $R_{\mathrm{s}}$ (soil-surface respiration with the grass clipped to $20 \mathrm{~mm}$ ) and $R_{\mathrm{SG}}$ (soil-surface respiration with the grass clipped to soil surface) and the contribution of $R_{\mathrm{s}}$ to $R_{\mathrm{e}}, R_{\mathrm{aa}}$ to $R_{\mathrm{e}}$, and $R_{\mathrm{sG}}$ to $R_{\mathrm{e}}$, and standard errors (SE). $n=10$

Table 3-3 Fitted parameters for the chamber based soil-surface respiration model as determined in chapter 2. $E_{0}$ is related to the energy of activation, $\theta_{c}$ is the point at which root-zone water content no longer influences respiration. The $R_{10}$ value comes from direct soil-surface respiration measurements made in the field at $10^{\circ} \mathrm{C}$ with a closed chamber.

Table 3-4 Total eddy covariance soil-surface respiration $\left(R_{\mathrm{SE}}\right)$ and estimates using the chamber based model of $R_{\mathrm{s}}$ for the 58 nights of valid measurements,

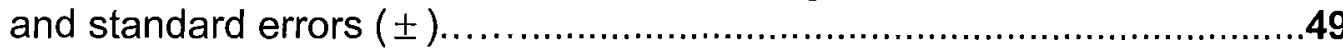




\section{List of Plates}

Plate 2-1 Study site during the growing season measurement period...............16

Plate 2-2 One of thirteen soil cores used in laboratory study being dug out of the pasture.

Plate 3-1 System used to measure net ecosystem exchange (section 3.2.2). The dome $\mathrm{CO}_{2}$ exchange chamber can be seen on top of soil collar previously inserted $20 \mathrm{~mm}$ into the ground. A battery powering the infrared gasanalyser can be seen on the right of the picture.

Plate 3-2 Eddy covariance system used to measure $\mathrm{CO}_{2}$ exchange. The sonic anemometer can be seen attached to the top of the tower. The gas analyser is located inside the temperature controlled box. 


\section{List of Symbols}

$E_{0} \quad$ related to the energy of activation

GPP gross primary productivity

$L \quad$ leaf area index

NEE net ecosystem exchange $N E E=G P P-R_{\mathrm{e}}$

NPP net primary productivity $N P P=G P P-R_{\mathrm{a}}$

$R_{\mathrm{a}} \quad$ autotrophic respiration

$R_{\text {aa }} \quad$ above-ground autotrophic respiration

$R_{\mathrm{ab}} \quad$ below-ground autotrophic respiration

$\theta \quad$ root-zone volumetric water content

$\theta_{\max } \quad$ maximum value of $\theta_{\mathrm{n}}$

$\theta_{\mathrm{n}} \quad$ normalised root-zone volumetric water content $\theta_{\mathrm{n}}=\theta / \theta_{\max }$

$\theta_{\mathrm{c}} \quad$ value of $\theta_{\mathrm{n}}$ above which $\theta_{\mathrm{n}}$ no longer influences $R_{\mathrm{s}}$
$R_{\mathrm{e}}$

ecosystem respiration

$R_{\mathrm{e}}=R_{\mathrm{aa}}+R_{\mathrm{ab}}+R_{\mathrm{h}}$

$R_{\mathrm{e}}=R_{\mathrm{aa}}+R_{\mathrm{s}}$

$R_{\mathrm{h}} \quad$ heterotrophic respiration

$R_{\mathrm{S}} \quad$ soil-surface respiration $R_{\mathrm{s}}=R_{\mathrm{ab}}+R_{\mathrm{h}}$

$R_{\mathrm{SE}} \quad$ eddy covariance soilsurface respiration

$R_{\mathrm{SG}} \quad$ soil-surface respiration with the grass clipped to the soil-surface

$R_{10} \quad$ rate of respiration at $10^{\circ} \mathrm{C}$

$T_{\mathrm{s}}$

soil temperature 


\section{Introduction}

Humans have significantly perturbed the global carbon (C) cycle through the combustion of fossil fuels and the clearing of forests. These activities have transferred $\mathrm{C}$ from terrestrial storage on Earth, to the Earth's atmosphere mainly in the form of carbon dioxide $\left(\mathrm{CO}_{2}\right)$. As a consequence, atmospheric concentrations of $\mathrm{CO}_{2}$ have increased from pre-industrial levels of approximately $280 \mu \mathrm{mol} \mathrm{mol}^{-1}$ to current levels of approximately $380 \mu \mathrm{mol} \mathrm{mol}^{-1}$ (Kennedy and Hanson 2006).

There is now a scientific consensus that the increases in concentrations of atmospheric $\mathrm{CO}_{2}$ and other greenhouse gases are leading to a warming of the Earth's average surface temperature, which if continued unchecked could lead to profound and likely irreversible climate changes, such as increases in extreme weather and sea level rise (Houghton 2004).

Over the past century, the mean global surface temperature has increased by more than $0.5^{\circ} \mathrm{C}$ (Houghton 2004). Under 'business-as-usual' conditions, with fossil fuel $\mathrm{CO}_{2}$ emissions continuing to increase, global surface temperatures are expected to continue to rise by $2-3^{\circ} \mathrm{C}$ by 2100 (Hansen 2005). According to recent studies (Hansen 2005; Overpeck et al. 2006), the Earth's past history suggests that a warming of $2-3^{\circ} \mathrm{C}$ would lead to increased melting of ice from the Greenland ice sheet and ice sheets in west Antarctica and a portion of the ice sheet in east Antarctica, raising the sea level by up to 25 meters (Hansen 2005). Despite this risk, global fossil fuel emissions continue to climb at $1-1.5 \%$ per year (Houghton et al. 2001).

In the global $\mathrm{C}$ cycle there are four major reservoirs: the atmosphere, the oceans, terrestrial systems, and fossil fuels (Fig.1-1), and C may be transferred between reservoirs in seconds (e.g., the photosynthetic fixation of atmospheric $\mathrm{CO}_{2}$ by plants) or over millennia (e.g., the accumulation of fossil C) (Houghton 2003). The largest $C$ flux occurs through ecosystem photosynthesis, known as gross primary productivity (GPP), where plants convert atmospheric $\mathrm{CO}_{2}$ into organic substances which make up plant tissues. Annually, GPP is approximately $120 \mathrm{Pg} \mathrm{C}$. About half $(60 \mathrm{Pg} \mathrm{C})$ of the $\mathrm{CO}_{2}$ 
taken in during photosynthesis is used in plant fixation and the other half $(60 \mathrm{Pg} \mathrm{C})$ is respired by the plant leaves, stems and roots to provide energy that supports growth and maintenance (Chapin et al. 2002). This respiration from plants is referred to as autotrophic respiration $\left(R_{a}\right)$. Net primary production (NPP) is the rate of photosynthesis in excess of $R_{a}$ (Jacobson et al. 2000), such that

$N P P=G P P-R_{\mathrm{a}}$

Autotrophic respiration, which occurs in the presence of light and nocturnally, can be sub-divided into above-ground autotrophic respiration $\left(R_{\mathrm{aa}}\right)$, which originates from plant leaves and stems, and below-ground autotrophic respiration $\left(R_{\mathrm{ab}}\right)$, that originates from plant roots.

Heterotrophic respiration $\left(R_{\mathrm{h}}\right)$ occurs in the soil as a result of the microbial decomposition of soil organic matter (Davidson and Janssens 2006). Total ecosystem respiration $\left(R_{e}\right)$ can thus be defined as,

$R_{\mathrm{e}}=R_{\mathrm{aa}}+R_{\mathrm{ab}}+R_{\mathrm{h}}$

Annually global $R_{\mathrm{e}}$ is estimated to be $117 \mathrm{Pg} \mathrm{C}$, of which $R_{\mathrm{aa}}$ and $R_{\mathrm{ab}}$ together contribute $60 \mathrm{Pg} \mathrm{C}$ and $R_{\mathrm{h}}$ contributes approximately $58 \mathrm{Pg} \mathrm{C}$ (Fig. 1-2), although the relative contributions of $R_{\mathrm{aa}}, R_{\mathrm{ab}}$, and $R_{\mathrm{h}}$ to $R_{\mathrm{e}}$ vary in space and time (Houghton 2003). For instance, Chambers et al. (2004) estimated that in a tropical forest ecosystem, the average annual contribution of $R_{\mathrm{aa}}, R_{\mathrm{ab}}$, and $R_{\mathrm{h}}$ to $R_{\mathrm{e}}$ were 52,19 and $29 \%$. In a tropical savanna ecosystem in northern Australia, Chen et al. (2003) reported that $R_{\mathrm{aa}}, R_{\mathrm{ab}}, R_{\mathrm{h}}$ contributed 16,42 and $42 \%$ to total $R_{\mathrm{e}}$ respectively.

Respiration is measured using respiration cuvettes and chambers, and the eddy covariance technique. Leaf cuvettes are placed over above-ground vegetation, and provide a direct measurement of $R_{\mathrm{aa}}$. Soil-surface respiration chambers, placed on a vegetation free soil-surface, can be used to measure the combined respiration of $R_{\mathrm{ab}}$ and $R_{\mathrm{h}}$. Since photosynthesis is exclusive to daylight hours, nocturnal measurements by eddy covariance systems, instrumented on towers above an ecosystem, can also 
provide a direct measurement of total $R_{\mathrm{e}}$. The techniques for measuring respiration are discussed in greater detail in sections 2.2 and 3.2.

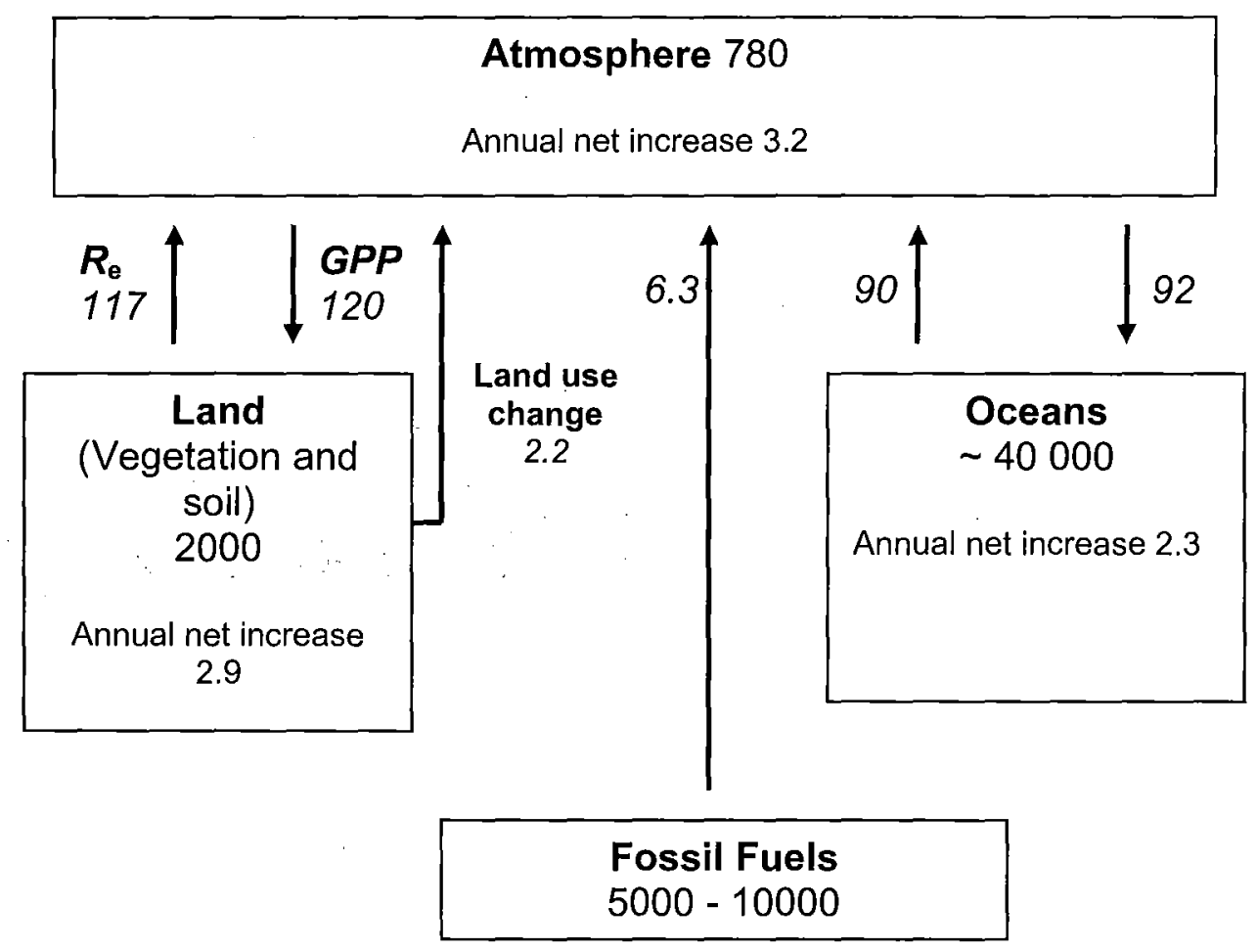

Figure 1-1 The biogeochemical carbon (C) cycle in simplified form. Shown are the $\mathrm{C}$ reservoirs $(\mathrm{PgC})$ and the annual fluxes of $\mathrm{C}\left(\mathrm{PgC} y \mathrm{r}^{-1}\right)$ between these reservoirs. $R_{\mathrm{e}}$ is ecosystem respiration and GPP is gross primary productivity. The terrestrial biosphere is shown to be currently acting as a $C$ sink. An annual atmospheric $\mathrm{CO}_{2}$ concentration increase of approximately 3.2 $\mathrm{PgC}$ is observed (Grace 2004). 
It follows that net ecosystem exchange (NEE) is the whole ecosystem GPP minus total $R_{\mathrm{e}}$, with NEE reflecting the annual budget balance of ecosystem $\mathrm{C}$ storage or loss (Chen et al. 2003).

$N E E=G P P-R_{\mathrm{e}}$

Scientific inventories of the global $\mathrm{C}$ cycle have recognised an imbalance in the amount of anthropogenically produced $\mathrm{C}$ emissions and the rise in atmospheric $\mathrm{CO}_{2}$. 'C sinks', which have been identified primarily as oceanic and terrestrial, are absorbing roughly half of the anthropogenic $\mathrm{CO}_{2}$ emissions (White et al. 2000; Powlson 2005) (Fig. 1-1). Consequently, the biosphere as a whole is absorbing more $\mathrm{CO}_{2}$ through photosynthesis than it is respiring, resulting in a substantial terrestrial $\mathrm{C}$ sink (Fig.1-3). 


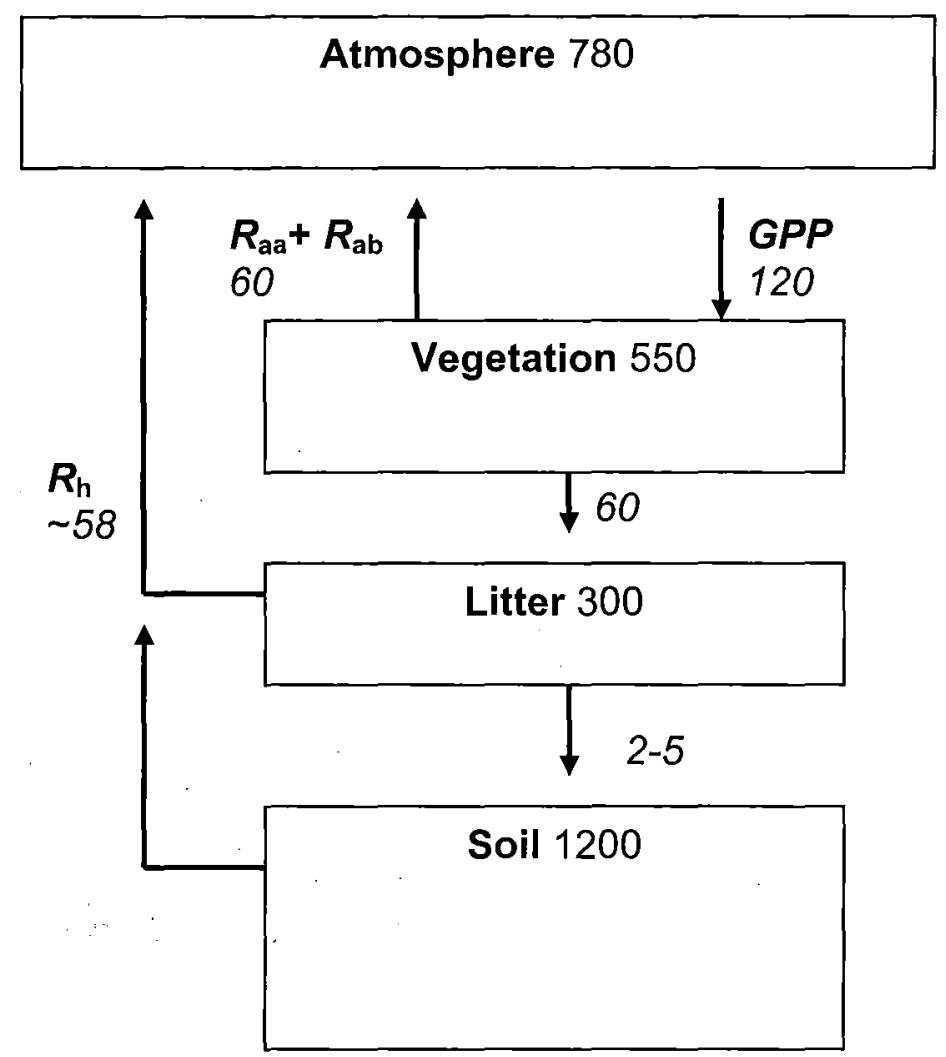

Figure 1-2 Carbon $(C)$ exchange between the Earth's terrestrial biosphere and the atmosphere in simplified form. Shown are the $\mathrm{C}$ reservoirs $(\mathrm{PgC})$ and the annual fluxes of $\mathrm{C}$ between these reservoirs $\left(P g C y r^{-1}\right)$. $R_{\text {aa }}$ is above-ground autotrophicrespiration, $R_{\mathrm{ab}}$ is below-ground autotrophic respiration, $R_{\mathrm{h}}$ is heterotrophic respiration and GPP is gross primary productivity (Houghton 2003). 


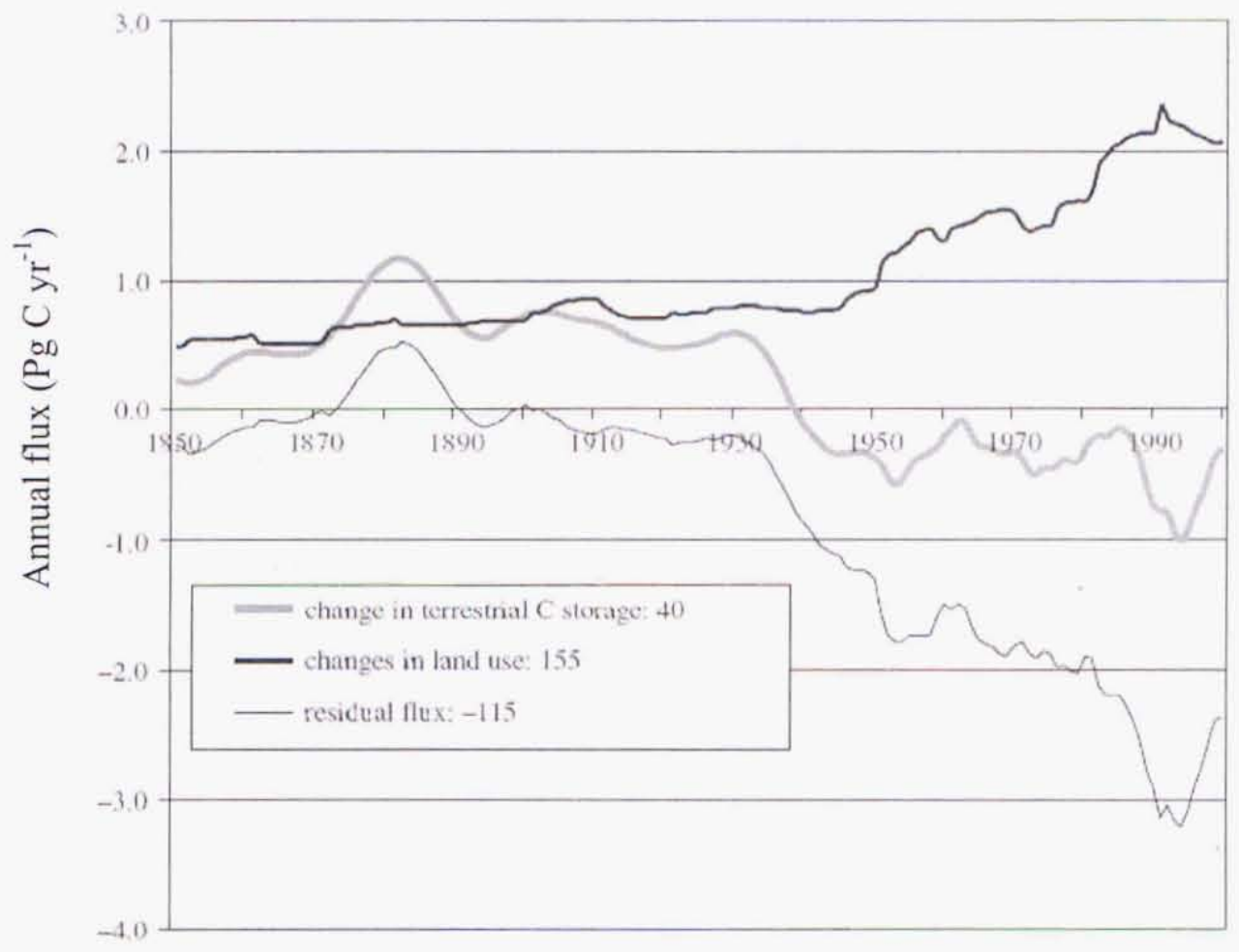

Figure 1-3 The net change in terrestrial carbon (C) storage (including changes in land-use) (thick grey line), the flux of $\mathrm{C}$ from changes in land-use (black line), and the difference between the net flux and the flux from change in land-use (thin grey line). Positive values indicate a terrestrial $\mathrm{C}$ source and negative values indicate a terrestrial C sink. From: Houghton (2003) pp.485.

Many mechanisms are thought to be responsible for the increasing size of the terrestrial $\mathrm{C}$ sink. Briefly, those that are thought to be most important include:

(1) $\mathrm{CO}_{2}$ fertilisation effect. The approximately $30 \%$ increase in the atmospheric $\mathrm{CO}_{2}$ concentration since pre-industrial times is having a fertilisation effect on terrestrial ecosystems (Grace and Rayment 2000). This occurs because most plants respond to elevated concentrations of atmospheric $\mathrm{CO}_{2}$ by increasing rates of photosynthesis and growth (Grace 2004). However, it is not currently known if this fertilisation effect will result in a long-term increase in terrestrial $\mathrm{C}$ storage, because measurements have 
demonstrated that the effects of higher concentrations of $\mathrm{CO}_{2}$ on plant growth are often reduced or absent over long time periods (Oren et al. 2001).

(2) Nitrogen fertilisation. Human activity has increased the amount of biologically active forms of nitrogen present in ecosystems. This has occurred through the production and use of fertilisers, the cultivation of atmospheric nitrogen fixing legumes, and through the combustion of fossil fuels (Houghton 2003). The increase in the availability of nitrogen has led to increased plant growth and hence, terrestrial C storage (Grace and Rayment 2000; Melillo et al. 2002). However, the long term effects of nitrogen deposition on the terrestrial $\mathrm{C}$ balance remain unclear.

(3) Climate change and variability. The increase in the global surface temperature during the last few decades has led to a prolonged growing season in the middle and high latitude ecosystems, which has generally resulted in an increase in NPP at these latitudes. However, measurements of $\mathrm{CO}_{2}$ exchange in these ecosystems do not consistently show a net $\mathrm{C}$ uptake, presumably because warmer soils have higher rates of respiration (Grace and Rayment 2000).

(4) Forest regrowth. The large scale regrowth of forests following disturbance by humans in the past has also led to an increased terrestrial $\mathrm{C}$ sink. This is particularly so in the Northern Hemisphere where processes such as fire suppression, the growth of forests on land abandoned after agriculture, and the growth of forests previously harvested is leading to increased forest $C$ storage (Houghton 2003).

Large quantities of $\mathrm{C}$ are located in the terrestrial biosphere with rapid exchange occurring between the atmosphere, terrestrial biota and soils (Fig.1-2). The world's soils hold approximately twice as much $\mathrm{C}(1500 \mathrm{Pg}$ - including soil-surface litter) as the atmosphere $(780 \mathrm{Pg})$ and two-thirds of terrestrial ecosystem C (Powlson 2005). In grasslands, the $\mathrm{C}$ stored in litter, recalcitrant and labile soil $\mathrm{C}$ pools accounts for over $90 \%$ of total ecosystem C (Ryan and Law 2005). As respiration from the Earth's soils is the second largest flux in the annual global carbon budget, following GPP (Powlson 2005), changes in soil $C$ dynamics have the potential to influence the $C$ balance at local, 
regional and global scales (Chen et al. 2002). Consequently, quantifying how the soilsurface respiration rate is regulated by the environment is critical.

Soil-surface $\mathrm{CO}_{2}$ respiration $\left(R_{\mathrm{s}}\right)$ is a sensitive indicator of the metabolic activity of the soil and the rate of conversion of soil organic matter to atmospheric $\mathrm{CO}_{2}$ (Rochette et al. 1997). It is a complex process, as it includes both the below-ground autotrophic respiration of plant roots and rhizomes $\left(R_{\mathrm{ab}}\right)$, and the heterotrophic decomposition of soil organic compounds and detritus $\left(R_{\mathrm{h}}\right)$ (equation 1.4). Studies examining the relative contribution of $R_{\mathrm{ab}}$ and $R_{\mathrm{h}}$ to $R_{\mathrm{s}}$ indicate that $R_{\mathrm{ab}}$ can account for as little as 10 percent to $>$ than 90 percent of total $R_{\mathrm{s}}$ depending on vegetation type and season of the year (Hanson et al. 2000).

$R_{\mathrm{s}}=R_{\mathrm{ab}}+R_{\mathrm{h}}$

Global $R_{\mathrm{s}}$ is estimated to be approximately $76.5 \mathrm{Pg} \mathrm{C}$ per year (Conant et al. 2004). Therefore relatively small changes in the net amount of $C$ flowing in and out of soils have the potential to influence atmospheric $\mathrm{CO}_{2}$ concentrations (Powlson 2005) and as a result, global climate. At the present time, there is considerable uncertainty about changes in $R_{\mathrm{s}}$ as $\mathrm{CO}_{2}$ continues to accumulate in the atmosphere (Cramer et al. 2001; Steffen et al. 2001) and the climate continues to warm (Norby and Lou 2004). Research points to a short-term $\mathrm{C}$ sink which will weaken and eventually switch to become a $\mathrm{C}$ source (Grace and Rayment 2000; Powlson 2005), thus exacerbating global warming in a feed forward response.

Many studies, in a variety of ecosystems, have demonstrated that the main cause of change in the $R_{\mathrm{s}}$ rate is soil temperature ( $T_{\mathrm{s}}$ ) (Lloyd and Taylor 1994; Conant et al. 2004; Trumbore 2006). For example, Fang and Moncrieff (2001) found that soils from both a farmland and a Sitka spruce site in Scotland showed an exponential increase in respiration with increasing $T_{\mathrm{s}}$ over a 10 to $30^{\circ} \mathrm{C}$ temperature range. The influence of $T_{\mathrm{s}}$ on $R_{\mathrm{s}}$ is often described using an Arrhenius type equation, such as that developed by Lloyd and Taylor (1994) (see chapter 2). Recently, Davidson et al. (2006a) noted that current functions used to describe the response of respiration to temperature, such as that developed by Lloyd and Taylor (1994) are somewhat inadequate, since respiration 
from soils is comprised of $\mathrm{CO}_{2}$ generated from several temperature sensitive processes. These include enzyme activity, diffusion of oxygen and soluble $\mathrm{C}$ substrates through soil air and water and across cellular membranes, and growth of root tissues and microbial populations, which can have multiplicative effects on total $R_{\mathrm{s}}$ (Davidson et al. 2006b).

Root-zone volumetric water content $(\theta)$ has also been found to play a role in the regulation of $R_{\mathrm{s}}$ (Davidson et al. 2006a). The effect of $\theta$ on $R_{\mathrm{s}}$ has been described by linear, logarithmic, quadratic, and parabolic functions of root-zone water content expressed as either soil matric potential, soil gravimetric or volumetric water content, soil water holding capacity, soil water-filled pore space, precipitation indices, and depth to water table (Davidson et al. 2000). Some studies such as those conducted by Conant et al. (2004), on a series of soils from semi-arid sites in the USA, and Reichstein et al. (2003), who performed an analysis on $R_{\mathrm{s}}$ from 17 different forest and shrubland sites in Europe and North America have found that the temperature response of $R_{\mathrm{s}}$ is reduced as the $\theta$ decreases. Xu et al. (2004) observed that when $\theta$ fell below $0.15 \mathrm{~m}^{3} \mathrm{~m}^{-3}$ at an oak/grass savanna in the USA, $R_{\mathrm{e}}$ (and therefore presumably $R_{\mathrm{s}}$ ) almost shut down.

Root-zone volumetric water content can limit $R_{\mathrm{s}}$ in two ways, either by limiting aeration when $\theta$ is high, or by stressing plant root and soil microbial communities when it is low (Rey et al. 2002). Low $\theta$ can limit microbial respiration because both the diffusion of extracellular enzymes produced by microbes for breaking down organic matter and the diffusion of soluble $\mathrm{C}$ substrates that can be assimilated by the microbial cells must occur in the presence of water (Davidson et al. 2006b). In plants, low $\theta$ can lead to loss of tissue turgor, stomatal closure, and leaf shedding, which can result in substantial reductions in root respiration per unit biomass or loss in total respiratory biomass (Aber and Melillo 1991). Borken et al. (2006) note that root respiration may be less affected by low $\theta$ than microbial respiration if plants can compensate for low surface $\theta$ by up-taking water from wetter soil, deeper in the soil profile. Thus, the temperature sensitivity of $R_{\mathrm{s}}$ can become less under dry conditions, mainly due to the limited diffusion of $\mathrm{C}$ solutes in thin soil water films (Davidson et al. 2006b). Consequently, models of $R_{\mathrm{s}}$, in environments where the soil water content can become limiting, need to incorporate the response to $\theta$. 
Since grasslands cover one-third of the Earth's land surface, and store between $10-30 \%$ of the world's soil carbon (Risch and Frank 2006), they are an important component of the global terrestrial $\mathrm{C}$ cycle. In broad terms grasslands are defined as ecosystems where the dominant vegetation component is comprised of herbaceous species (Jones and Donnelly 2004). Recently, several studies have examined the regulation of grassland $R_{\mathrm{s}}$. Franzluebbers et al. (2002) investigated the spatial and temporal determinants of $R_{\mathrm{s}}$ from a tallgrass prairie in Kansas, USA, using nighttime exposure of static chambers to alkali absorption. The study determined the main drivers of $R_{\mathrm{s}}$ to be soil organic $\mathrm{C}$, soil temperature $\left(T_{\mathrm{s}}\right), \theta$, and plant growth rate. Verburg et al. (2005) conducted an experiment comparing the $R_{\mathrm{s}}$ from soil cores collected from a tallgrass prairie in Oklahoma, USA, and found that a combined $T_{\mathrm{s}}$ and $\theta$ regression explained $64 \%$ of the observed variation in respiration rates. Other $R_{\mathrm{s}}$ studies have been conducted on semi-arid grasslands and savannas. Tang and Baldocchi (2005) reported that the seasonal pattern of $R_{\mathrm{s}}$ in an oak-grass savanna ecosystem in California, USA, was driven by both $T_{\mathrm{s}}$ and $\theta$.

Despite the recent interest in quantifying $R_{\mathrm{s}}$ from grasslands, relatively few studies have been published on $R_{\mathrm{s}}$ from temperate pastures. In particular there is a lack of data from intensively managed temperate pastures (Byrne et al. 2005). In one temperate, natural grassland study in Yellowstone National Park, USA, which was primarily concerned with the effects of ungulate grazing, Risch and Frank (2006) measured $\mathrm{CO}_{2}$ exchange over a site grazed by elk, bison and pronghorn. They compared $R_{\mathrm{s}}$ rates from sites inside and outside long term ungulate enclosures, in dry to mesic conditions, and found that temporal and spatial variations in $R_{\mathrm{s}}$ were ultimately related to variability in $\theta$. They reported no differences in respiration rates between grazed and un-grazed sites.

In New Zealand, pastures occupy $6.67 \times 10^{4} \mathrm{~km}^{2}(26 \%)$, forming the largest single land cover type (Trotter et al. 2004). However, to date, there have been no known detailed studies of how $R_{\mathrm{s}}$ is regulated by $T_{\mathrm{s}}$ and $\theta$ in pastoral systems in New Zealand. Nieveen et al. (2005) conducted a study on the $C$ exchange of a pasture over a drained peat soil in New Zealand, but examined only total $R_{\mathrm{e}}$ (using the eddy covariance technique). Hunt et al. (2002) also used the eddy covariance technique to measure total 
$R_{\mathrm{e}}$ from a New Zealand tussock grassland, but did not measure $R_{\mathrm{s}}$ independently. Hunt et al. (2004), also in a grazed New Zealand tussock grassland, did measure $R_{\mathrm{s}}$ with a soil respiration chamber, but focused on the effects of drought and rainfall, and only measured $R_{\mathrm{s}}$ immediately before and after a rainfall event. Because pastures are the primary land cover type in New Zealand, quantifying the respiration from these soils is critical in determining the $\mathrm{C}$ balance of New Zealand.

In a recent review of ecosystem respiration, Trumbore (2006) noted, that while the variables which regulate respiration are well known, the specific details of how ecosystem respiration and $R_{\mathrm{s}}$ depend on these variables, at any given time, are still largely unknown. Trumbore (2006) comments that the "problem is both with a lack of a theory of respiration that explains how all the driving variables may interact, as well as in obtaining relevant data to test models based on theory". Hence, in order to construct global carbon budgets, detailed information at the local scale is needed from a diverse range of ecosystems and climate zones (Rayment and Jarvis 2000; Law et al. 2001; Raich et al. 2002). This will allow a theory of ecosystem respiration and $R_{\mathrm{s}}$ to be developed and, as a result, better models of future ecosystem and global $\mathrm{C}$ budgets. This study will contribute to filling the current gap in $R_{\mathrm{s}}$ data from temperate cattlegrazed pastures.

\subsection{Nature and scope of thesis}

This study was a component of a long term programme conducted by Landcare Research, investigating changes in $\mathrm{C}$ cycling as pastures are converted to shrubland. This thesis contributed to the overall study by quantifying rates of $R_{\mathrm{s}}$ in a New Zealand grazed pasture and investigating the seasonal regulation of $R_{\mathrm{s}}$ by environmental variables. The principal objectives were to:

1. Quantify rates of $R_{\mathrm{s}}$ in a New Zealand grazed pasture.

2. Measure seasonal variation in $R_{\mathrm{s}}$ in relation to $T_{\mathrm{s}}$ and $\theta$.

3. Model $R_{\mathrm{s}}$ and validate modelled rates of respiration against field measurements. 
4. Estimate total growing-season $R_{\mathrm{S}}$

\subsection{Thesis structure}

Chapter 2 describes a controlled laboratory experiment undertaken to measure $R_{\mathrm{s}}$ over a range of $T_{\mathrm{s}}$ and $\theta$ values. These measurements were used to construct a model of $R_{\mathrm{s}}$ which was then validated against $R_{\mathrm{s}}$ measurements made in the field under natural environmental conditions. The results of a partitioning exercise to determine the contribution of $R_{\mathrm{s}}$ to $R_{\mathrm{e}}$ are presented in Chapter 3. The soil-surface respiration model, developed in Chapter 2, was validated against partitioned nocturnal eddy covariance respiration data made available through the Landcare Research programme and the $R_{\mathrm{s}}$ model was used to estimate the total growing season $R_{\mathrm{s}}$ from the field site. Chapter 4 presents final conclusions and future work. 


\section{Soil temperature and root-zone water content regulation of soil-surface respiration in a New Zealand grazed pasture}

\subsection{Introduction}

The terrestrial biosphere currently absorbs approximately one-third of all anthropogenic $\mathrm{CO}_{2}$ emissions (Schimel et al. 2001). Since the Earth's climate is regulated to a high degree by the atmospheric $\mathrm{CO}_{2}$ concentration (Houghton 2001), it is critical to understand what regulates carbon $(C)$ exchange between the world's terrestrial ecosystems and the atmosphere. Soil respiration at the soil-surface $\left(R_{\mathrm{s}}\right)$ comprises $\mathrm{CO}_{2}$ production from both plant roots, and the microbial decomposition of soil organic compounds and detritus (Reth et al. 2005). After photosynthesis, $R_{\mathrm{s}}$ constitutes the largest exchange of $C$ between the terrestrial biosphere and the atmosphere (Reichstein et al. 2005). Thus a small increase in the rate of $R_{\mathrm{s}}$ could potentially have a large impact on atmospheric $\mathrm{CO}_{2}$ concentrations. While $\mathrm{C}$ exchange has been studied over a range of grassland ecosystems, including an oak-grass savanna (Tang and Baldocchi 2005), a northern temperate grassland (Flanagan and Johnson 2005), and a tall-grass prairie (Franzluebbers et al. 2002), there remains a need for information on the regulation of $R_{\mathrm{S}}$ in temperate, intensively grazed pastures (Byrne et al. 2005). In New Zealand, the respiration from pastoral soils is a potentially important component of the terrestrial $\mathrm{C}$ cycle, because pastoral ecosystems comprise almost $30 \%$ of New Zealand's terrestrial surface area (Trotter et al. 2004). Thus, it is important to quantify the $R_{\mathrm{s}}$ flux density from pastoral systems in New Zealand, in order to understand what potential changes in the seasonal $R_{\mathrm{s}}$ rate might occur in relation to climatic changes.

It is well documented that $R_{\mathrm{s}}$ increases exponentially with increasing soil temperature $\left(T_{\mathrm{s}}\right)$ (Lloyd and Taylor 1994). However, root-zone volumetric water content $(\theta)$ has also been shown to regulate $R_{\mathrm{s}}$ (Borken et al. 2006). For instance, several studies in a variety of ecosystems have reported the temperature response of $R_{\mathrm{s}}$ to be limited at low $\theta$ (Davidson et al. 2000; Conant et al. 2004). Davidson et al. (2000) found that $R_{\mathrm{s}}$ rates decreased with low $\theta$ for both Amazonian pasture and forest soils. In a 
North American prairie study, Franzluebbers et al. (2002) found that when water-filled pore space was $<0.4 \mathrm{~m}^{3} \mathrm{~m}^{-3}$, increasing $T_{\mathrm{s}}$ had little effect on $R_{\mathrm{s}}$, but when water-filled pore space was $>0.4 \mathrm{~m}^{3} \mathrm{~m}^{-3}$, increasing $T_{\mathrm{s}}$ positively influenced $R_{\mathrm{s}}$. Very high values of $\theta$ can also reduce $R_{\mathrm{s}}$, due to limitations on oxygen diffusion (Linn and Doran 1984). In a study on a temperate mixed-hardwood forest, Davidson et al. (1998), found that when $\theta$ was $>0.12 \mathrm{~m}^{3} \mathrm{~m}^{-3}, R_{\mathrm{s}}$ decreased with increases in $\theta$, and when $\theta$ was $>$ $0.7 \mathrm{~m}^{3} \mathrm{~m}^{-3} R_{\mathrm{s}}$ was usually very low (less than $1.6 \mu \mathrm{mol} \mathrm{m} \mathrm{m}^{-2} \mathrm{~s}^{-1}$ ). In a review of previous $R_{\mathrm{s}}$ studies, none of which took place over an intensively grazed temperate pasture, Davidson et al. (2000) noted that the optimal rate of soil $\mathrm{CO}_{2}$ production frequently occurs at relatively intermediate $\theta$, often near field capacity and declines at wetter and drier soil conditions.

Since soil temperature and root-zone volumetric water content often co-vary in the field, determining the relative influence each factor has on $R_{\mathrm{s}}$ has been problematic (Borken et al. 2006). This study attempts to overcome this challenge by undertaking a laboratory study using pasture soils collected from the field, and controlling $T_{\mathrm{s}}$ and $\theta$ independently. This technique proved to be successful when determining $R_{\mathrm{s}}$ in a tallgrass prairie in Oklahoma, USA (Verburg et al. 2005). Laboratory studies are a useful way of determining the relative influence each of these variables has on $R_{\mathrm{s}}$, as respiration measurements can be made across a wide range of either $T_{\mathrm{s}}$ or $\theta$.

The objectives of this portion of the study were to:

- Conduct a laboratory experiment to determine how $R_{\mathrm{s}}$ from a New Zealand cattlegrazed pasture was regulated by $T_{\mathrm{s}}$ and $\theta$.

- Use these relationships to develop a model of $R_{\mathrm{s}}$.

- Validate the model of $R_{\mathrm{s}}$ against field measurements of $R_{\mathrm{s}}$. 


\subsection{Methods}

\subsubsection{Site description}

The field measurements were carried out in an established cattle-grazed pasture, located near Oxford in Canterbury, New Zealand (latitude $43.3^{\circ} \mathrm{S}$, longitude $172.2^{\circ} \mathrm{E}$, elevation above sea level $34 \mathrm{~m}$ ) (Plate 2.1). The pasture was dominated by perennial ryegrass (Lolium perenne L.) with the remaining vegetation comprised of white clover (Trifolium repens L.),yorkshire fog (Holcus lanatus L.), creeping bent (Agrostis stolonifera L.) and browntop (Agrostis capillaris L.). During the measurement period cattle grazed the pasture three times, from 9 October to 22 October 2005, from 25 November to 8 December 2005, and from 3 February to 16 February 2006.

The soil was a Taitapu Typic Orthic Gley (New Zealand soil classification) (Hewitt 1998), poorly drained, with a perched water table. This type of soil typically develops on wet sites and in depressions at the bases of hills. For much of the year, the water table is near to the surface and the soil profile has a pale subsoil colour. At field capacity, the root-zone volumetric water content $(\theta)$ is approximately $0.49 \mathrm{~m}^{3} \mathrm{~m}^{-3}$. The average $\mathrm{C}: \mathrm{N}$ ratio ( $0-300 \mathrm{~mm}$ soil depth) is 14.2. Mixed forests comprised of Nothofagus and Podocarpus species were present at this location before conversion to pasture, more than a century ago. The underlying zonal soils are derived from greywacke and tertiary rocks with a covering of loess, which developed during the last glaciation (18-20000 years ago). Soil pH is typically 5.3 . At depths $>300 \mathrm{~mm}$, the soil becomes white and mottled.

At Darfield, located $20 \mathrm{~km}$ from the field site, the mean 30 year annual air temperature is $11.7^{\circ} \mathrm{C}$ (NIWA 2006). The climate is characterized by cool, moist winters (average daily air temperature $7^{\circ} \mathrm{C}$ ) and warm summers (average daily air temperature $16{ }^{\circ} \mathrm{C}$ and average daily maximum air temperature $22^{\circ} \mathrm{C}$ ). The average yearly rainfall is $782 \mathrm{~mm}$ with the rainfall being evenly distributed throughout the year (NIWA 2006). 


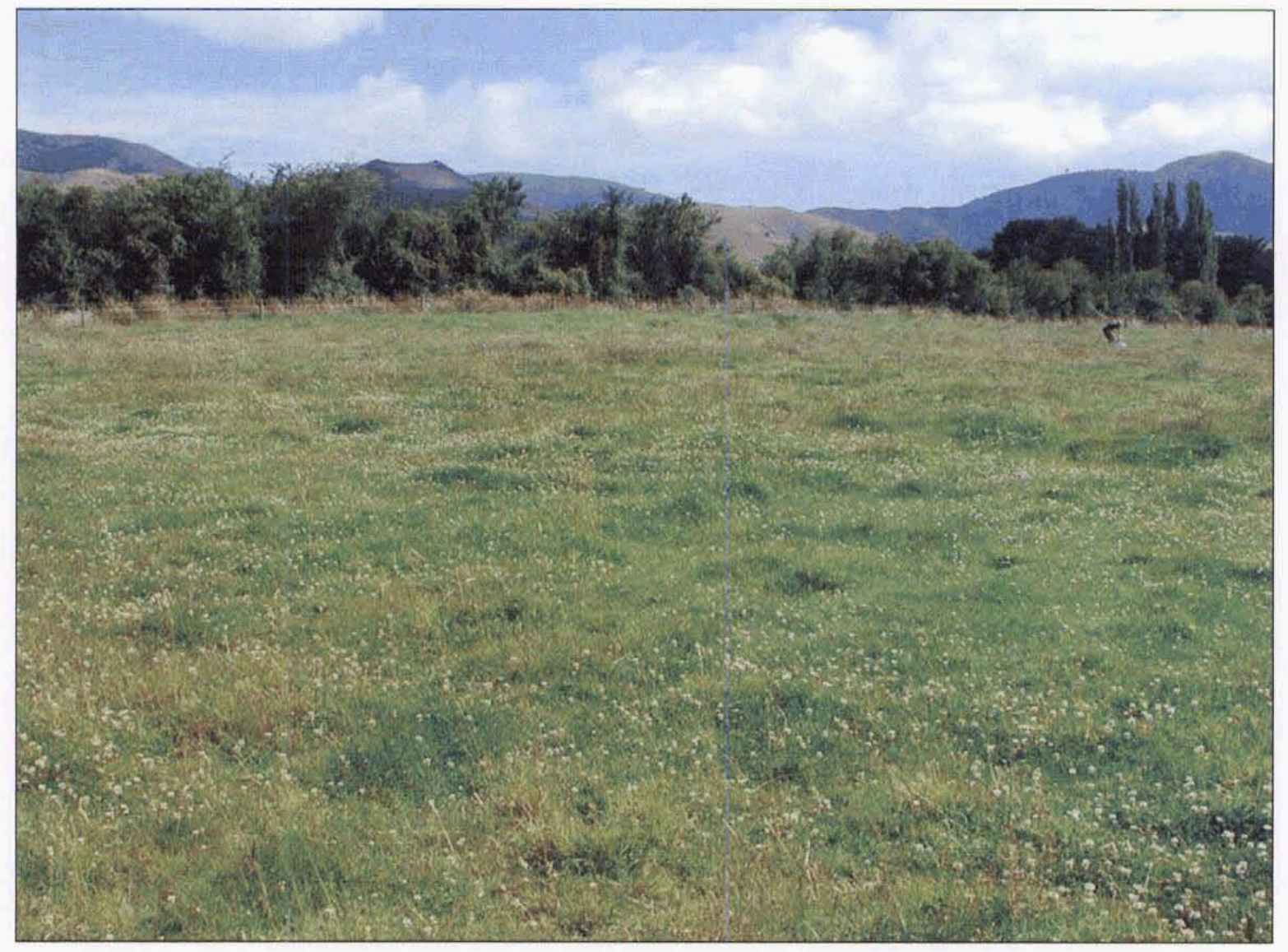

Plate 2-1 Study site during the growing season measurement period.

\subsubsection{Soil-surface respiration measurements made in the field}

In order to measure $R_{\mathrm{S}}$ in the field (section 1.1, objective 1), 24 soil collars were made from PVC pipe (100 mm in diameter and $150 \mathrm{~mm}$ in length). These were permanently inserted to a depth of $125 \mathrm{~mm}$ into the soil-surface of the pasture, at spaced intervals of $10 \mathrm{~m}$. This left exposed above the soil-surface a $25 \mathrm{~mm}$ soil 'collar' upon which a $\mathrm{CO}_{2}$ respiration chamber could be placed, as described below.

Immediately prior to $\mathrm{CO}_{2}$ respiration measurements, the grass growing inside the collars was clipped to $20 \mathrm{~mm}$ above the soil-surface using hand shears. Clipping was done to ensure that the respiration measurements would be comprised almost entirely of soil-surface respiration (equation 1.4), and not include above-ground autotrophic 
respiration from above-ground vegetation. The $\mathrm{CO}_{2}$ flux density was measured using a portable closed-chamber attached to an infrared gas analyser (models SRC-1 and EMG1, PP Systems, Hitchin, UK). The chamber was placed on each of the 24 PVC collars in turn. Measurements of the $\mathrm{CO}_{2}$ fluxes were conducted approximately every two weeks, beginning in September 2005 and continuing until March 2006. Each respiration measurement was conducted over a period of $2 \mathrm{~min}$.

Since the pasture had been clipped to a height of $20 \mathrm{~mm}$, the measured $\mathrm{CO}_{2}$ exchange was equivalent to soil-surface respiration, and is subsequently referred to as $R_{\mathrm{s}}$. It should also be noted here that further measurements (see section 3.3.1 chapter 3 ) confirmed that cutting the pasture to a height of $20 \mathrm{~mm}$ effectively removed the aboveground autotrophic respiration component of the $R_{\mathrm{s}}$ measurement.

Soil temperature $\left(T_{\mathrm{s}}\right)$ at $50 \mathrm{~mm}$ depth, was measured by inserting a thermistor directly into the soil next to the PVC collars during each $R_{\mathrm{S}}$ measurement. The value of root-zone volumetric water content $(\theta)$ was continuously determined, and recorded at 30 min intervals, using electronic probes (ThetaProbe, Delta-T, Cambridge, UK) linked to a data-logger (CR10X Campbell Scientific) at depths of 50,100 and $300 \mathrm{~mm}$ at one location in the pasture. For analysis purposes, the $\theta$ measurements at each depth were integrated to provide a single $\theta$ value over the $0-300 \mathrm{~mm}$ soil profile. To integrate $\theta$, values at the 50, 100 and $300 \mathrm{~mm}$ depths, which represented $0-75,75-200$, and 200 $-300 \mathrm{~mm}$ of the soil profile, were multiplied by the proportion of the profile they measured (25, 41.6 and $33.3 \%$ respectively) and then the values were added together.

\subsubsection{Laboratory measurements of soil-surface respiration}

In order to reveal how $T_{\mathrm{s}}$ and $\theta$ interacted to regulate $R_{\mathrm{s}}$ (section 1.1, objective 2), a laboratory study was conducted. To achieve this, thirteen intact soil cores, $300 \mathrm{~mm}$ in length and $200 \mathrm{~mm}$ in diameter, were removed from the pasture by inserting PVC pipes (300 $\mathrm{mm}$ long and $200 \mathrm{~mm}$ diameter) into the soil-surface and then carefully digging around the casings (Plate 2.2). The soil cores, inside their casings, were removed from the pasture while the soils were wet and near field capacity. While still in the field, PVC collars, (100 mm diameter, $70 \mathrm{~mm}$ long), were inserted into the surface of the cores to a 
depth of $50 \mathrm{~mm}$. The base of the casings were covered with mesh $(2 \mathrm{~mm})$ to ensure containment of the soil cores and yet allow excess water to drain. The soil cores were then transported to the laboratory so that $R_{\mathrm{s}}$ could be measured in controlled conditions in a growth cabinet.

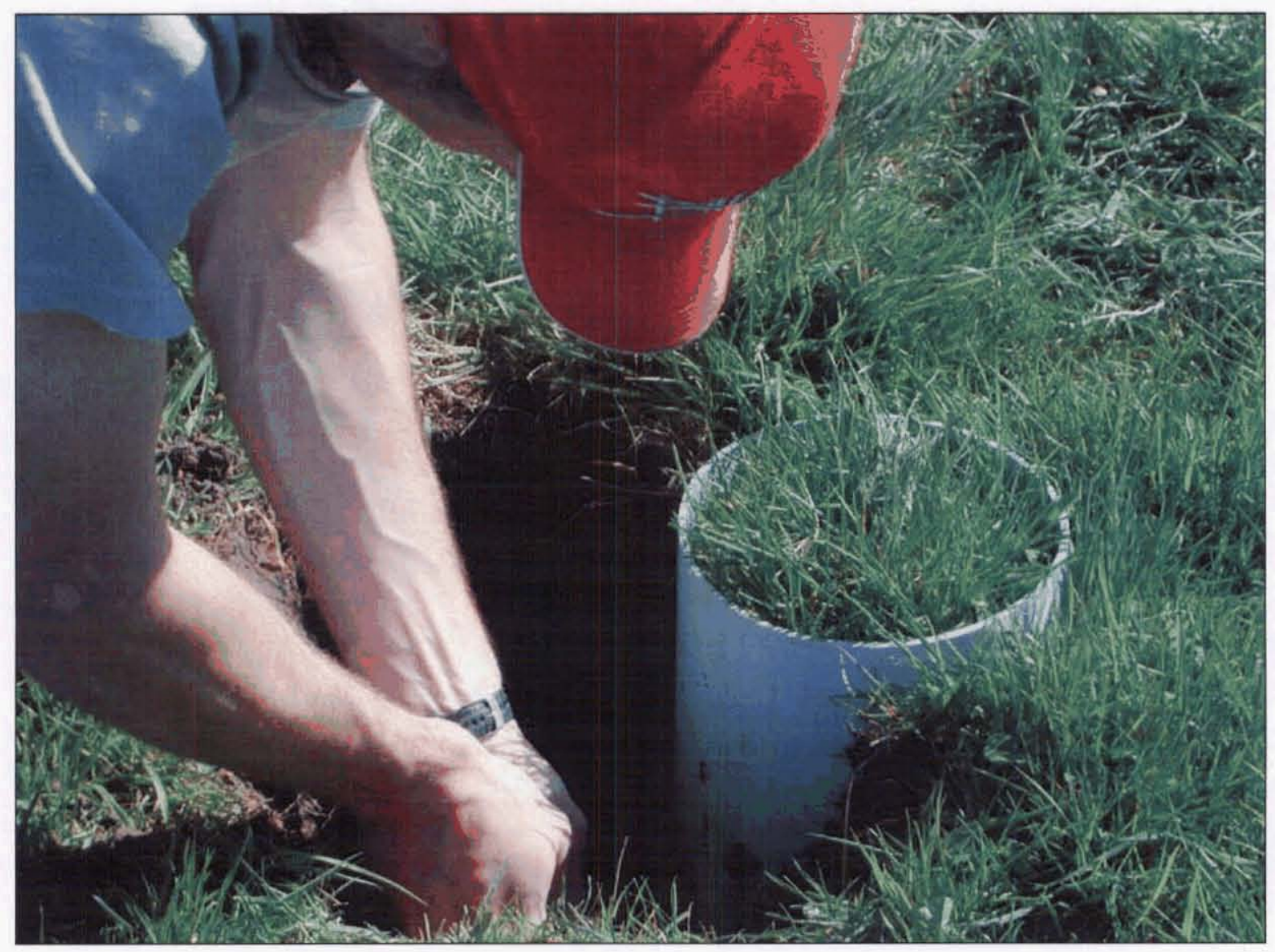

Plate 2-2 One of thirteen soil cores used in laboratory study being dug out of the pasture. 
Prior to being placed in the growth cabinet (Temperzone, Temperzone Ltd., Auckland, New Zealand) (dimensions: $0.90 \times 1.2 \times 1.8 \mathrm{~m}$ ), the thirteen soil cores were saturated by immersing in water for approximately four hours, thus allowing water to percolate throughout the core. The cores were then placed on a rack in the growth cabinet, where excess water was allowed to drain for two days, so that at the beginning of the experiment the cores were considered to be at their maximum water holding capacity. Herbage on the soil cores was left as it was when the cores were removed from the field.

In the growth cabinets water loss from the soil cores occurred via evaporation from the soil-surface and plant transpiration. The rate of water loss was controlled by varying humidity in the growth cabinets as required. In order to dry the soil cores the humidity was reduced to $15 \%$, while to maintain $\theta$ at fixed values, the humidity was increased to $80 \%$. At any given time when measurements of $R_{\mathrm{s}}$ were made, the humidity in the growth cabinet was maintained within narrow limits (70-80\%). For each set level of $\theta, R_{\mathrm{s}}$ was measured at $T_{\mathrm{s}}$ values of approximately $5,10,15,20,25$ and $30^{\circ} \mathrm{C}$.

The values of $T_{\mathrm{s}}$ were measured using thermocouples placed in the centre of three of the cores while the values of $T_{s}$ were controlled by adjusting the air temperature of the growth cabinet. As per the field measurements, when respiration measurements were made $T_{s}$ was measured with a thermistor at $50 \mathrm{~mm}$ depth from the soil-surface. This process was repeated until respiration measurements had been made at a broad range of $T_{\mathrm{s}}\left(5-30^{\circ} \mathrm{C}\right)$ and under wet to dry soil conditions that constituted seven levels of $\theta\left(\sim 0.1-0.5 \mathrm{~m}^{3} \mathrm{~m}^{-3}\right)$.

The volume of the soil cores were measured at the beginning of the laboratory study. On the day of each $R_{\mathrm{s}}$ measurement, the cores were weighed to determine their mass, so that the exact water content could be calculated subsequently. Following the experiment, the soil cores were oven-dried and weighed again to determine the ovendry soil mass. These data were used to calculate the soil bulk density for each core $\left(\rho_{\text {soil }}\right)$, which enabled the value of $\theta$ to be determined during any particular $R_{\mathrm{s}}$ measurement as follows: 
$\rho_{\text {Soil }}=M_{s} / V_{t}$

where $M_{s}$ is the mass of soil and $V_{t}$ is the total core volume.

$V_{\mathrm{w}}=M_{\mathrm{w}} / \rho_{\text {water }}$

where $V_{w}$ is the volume of water, $M_{w}$ is the mass of water $(\mathrm{g})$ and $\rho_{\text {water }}$ is the bulk density of water; assumed to be $1000 \mathrm{~kg} \mathrm{~m}^{-3}$.

$\theta=V_{\mathrm{w}} / V_{\mathrm{t}}$

where $\theta$ is the root-zone volumetric water content.

As with the field $R_{\mathrm{s}}$ measurements, the grass on the soil cores in the growth cabinets was clipped to a height of $20 \mathrm{~mm}$ before respiration measurements were made. However, the grass was not clipped more than once a week, to avoid unwanted clipping effects, such as those identified by Wan and Luo (2003). These researchers conducted a clipping experiment in a tallgrass North American prairie, and showed that clipping reduced below-ground substrate supply and as a result, led to reduced rates of $R_{\mathrm{s}}$. Bremer et al. (1998) also found that in a tallgrass prairie in Kansas, USA, clipping typically reduced $R_{\mathrm{s}}$ by $21-49 \%$ by the second day after clipping.

\subsubsection{Data Analysis}

To determine the influence of $T_{\mathrm{s}}$ and $\theta$ on $R_{\mathrm{s}}$, a non-linear regression model (section 1.1, objective 3) was constructed that included an Arrhenius-type function for the $T_{\mathrm{s}}$ response (Lloyd and Taylor 1994) and a linear function for the $\theta$ response (the selection of a linear $\theta$ function is discussed in section 2.3.1).

During the laboratory study, the bulk density of the individual soil cores varied considerably, from 0.46 to $1.13 \mathrm{~m}^{3} \mathrm{~m}^{-3}$. Reichstein et al. (2003) noted that $\theta$ was not a good measure of water availability when soils of different texture were compared. Thus, 
it was decided to use a normalised root-zone water content $\left(\theta_{n}\right)$, defined as the rootzone volumetric water content available relative to the maximum root-zone volumetric water $\left(\theta_{\max }\right)$ (equation 2.4$)$ for each individual core. The water content function of the equation also included a parameter, $\theta_{\mathrm{c}}$ defined as the $\theta_{\mathrm{n}}$ value at which a further increase in $\theta_{n}$ no longer influences respiration, so that when $\theta_{n}>\theta_{c}$, equation 2.5 was utilised, however when $\theta_{n}<\theta_{c}$, equation 2.6 was utilised.

$\theta_{\mathrm{n}}=\theta / \theta_{\max }$

$R_{s}=R_{10} e^{E_{o}\left[\frac{1}{56.02}-\frac{1}{T_{s}-227.13}\right]}$

$R_{s}=R_{10} e^{E_{o}\left[\frac{1}{56.02}-\frac{1}{T_{s}-227: 13}\right]} \cdot\left[\frac{\theta_{n}}{\theta_{c}}\right]$

$R_{10}$ is the base respiration rate at $10^{\circ} \mathrm{C}, T_{\mathrm{s}}$ is the soil temperature $(\mathrm{K})$ and $E_{0}$ is a parameter related to the energy of activation $(K)$.

The model adopted was a non-linear mixed effects model, fit by maximum likelihood (Pinheiro and Bates 2000). This model was used as it allowed for random differences between the soil cores, correctly adding their variability into that of parameter estimates. The model allowed $R_{10}$ to have a component of variation from the soil cores, and considered correlation between successive measurements on the same soil core, correctly lessening the influence of individual measurements, particular those close together in time. Finally, the model allowed for greater variability at higher levels of $R_{\mathrm{s}}$, which was observed in the data (Note: this type of model does not provide an $r^{2}$ or $r^{2}$ equivalent value). 


\subsection{Results}

\subsubsection{Laboratory measurements of soil-surface respiration}

In the laboratory experiment, $R_{\mathrm{s}}$ increased markedly with increases in $T_{\mathrm{s}}$ (Fig. 2-1). The temperature response of $R_{\mathrm{s}}$ was greater when $\theta_{\mathrm{n}}$ was relatively high. To determine the nature of the response of $R_{\mathrm{s}}$ to $\theta_{\mathrm{n}}, R_{\mathrm{s}}$ measurements were normalised to $10^{\circ} \mathrm{C}\left(R_{10}\right)$. To do this for each soil core, $R_{\mathrm{s}}$ measurements were grouped into classes of $\theta_{\mathbf{n}}(0.80-$ $0.90,0.70-0.79,0.60-0.69,0.50-0.59,0.40-0.49,0.30-0.39$ and $<0.30)$ and equation 2.5 was fitted to the $R_{\mathrm{s}}$ measurements in each class (Fig.2-2). A linear function best described the increase in $R_{\mathrm{s}}$ with $\theta_{\mathrm{n}}$ until a threshold value of $0.90\left(\theta_{\mathrm{c}}\right)$, after which point a further increase in $\theta_{n}$ no longer had an influence on respiration. 


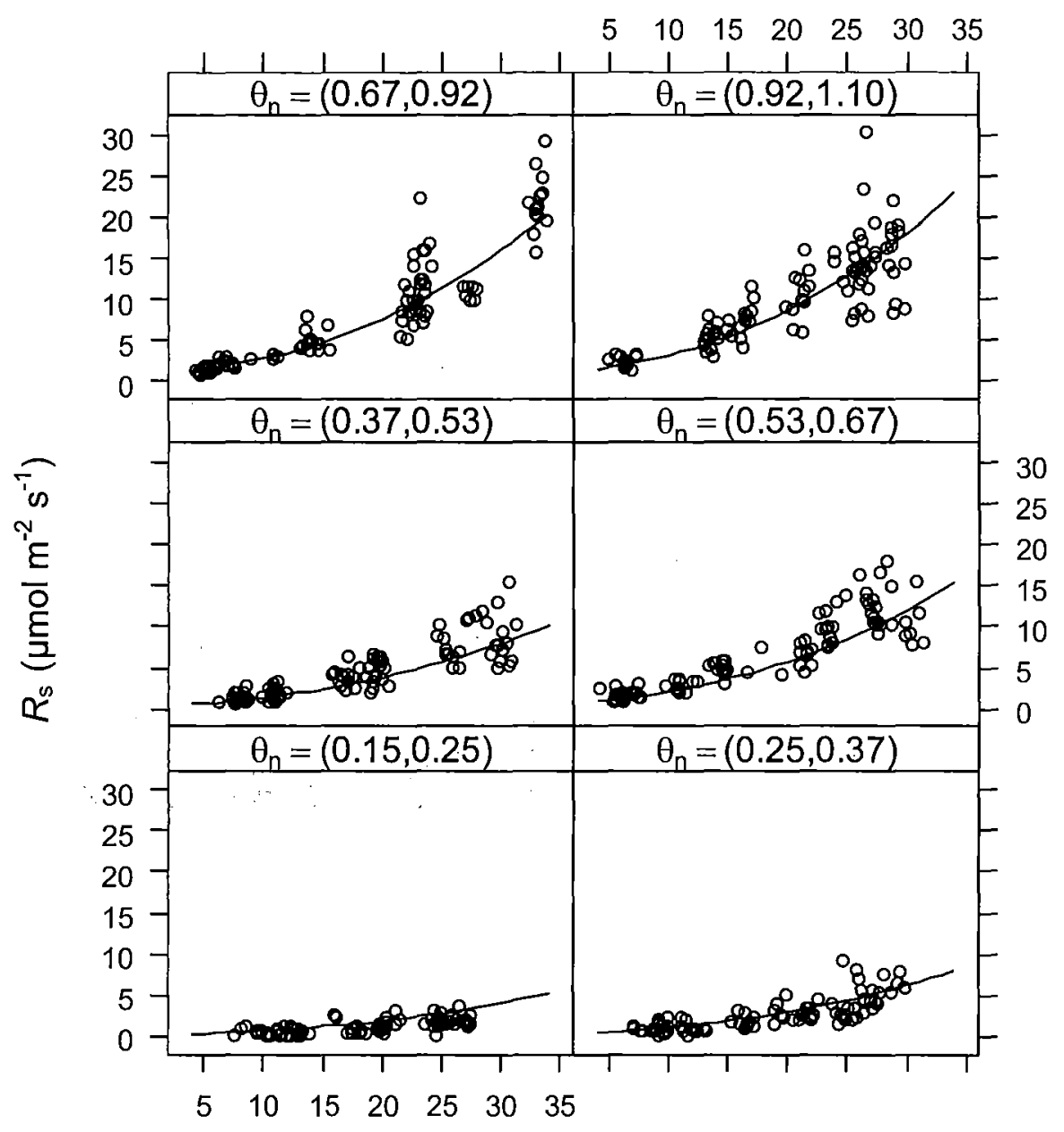

Soil temperature $\left({ }^{\circ} \mathrm{C}\right)$

Figure 2-1 Laboratory measurements of $R_{\mathrm{s}}$ (soil-surface respiration) of all soil cores in relation to soil temperature at a depth of $50 \mathrm{~mm}$, at six different classes of $\theta_{n}$ (normalised root-zone water content) (numbers in brackets represent the range of $\theta_{n}$ in each class). The line is fitted using the model (equations 2.5 and 2.6). 


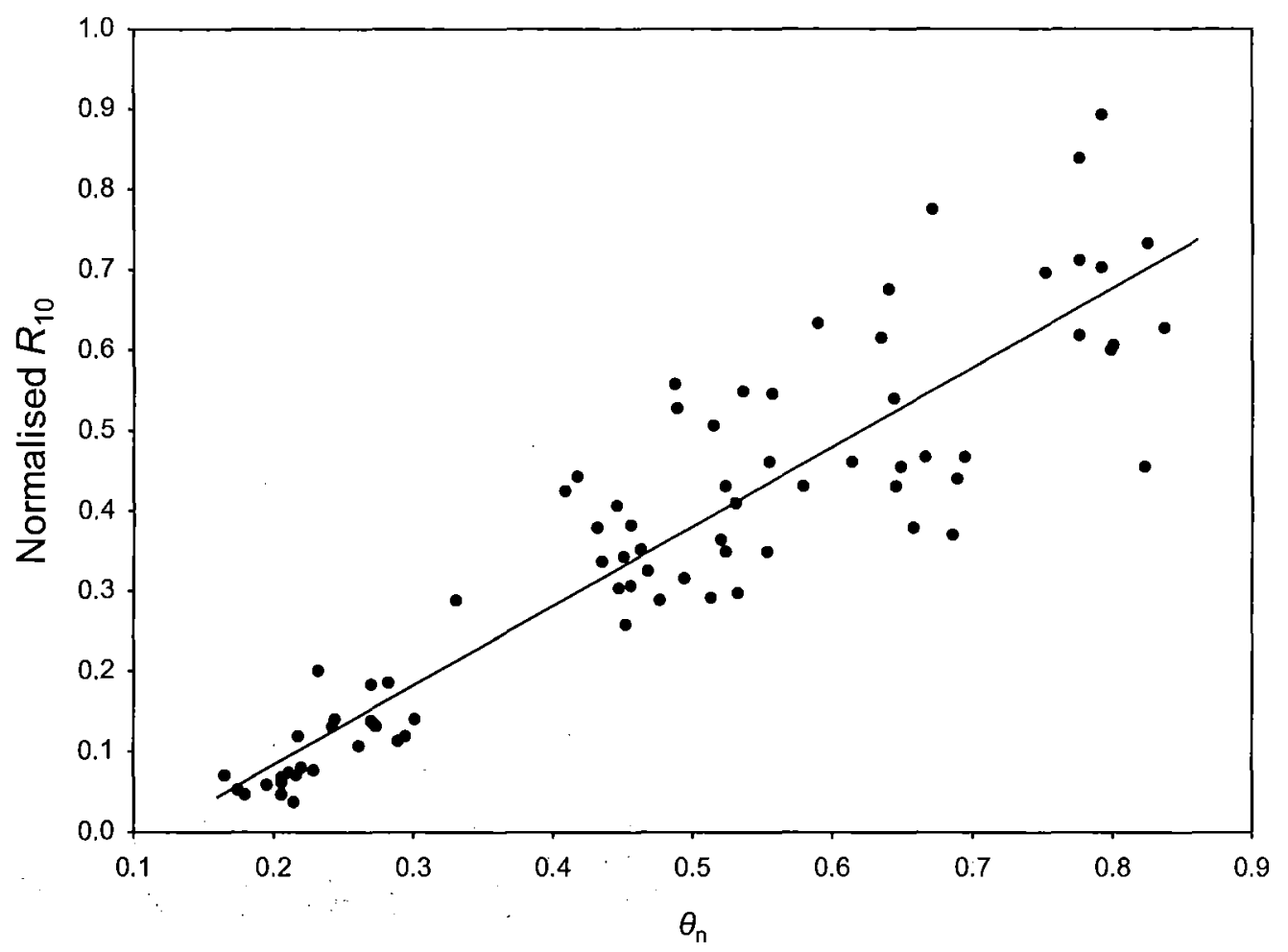

Figure 2-2 Soil-surface respiration normalised to $10^{\circ} \mathrm{C}\left(R_{10}\right)$ and $\theta_{n}$ (normalised rootzone volumetric water content) when $\theta_{\mathrm{n}}$ is $<0.90\left(\theta_{\mathrm{c}}\right) . R_{10}$ values are normalised to the maximum $R_{10}$ value. $R_{10}$ values were determined by fitting equation 2.5 to respiration measurements in $\theta_{n}$ classes of $0.80-0.90,0.70-0.79,0.60-0.69,0.50-$ $0.59,0.40-0.49,0.30-0.39$ and $<0.30$, in each of the thirteen soil cores. $r^{2}=0.84$; $y=-0.1141+0.9891^{*} x$

\subsubsection{Modelling of laboratory measurements}

Using the relationships between $R_{\mathrm{s}}$ and $T_{\mathrm{s}}$ and $\theta_{\mathrm{n}}$ established in the laboratory, a nonlinear mixed effects model was developed, fitted with maximum likelihood, using equations 2.5 and 2.6 (section 2.2.4). The parameters generated by the model are presented in Table 2-1. 
Table 2-1 Fitted parameters ( \pm standard errors) derived from the soil-surface respiration model. $R_{10}$ is the soil-surface respiration rate at $10^{\circ} \mathrm{C} . E_{0}$ is related to the energy of activation, and $\theta_{\mathrm{c}}$ is the threshold point at which a further increase in normalised root-zone water content no longer has an influence on soil-surface respiration.

\begin{tabular}{lll}
\hline$R_{10}\left(\mu \mathrm{mol} \mathrm{m}^{-2} \mathrm{~s}^{-1}\right)$ & $E_{\mathrm{o}}(\mathrm{K})$ & $\boldsymbol{\theta}_{\mathrm{c}}$ \\
\hline $3.19 \pm 0.2$ & $369.2 \pm 8.5$ & $0.90 \pm 0.04$ \\
\hline
\end{tabular}

\subsubsection{Field measurements of soil-surface respiration}

When the first two field $R_{\mathrm{s}}$ measurements were made in the late winter, $T_{\mathrm{s}}$ was $13^{\circ} \mathrm{C}$. During the spring and early summer, $T_{\mathrm{s}}$ increased rapidly to $20^{\circ} \mathrm{C}$ and stayed near this temperature until early autumn, when $T_{\mathrm{s}}$ fell to $15^{\circ} \mathrm{C}$ prior to the last measurement in March (Figure 2-3a). Field root-zone water content measurements were converted to $\theta_{n}$ so that they were directly comparable to the laboratory measurements of $\theta_{n}$. To normalised $\theta$, the value of $\theta$ during each field measurement day was divided by the maximum $\theta$ value $\left(\theta_{\max }\right)$ reached during field measurements. Maximum $\theta$ was $0.48 \mathrm{~m}^{3}$ $\mathrm{m}^{-3}$. Normalised root-zone water content values commenced at near maximum water holding capacity in September and remained high $(>0.90)$ throughout the early summer. In January, $\theta_{n}$ values fell relatively rapidly and reached a low of approximately 0.55 in early February. Soil $\theta_{\mathrm{n}}$ values then fluctuated, due to intermittent rainfall, for the remainder of the measurement period. $R_{\mathrm{s}}$ ranged from 6 to $8 \mu \mathrm{mol} \mathrm{m} \mathrm{m}^{-2} \mathrm{~s}^{-1}$ during the late winter and gradually increased as spring progressed into summer, when $R_{\mathrm{s}}$ reached a maximum rate of $11 \mu \mathrm{mol} \mathrm{m} \mathrm{m}^{-2} \mathrm{~s}^{-1}$. During February and March, $R_{\mathrm{s}}$ fell slightly to rates of approximately $9 \mu \mathrm{mol} \mathrm{m} \mathrm{m}^{-2} \mathrm{~s}^{-1}$ (Fig. 2-3b). 

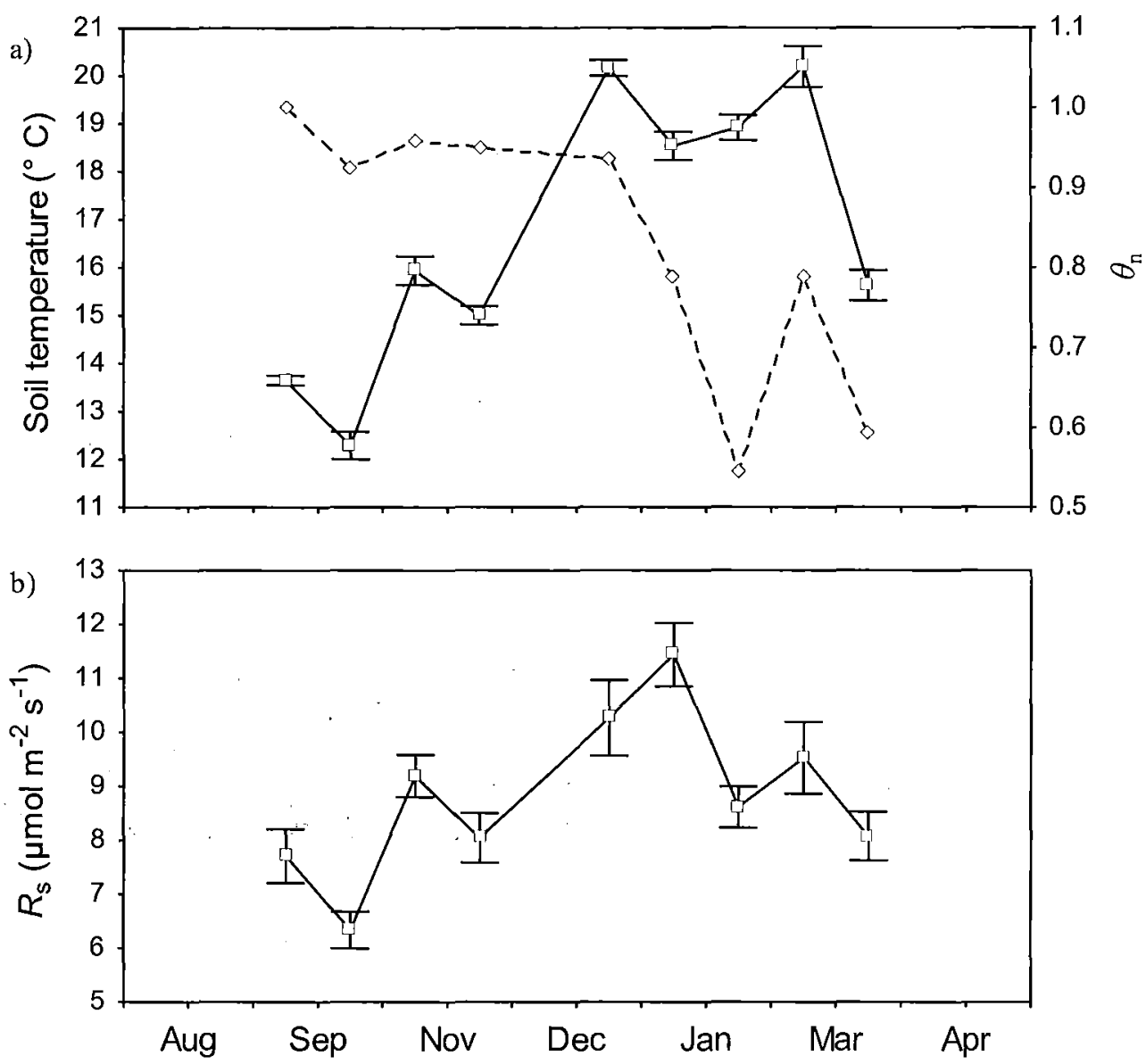

Figure 2-3 (a) Field measurements of soil temperature at $50 \mathrm{~mm}$ (square points connected with solid line) and $\theta_{\mathrm{n}}$ (normalised root-zone water content) (diamond points connected with dashed line) and, (b) $R_{\mathrm{s}}$ (soil-surface respiration) measurements from September 2005 to March 2006. Individual points represent averages of measurements made at 24 collars and bars represent standard errors.

\subsubsection{Modelling soil-surface respiration in the field}

The model developed as a result of the laboratory experiment, was used to predict $R_{\mathrm{s}}$ with inputs of $T_{\mathrm{s}}$ (at $50 \mathrm{~mm}$ depth) and $\theta_{\mathrm{n}}(0-300 \mathrm{~mm}$ soil depth) data that were measured in the field. Thus, a prediction of $R_{\mathrm{s}}$ in the field could be made using the laboratory model. The $R_{10}$ value used in the model, during this exercise, was established by calculating the average of field $R_{\mathrm{s}}$ measurements made when $T_{\mathrm{s}}$ was close to $10^{\circ} \mathrm{C}$. The field measured $R_{10}$ value was $4.7 \mu \mathrm{mol} \mathrm{m} \mathrm{m}^{-2} \mathrm{~s}^{-1}$, was higher than the $R_{10}$ laboratory 
fitted value of $3.19 \mu \mathrm{mol} \mathrm{m}^{-2} \mathrm{~s}^{-1}$, indicating that $R_{\mathrm{s}}$ was greater in the field than in the laboratory. Thus, if the laboratory fitted value of $R_{10}$ was used to run the model, the model would have underestimated measured field $R_{\mathrm{s}}$. Hence, the field measured $R_{10}$ value was used to run the model. There was a significant regression relationship $\left(r^{2}=0.52, P<0.05\right)$ between the rates of actual measured field $R_{\mathrm{s}}$ and the rates of modelled field $R_{\mathrm{s}}$ (Fig. 2-4). A concordance correlation test was also performed which measured the variation of the linear relationship between values of measured and modelled $R_{\mathrm{s}}$, from the line of unity (Lin 1989). The concordance correlation coefficient measures both how far each observation deviates from the line to the data (precision), and also how far this line deviates from the line through the origin (accuracy) (Lin 1989). The concordance correlation coefficient was 0.66 . Differences between modelled and measured $R_{\mathrm{s}}$ became greater in the latter part of the summer when $\theta_{\mathrm{n}}$ in the field fell bellow approximately 0.8 . 

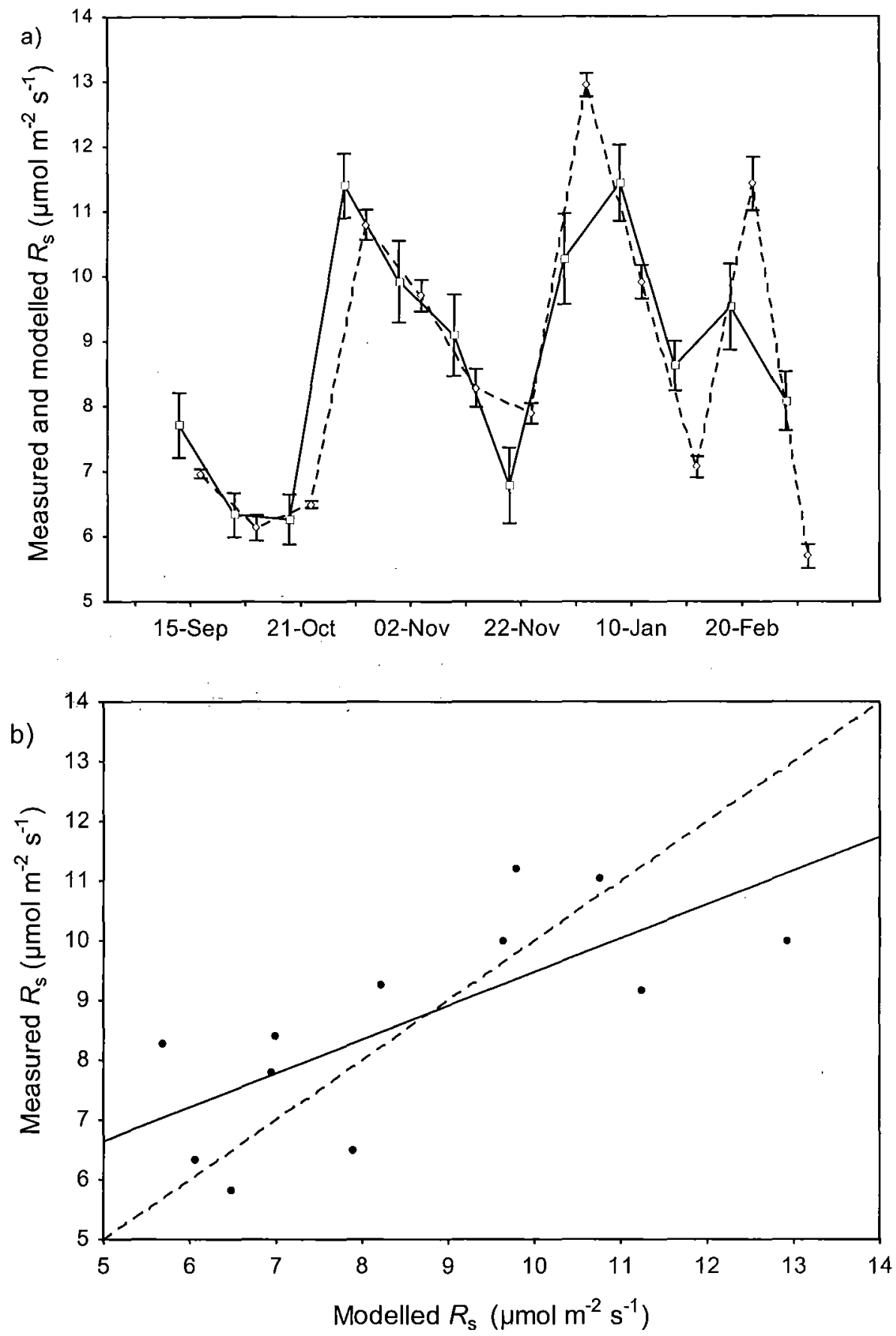

Figure 2-4 (a) Field measured soil-surface respiration $\left(R_{\mathrm{s}}\right)$ (dashed line, $\left.\mathrm{n}=24\right)$ and modelled soil-surface respiration $\left(R_{\mathrm{s}}\right)$ (solid line) throughout the year and standard error bars. Modelled values are slightly offset measured values of $R_{\mathrm{s}}$ to avoid overlap. (b) Field measured and modelled rates of soil-surface respiration $\left(R_{\mathrm{s}}\right) r^{2}=$ 0.52; $P<0.05$. Dashed line represents the line of unity. The concordance correlation coefficient was 0.66 , indicating agreement between measured and modeled $R_{\mathrm{s}}$. 


\subsection{Discussion}

\subsubsection{Laboratory measurements}

The laboratory experiment allowed the response of soil surface respiration to $T_{\mathrm{s}}$ and $\theta_{\mathrm{n}}$ to be determined. Equation 2.5 provided an accurate description of the response of $R_{\mathrm{s}}$ to soil temperature. The value of $\theta_{\mathrm{c}}$ of 0.90 fitted by the respiration model indicated that at $\theta_{\mathrm{n}}$ less than this value $R_{\mathrm{s}}$ was limited by $\theta$. Low $\theta$ can limit $R_{\mathrm{s}}$ by stressing microbial communities and plant roots (Rey et al. 2002). Many other studies have also reported respiration limitations as $\theta$ decreased (Reichstein et al. 2005; Davidson et al. 1998). For instance, Risch and Frank (2006) reported that in a temperate natural grassland, spatial and temporal variability in $R_{\mathrm{s}}$ was ultimately related to variability in $\theta$, which ranged from a high of $\sim 30 \%$ in May to a low $\sim 10 \%$ in August, which when normalised by myself (following the procedure described in section 2.2.4), ranged from a $\theta_{n}$ of $1-\sim 0.33$ and averaged $\sim 0.7$ throughout the growing season, which, results from this study suggest, is well within the range where low $\theta$ limits $R_{\mathrm{s}}$. In a Canadian prairie, Flanagan and Johnson (2005) reported that the $Q_{10}$ (proportional change in respiration with a $10^{\circ} \mathrm{C}$ change in temperature) of ecosystem respiration $\left(R_{\mathrm{e}}\right)$ decreased with declining soil water availability. In this current study, $R_{\mathrm{s}}$ was not limited when $\theta_{\mathrm{n}}$ was $>\theta_{\mathrm{c}}$.

\subsubsection{Field measurements of soil-surface respiration}

Compared to other temperate grassland respiration studies, field $R_{\mathrm{s}}$ rates were relatively high in this study. The $R_{10}$ of $4.7 \mu \mathrm{mol} \mathrm{m} \mathrm{m}^{-2} \mathrm{~s}^{-1}$ is comparable to the value of $4.27 \mu \mathrm{mol} \mathrm{m} \mathrm{m}^{-2} \mathrm{~s}^{-1}$ reported for a mountain meadow in Austria (Wohlfahrt et al. 2005), but higher than the ecosystem respiration $\left(R_{\mathrm{e}}\right) R_{10}$ value of $2.44 \mu \mathrm{mol} \mathrm{m}{ }^{-2} \mathrm{~s}^{-1}$ reported by Nieveen et al. (2005) for a grazed New Zealand pasture over a drained peat soil. Bolstad and Vose (2005) reported $R_{\mathrm{s}}$ values at $10^{\circ} \mathrm{C}$ of approximately $2 \mu \mathrm{mol} \mathrm{m} \mathrm{m}^{-2} \mathrm{~s}^{-1}$ at pastoral sites in the southern Appalachian Mountains, USA. Soil-surface respiration rates were also much lower at grazed and ungrazed sites in a temperate grassland in Yellowstone National Park, USA, which reached maximum rates of $\sim 4 \mu \mathrm{mol} \mathrm{m} \mathrm{m}^{-2} \mathrm{~s}^{-1}$ in the autumn at a $T_{\mathrm{s}}$ of approximately $15^{\circ} \mathrm{C}$ (Risch and Frank 2006). Flanagan and Johnson (2005) reported a maximum $R_{10}$ value of $3.6 \mu \mathrm{mol} \mathrm{m} \mathrm{m}^{-2} \mathrm{~s}^{-1}$ for $R_{\mathrm{e}}$ in well watered soils in a Canadian temperate grassland. One explanation for the relatively high $R_{10}$ 
found in this study is that $\theta$ remained high throughout most of the measurement period and rarely reached levels low enough to have a limiting effect.

\subsubsection{Comparison of modelled and measured soil-surface respiration in the field}

The respiration model developed, using equations 2.5 and 2.6, fitted the field $R_{\mathrm{s}}$ data well. Using regression analysis, the model was able to explain $52 \%$ of the variation in field $R_{\mathrm{s}}$ measurements. The concordance correlation coefficient was 0.66 , indicating good agreement between measured and modelled $R_{\mathrm{s}}$, but some deviation from the line of unity. The model generally underestimated $R_{s}$ when $\theta_{\mathrm{n}}$ was less than $\sim 0.8$. It is possible that during periods of dry soil-surface conditions in the field, some grass roots are able to compensate for this by accessing soil water from deeper down the soil profile. Many grass roots were observed at soil depths of $300 \mathrm{~mm}$. Other differences between the modelled and measured field respiration rates are possibly due to the field $R_{\mathrm{s}}$ responses to $T_{\mathrm{s}}$ and $\theta_{\mathrm{n}}$ being confounded by other factors such as variations in radiation, vegetation development and $\mathrm{C}$ allocation and precipitation (Risch and Frank 2006; Trumbore 2006: Salimon et al. 2004).

At the field site, cattle periodically grazed the pasture. There are several possible mechanisms by which grazing can affect $R_{\mathrm{s}}$. The removal of above-ground vegetation by grazing results in reduced photosynthesis (Bremer et al. 1998), which can reduce $R_{\mathrm{s}}$ since below-ground autotrophic respiration is partially dependent on plant $\mathrm{C}$ allocation below-ground (Flanagan and Johnson 2005). Heterotrophic respiration is also influenced by the supply of root exudates, which may decline following grazing (Garcia 1992). Following grazing many grass species relocate $\mathrm{C}$ assimilate to regrowing shoots at the expense of roots, so less $C$ is translocated to the roots (Bremer et al. 1998). Crider (1955) reported that the removal of half or more of the foliage from several grass species caused root growth to stop for up to six weeks.

In this study the effects of grazing on $R_{\mathrm{s}}$ via reduced above-ground biomass could not be determined. This was because the grass inside the soil collar was cut to $20 \mathrm{~mm}$ prior to $R_{\mathrm{s}}$ being measured (approximately every two weeks), which meant that the 
length of the grass growing inside the soil collar did not vary greatly over the measurement period, regardless of whether the pasture had been grazed. Furthermore, the soil collars were placed relatively deep $(130 \mathrm{~mm})$ into the soil to prevent them from being damaged by cattle stepping on them. Since $90 \%$ of root biomass occurred within the top $100 \mathrm{~mm}$ of the soil horizon, the majority of the root respiration included in the $R_{\mathrm{s}}$ measurements must have originated from the roots of the grass growing inside the embedded soil collars. Thus, roots from grass growing outside the soil collars, which was not clipped, and hence would be expected to be affected by dramatic reductions in above-ground biomass due to grazing, would only occur at depths greater than $130 \mathrm{~mm}$.

Previous studies have found grazing can cause $R_{\mathrm{s}}$ to increase or decrease, while other studies have reported no effects. For instance, Bremer et al. (1998) conducted a clipping experiment to simulate grazing and found that clipping reduced annual $R_{\mathrm{s}}$ by $17.5 \%$ due to reduced vegetative photosynthesis. LeCain et al. (2000), over a three year period found no seasonal difference in $R_{\mathrm{s}}$ between cattle grazed and un-grazed semiarid sites in Wyoming, USA, but found that in the early spring, $R_{\mathrm{s}}$ was greater in grazed than ungrazed sites. LeCain et al. (2000) attributed this to better light penetration and a warmer soil surface in the grazed sites, which led to a higher rate of $R_{\mathrm{s}}$. Risch and Frank (2006) found no effect of grazing by elks, bison and pronghorn on $R_{\mathrm{s}}$ in a temperate grazed grassland study, and suggested that soil water stress during the measurement period and a lower than usual grazing intensity could have reduced the effects of grazing on $R_{\mathrm{s}}$ in that study.

Consideration was also given to the possibility that $R_{\mathrm{s}}$ might vary due to urine deposition from when the cattle were grazing in the pasture. Urine can increase soil $\mathrm{pH}$, nitrogen replete soil patches and increase microbial availability of soil organic matter (Kelliher et al. 2005). Kelliher et al. (2005) conducted a laboratory incubation experiment where they applied urea applications to soil samples collected from a temperate dairy cattle-grazed pasture near Lincoln, New Zealand, and found that microbial respiration increased by up to 5 times that of control soils a day after urea application. They reported that microbial respiration remained high for 4 days, and returned to pretreatment levels after 6 days. A study in which Clough et al. (2003) applied synthetic urine to soils sampled from a temperate sheep-grazed grassland near Lincoln, New 
Zealand, reported that over 9 days after urine application, total $R_{\mathrm{s}}$ was 4.3 times greater than that of control soils. In this present study, there was no noticeable effect on $R_{\mathrm{s}}$ from possible urine application by the cattle, although it is not known whether the cattle urinated on or near the $R_{\mathrm{s}}$ collars embedded in the pasture. The lack of a noticeable urination effect might be because $R_{\mathrm{s}}$ measurements were generally made more than a week after the site had been grazed. However, on 21 October $R_{\mathrm{s}}$ was measured while the cattle were in the pasture grazing and there was no significant change in $R_{\mathrm{s}}$ in relation to the previous and subsequent days on which measurements took place.

For more complete testing of the laboratory based model under field conditions, a wider range of $\theta_{n}$ is required. Inter-annual variability in rainfall could result in a wide range of $\theta$ at the field site, but periods of prolonged drought are rare. This suggests, therefore, that changes in $R_{\mathrm{s}}$ at this field site can be explained largely by $T_{\mathrm{s}}$, except under extreme drought conditions in exceptional years.

\subsubsection{Conclusions}

The results of the laboratory study showed that both $T_{\mathrm{s}}$ and $\theta_{\mathrm{n}}$ regulated $R_{\mathrm{s}}$ in this cattle grazed temperate pasture. In the laboratory, $\theta_{\mathrm{n}}$ had a limiting effect on respiration when $\theta_{\mathrm{n}}$ fell below 0.90 . However, in the field study the water limitation effect was minor, due to other factors such as grass roots accessing deeper soil water and high, well distributed rainfall. Thus, seasonal changes in $R_{\mathrm{s}}$ at the site are explained almost entirely by $T_{\mathrm{s}} . R_{\mathrm{s}}$ rates at this temperate grazed pasture are relatively high compared to those reported for other temperate grasslands, which might be due to the non water limiting conditions which persist for much of the year at this site. The soil-surface respiration model suggests that if the field site were to experience drier soil-surface conditions than experienced throughout this study period, $R_{\mathrm{s}}$ would likely be reduced due to $\theta$ limitations. 


\section{Measurement and modelling of soil-surface respiration from a grazed temperate pasture during the growing}

season

\subsection{Introduction}

Net ecosystem $\mathrm{CO}_{2}$ exchange (NEE) is determined from the difference between the photosynthetic $\mathrm{CO}_{2}$ input from the atmosphere to the ecosystem, which occurs via photosynthesis, and the $\mathrm{CO}_{2}$ outputs from the ecosystem due to ecosystem respiration $\left(R_{\mathrm{e}}\right)$ (equation 1.3). The magnitude of NEE is relatively small compared to the opposing photosynthetic and ecosystem respiration $\mathrm{CO}_{2}$ fluxes (section 1, Fig.1-1). Ecosystem respiration comprises $\mathrm{CO}_{2}$ from both above-ground and below-ground components. The above-ground $\mathrm{CO}_{2}$ source occurs as a result of autotrophic respiration $\left(R_{\mathrm{aa}}\right)$ which takes place through plant components. The below-ground $\mathrm{CO}_{2}$ source occurs as soil-surface respiration $\left(R_{\mathrm{s}}\right)$ which is the result of heterotrophic decomposition of soil organic compounds and detritus $\left(R_{\mathrm{h}}\right)$, along with root autotrophic respiration $\left(R_{\mathrm{ab}}\right)$ (Reth et al. 2005). Soil-surface respiration is the second largest $\mathrm{CO}_{2}$ flux in the global carbon cycle (Reichstein et al. 2005), thus it is extremely important to understand how this is regulated by environmental variables to predict future impacts of global climate change on carbon budgets for ecosystems (Law et al.1999a).

Common methods for measuring $R_{\mathrm{s}}$ include chambers placed on the soil-surface and the eddy covariance technique for whole ecosystem exchange. Chamber measurements can provide useful information on the spatial variation of $R_{\mathrm{s}}$ and how it responds to environmental variables. In chapter 2 chamber measurements under controlled laboratory conditions were used to show how $R_{\mathrm{s}}$ in a New Zealand grazed pasture was regulated by soil temperature $\left(T_{\mathrm{s}}\right)$ and root-zone volumetric water content $(\theta)$. This knowledge was subsequently used to develop a model to determine the response of $R_{\mathrm{s}}$ to driving environmental variables.

Eddy covariance systems measure the covariation between vertical wind velocities and $\mathrm{CO}_{2}$ concentrations, providing a direct measure of NEE across the canopy 
- atmosphere interface (Baldocchi 2003). During the nocturnal period, when photosynthesis is absent, the eddy covariance technique provides a direct measurement of $R_{\mathrm{e}}$. Nocturnal measurements of respiration using eddy covariance have an advantage over chamber measurements in that they reduce the inherent uncertainties that are involved with scaling up chamber measurements over time and space (Law et al. 1999b).

Eddy covariance nighttime measurements also provide a useful means of evaluating chamber based respiration models. This requires the up-scaling of chamber measurements. Alternatively, a comparison of techniques could involve the downscaling of eddy covariance data to the chamber based measurements.

The contribution of $R_{\mathrm{s}}$ to $R_{\mathrm{e}}$ has been measured in many ecosystems. For example, Wohlfahrt et al. (2005) used eddy covariance and chamber measurements in a mountain meadow in the Austrian Alps to show that the contribution of $R_{\mathrm{s}}$ to $R_{\mathrm{e}}$ varied from $100 \%$ in the winter to $40 \%$ in the summer following changes in the presence of above-ground vegetation. The contribution of $R_{\mathrm{s}}$ to $R_{\mathrm{e}}$, measured using respiration chambers, ranged from $50 \%$ to $77 \%$ during the growing season at grazed and ungrazed grassland sites in Yellowstone National Park, USA (Risch and Frank 2006). In the study by Risch and Frank (2006) $R_{\mathrm{s}}$, was almost constant over the growing season, however above-ground autotrophic respiration $\left(R_{\mathrm{aa}}\right)$ closely followed changes in soil and air temperature and vegetation development.

In New Zealand grazed pastures, the contribution of $R_{\mathrm{s}}$ to $R_{\mathrm{e}}$ is not known, thus the objectives of this part of the study were to:

- Determine the contribution of $R_{\mathrm{s}}$ to $R_{\mathrm{e}}$,

- Determine if measuring soil-surface respiration with the surface grass clipped to $20 \mathrm{~mm}$ above the soil-surface (as conducted in chapter 2 ) differs significantly from measuring soil-surface respiration with the grass clipped right to the soil surface,

- Compare chamber based modelled estimates of $R_{\mathrm{s}}$ with eddy covariance $R_{\mathrm{e}}$ measurements that have been partitioned into $R_{\mathrm{s}}$ and $R_{\mathrm{aa}}$, and 
- Use continuous half-hourly soil temperature and root-zone water content measurements to estimate total growing-season $R_{\mathrm{s}}$.

\subsection{Methods}

\subsubsection{Site description}

The study was conducted in an established cattle-grazed pasture, located near Oxford in Canterbury, New Zealand (latitude $43.3^{\circ} \mathrm{S}$, longitude $172.2^{\circ} \mathrm{E}$, elevation above sea level $34 \mathrm{~m}$ ). The pasture was dominated by perennial ryegrass (Lolium perenne L.). Other vegetation included white clover (Trifolium repens L.),yorkshire fog (Holcus lanatus L.), creeping bent (Agrostis stolonifera L.) and browntop (Agrostis capillaris L.). During the measurement period cattle grazed the pasture three times, from 9 October to 22 October 2005, from 25 November to 8 December 2005, and from 3 February to 16 February 2006.

The soil was a Taitapu Typic Orthic Gley (New Zealand soil classification) (Hewitt 1998), poorly drained, with a perched water table. This type of soil typically develops on wet sites and in depressions at the bases of hills. For much of the year, the water table is near to the surface and the soil profile has a pale subsoil colour. In this soil, field capacity, expressed as root-zone volumetric water content $(\theta)$, occurs at $0.49 \mathrm{~m}^{3} \mathrm{~m}^{-3}$. The average $\mathrm{C}: \mathrm{N}$ ratio $(0-300 \mathrm{~mm}$ depth) was 14.2. Mixed Nothofagus and Podocarpus forests were present at this location before conversion to pasture, more than a century ago. The underlying zonal soils are derived from greywacke and tertiary rocks with a covering of loess, which developed during the last glaciation (18 - 20000 years ago). The soil pH was 5.3. At depths greater than $300 \mathrm{~mm}$, the soil became white and mottled.

At Darfield, located $20 \mathrm{~km}$ from the field site, the 30 year mean annual air temperature is $11.7^{\circ} \mathrm{C}$ (NIWA 2006). The climate is characterized by cool, moist winters (average daily air temperature $7^{\circ} \mathrm{C}$ ) and warm summers (average daily air temperature $16^{\circ} \mathrm{C}$ and average daily maximum air temperature $22^{\circ} \mathrm{C}$ ). The average yearly rainfall is $782 \mathrm{~mm}$ with the rainfall being evenly distributed throughout the year (NIWA 2006). 


\subsubsection{Determining the contribution of soil-surface respiration to ecosystem} respiration

A partitioning exercise was conducted in spring 2005. At nine replicate sites, a closed gas exchange system was used to measure $N E E, R_{\mathrm{e}}, R_{\mathrm{s}}$ and soil-surface respiration with the grass clipped to ground level $\left(R_{\mathrm{sG}}\right)$. The system consisted of a clear dome chamber (height $200 \mathrm{~mm}$ ) placedon a collar (diameter $340 \mathrm{~mm}$, height $100 \mathrm{~mm}$ ) inserted $20 \mathrm{~mm}$ into the soil surface at random locations in the pasture, attached to an infrared gas analyser (Li-6200, Li-Cor, Lincoln, NE, USA) (Plate 3.1). The dome chamber had a height of $200 \mathrm{~mm}$, which was high enough to fit over the pasture without disturbing the system and the soil collars contained a rubber seal to ensure leaks were minimised during $\mathrm{CO}_{2}$ exchange measurements. By measuring the flux densities mentioned above, it was possible to calculate the contribution of $R_{\mathrm{s}}$ to $R_{\mathrm{e}}$.

The first measurement, made in natural daylight conditions, determined NEE. This was achieved by simply placing the air-flushed dome chamber onto the appropriate collar and then recording the time and concentration of $\mathrm{CO}_{2}$ every 30 seconds for a total period of $2.5 \mathrm{~min}$. This enabled the flux density to be calculated as,

$$
Q=\frac{\Delta c}{\Delta t} \cdot \frac{v}{a}
$$

where $Q$ is the $\mathrm{CO}_{2}$ flux density, $\Delta c$ is the change in $\mathrm{CO}_{2}$ concentration, $\Delta t$ is the change in time, $v$ is the volume of the total chamber and $a$ is the ground area occupied by the chamber. For each measurement the flux density was calculated as the mean of three measurements.

Following the NEE measurement, the chamber was opened, the headspace flushed with air, the dome replaced and an opaque canvas covering was placed over the chamber. The canvas covering ensured that no light entered the chamber thus making sure the only flux was $R_{\mathrm{e}}$, as photosynthesis does not occur in the dark. The measurement of $R_{\mathrm{e}}$ was made in the same manner as described above for NEE. 
Directly after $R_{\mathrm{e}}$ had been measured, the chamber was opened and the grass was clipped inside the soil collar to a height of $20 \mathrm{~mm}$ above the soil-surface and $R_{\mathrm{s}}$ was measured as described above. The clipping was done to the same level as conducted in chapter 2 (sections 2.2.2 and 2.2.3).

Finally, $R_{\mathrm{sG}}$ was measured as above, after clipping the remaining $20 \mathrm{~mm}$ of grass right down to the soil-surface.

As each $\mathrm{CO}_{2}$ exchange measurement was being conducted, soil temperature was measured using a thermistor placed in the soil at a depth of $50 \mathrm{~mm}$. During NEE measurements leaf temperature was also measured using a thermistor. Root-zone volumetric water content was measured as described in section 3.2.4.

Grass clipped prior to the $R_{\mathrm{s}}$ and $R_{\mathrm{sG}}$ measurements was collected so that aboveground biomass and leaf area index $(L)$ could be determined for each of the nine replicates. A biomass sub-sample was taken from the harvested clippings from each replicate. This was then scanned to determine the sub-sample leaf surface area. The sub-samples and the remaining clippings were then dried for 48 hours at $70^{\circ} \mathrm{C}$, and weighed to determine total above-ground biomass and $L$ for each replicate. 


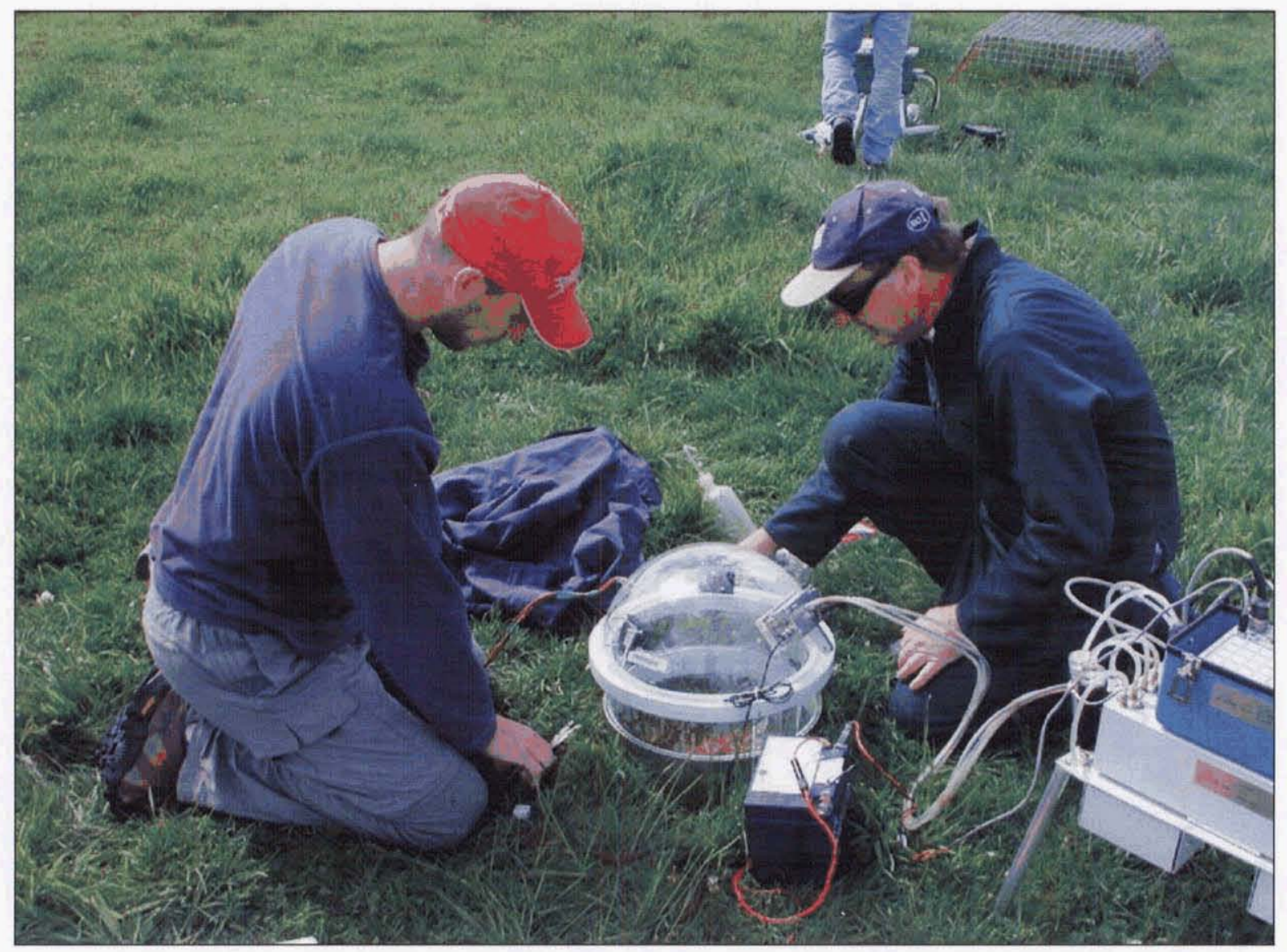

Plate 3.1 System used to measure net ecosystem exchange (section 3.2.2). The dome $\mathrm{CO}_{2}$ exchange chamber can be seen on top of a soil collar previously inserted $20 \mathrm{~mm}$ into the ground. A battery powering the infrared gas-analyser can be seen near the chamber.

\subsubsection{Eddy covariance ecosystem respiration measurements}

Ecosystem respiration $\left(R_{\mathrm{e}}\right)$ data were collected, from September 2005 (early spring) January 2006 (late autumn) with a closed-path, eddy-covariance system. The instrumentation consisted of a three-axis sonic anemometer (Solent, R3, Gill Instruments, Lymington, Hampshire, UK) mounted at a height of $4 \mathrm{~m}$ above the pasture (Plate 3.2). An air sampling suction pump, with a flow rate of $6 \mathrm{~L} \mathrm{~min}{ }^{-1}$, pulled air through Decabon tubing (ID $4 \mathrm{~mm}$ ), through a heat exchanger and then a closed-path, 
fast-response infrared gas analyser (Li-6262, Li-Cor, Lincoln, NE, USA) which measured the concentration of both $\mathrm{CO}_{2}$ and water vapour. The analyser was kept in a temperature controlled box and nitrogen gas was bled through the reference side of the analyser at $0.03 \mathrm{~L} \mathrm{~min}{ }^{-1}$. Calibration of the $\mathrm{CO}_{2}$ analyser was done infrequently, but when carried out drift was usually very small. The sampling tube was not heated because the lowered internal pressure caused by the inclusion of a $1 \mu \mathrm{m}$ filter reduced the dew point and prevented condensation formation. All wind and $\mathrm{CO}_{2}$ data were collected at $20 \mathrm{~Hz}$ (EddyMeas, Max-Planck-Institute for Biogeochemistry, Jena, Germany). Post-processing procedures used the analysis package developed by $R$. Clement at the University of Edinburgh (EdiRe) to determine 30 minute averages and closely followed the steps described by Moncrieff et al. (1997) and Aubinet et al. (2000). Changes in the average half-hour $\mathrm{CO}_{2}$ concentration stored in the air space below the sonic anemometer were calculated but found to be insignificant. By convention, the flux of $\mathrm{CO}_{2}$ away from the surface (respiration) is positive.

As this study was only interested in measurements of respiration in the absence of photosynthesis, only nighttime data were used. These data were further screened for suitable wind direction, when the wind was from the east or west (thus passing over the field site), and when sufficiently turbulent, the threshold value $u^{*}$ (friction velocity) $>0.3$ $\mathrm{m} \mathrm{s}^{-1}$, well within the range of $0.1-0.6 \mathrm{~m} \mathrm{~s}^{-1}$ often used to produce reliable nighttime data (Baldocchi 2003). For analysis purposes, data meeting these criteria were grouped by individual nights to attain nightly averages of $R_{\mathrm{e}}$. Only nightly averages of $R_{\mathrm{e}}$ that included three or more valid 30 min measurements, on nights when the cattle were not grazing the site were considered. The eddy covariance system was run by Dr. John Hunt of Landcare research, and nocturnal data were made available for this study. 


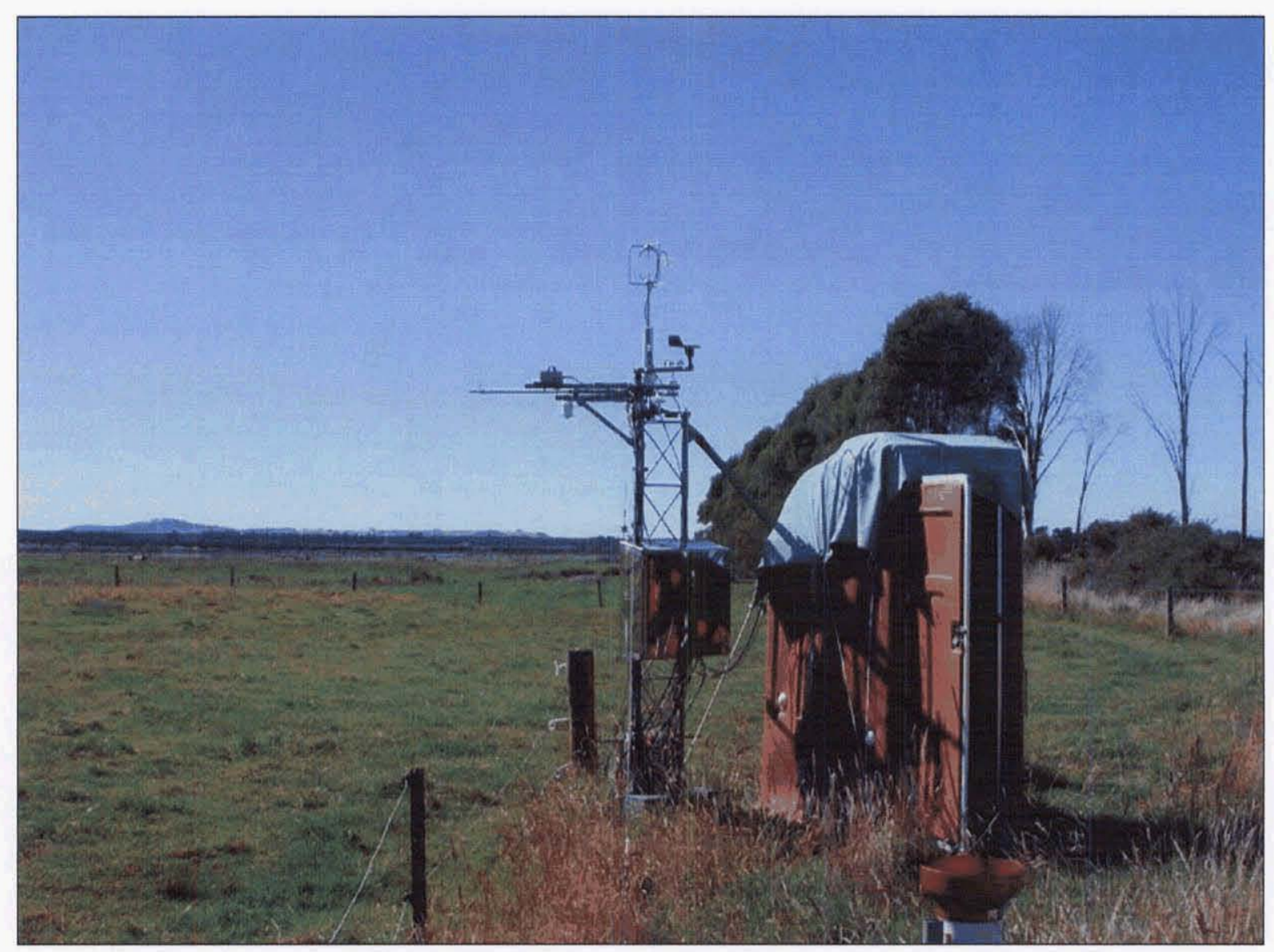

Plate 3.2 Eddy covariance system used to measure $\mathrm{CO}_{2}$ exchange. The sonic anemometer can be seen attached to the top of the tower. The gas analyser is located inside the temperature controlled box.

\subsubsection{Measurements of root-zone water content and soil temperature}

Data for root-zone volumetric water content $(\theta)$ and soil temperature $\left(T_{\mathrm{s}}\right)$ were measured half-hourly at 50, 100 and $300 \mathrm{~mm}$ soil depth from August 2005 to April 2006 using automated probes (ThetaProbe, Delta-T, Cambridge, UK) linked to data loggers (ML2 CR10X, Campbell Scientific, Logan, USA).

For analysis purposes, $\theta$ measurements were integrated to provide a single value for $0-300 \mathrm{~mm}$. To integrate $\theta$, values at the 50,100 and $300 \mathrm{~mm}$ depths, which 
represented $0-75,75-200$, and $200-300 \mathrm{~mm}$ of the soil profile, were multiplied by the proportion of the profile they measured $(25,41.6$ and $33.3 \%$ respectively) and then the values were added together. When soil samples were analysed, it was found that the bulk density of the soil varied considerably, from 0.456 to $1.132 \mathrm{~m}^{3} \mathrm{~m}^{-3}$. Thus, we decided to use a normalised value of root-zone water content $\left(\theta_{n}\right)$, defined as the amount of $\theta$ present relative to the maximum value $\left(\theta_{\max }\right)$.

$\theta_{\mathrm{n}}=\theta / \theta_{\max }$

\subsubsection{Modelling soil respiration}

The model of $R_{\mathrm{s}}$, developed in chapter 2, was used to model growing season $R_{\mathrm{s}}$ in the field using half-hourly measurements of $T_{\mathrm{s}}$ and $\theta_{\mathrm{n}}$ (section 3.2.4). Where,

$R_{s}=R_{10} e^{E_{o}\left[\frac{1}{56.02}-\frac{1}{T_{s}-227.13}\right]} \cdot\left[\frac{\theta_{n}}{\theta_{c}}\right]$

$R_{10}$ is the base respiration rate at $10{ }^{\circ} \mathrm{C}, T_{\mathrm{s}}$ is the soil temperature $(\mathrm{K})$ and $E_{\mathrm{o}}$ is a parameter related to the energy of activation $(K) . \theta_{c}$ is the point at which a further increase in $\theta_{n}$ no longer influences respiration. When $\theta_{n}$ was greater than $\theta_{c}$, the term $\left(\theta_{n} / \theta_{c}\right)$ is set to 1 . The model is a non-linear mixed effects model, fitted by maximum likelihood (Pinheiro and Bates 2000) (see section 2.2.4 for further details).

\subsubsection{Biomass measurements}

Twenty replicate samples for total aboveground biomass were collected once a month by Tony McSeveny (Landcare Research) by clipping vegetation to ground level within a $0.5 \mathrm{~m} \times 0.5 \mathrm{~m}$ plots. The plots were placed randomly throughout the pasture. Subsamples were collected from each main sample to determine the percentage of grass, herb and dead biomass within each replicate. The sub- and main samples were dried in an oven at $70^{\circ} \mathrm{C}$ for $48 \mathrm{~h}$ and then weighed to determine above-ground biomass. 


\subsection{Results}

\subsubsection{Determination of the contribution of soil-surface respiration to ecosystem respiration}

On the four days used to determine the contribution of $R_{\mathrm{s}}$ to $R_{\mathrm{e}}$, leaf temperature and $T_{\mathrm{s}}$ averaged 19.7 and $15.6{ }^{\circ} \mathrm{C}$ respectively (Table $3-1$ ). Normalised root-zone water content, measured next to the eddy covariance system, averaged 0.92 which was above the threshold $\theta_{\mathrm{c}}$ value of 0.90 (as determined in section 2.3.2), indicating that root-zone water content was not limiting respiration at this time.

Table 3-1 Leaf and soil temperatures, and normalised root-zone water content $\left(\theta_{n}\right)(0$ $-300 \mathrm{~mm}$ ) during the days of the partitioning experiment.

\section{Leaf temperature Soil temperature $\left({ }^{\circ} \mathrm{C}\right) \quad \theta_{n}$ \\ $\left({ }^{\circ} \mathrm{C}\right)$}

\begin{tabular}{lccl}
\hline 14 November & 24.0 & 15.6 & 0.91 \\
16 November & 18.3 & 14.6 & 0.93 \\
17 November & 13.3 & 15.0 & 0.93 \\
18 November & 23.0 & 17.3 & 0.92 \\
\hline
\end{tabular}


Averages of the partitioned $\mathrm{CO}_{2}$ fluxes measured with the clear chamber, showed that the NEE was negative, indicating a net uptake of $\mathrm{CO}_{2}$ by the ecosystem (Table 3-2). Ecosystem respiration and $R_{\mathrm{s}}$ were 13.8 and $11.1 \mu \mathrm{mol} \mathrm{m}^{-2} \mathrm{~s}^{-1}$, indicating that $84 \%$ of $R_{\mathrm{e}}$ was comprised of respiration from the soil-surface. This implies that the remaining $16 \%$ of $R_{\mathrm{e}}$ was due to $R_{\mathrm{aa}}$. Rates of $R_{\mathrm{sG}}$ were slightly lower then $R_{\mathrm{s}}$ and comprised $80 \%$ of $R_{\mathrm{e}}$. Among the nine replicates there was a significant relationship between the contribution of $R_{\mathrm{s}}$ to $R_{\mathrm{e}}$ and $L$ (Fig. 3-1).

Table 3-2. Direct measurements of net ecosystem exchange (NEE), ecosystem respiration $\left(R_{\mathrm{e}}\right)$, soil-surface respiration with the grass clipped to $20 \mathrm{~mm}\left(R_{\mathrm{s}}\right)$, and soil-surface respiration with the grass clipped to soil surface $\left(R_{\mathrm{SG}}\right)$ and the contribution of $R_{\mathrm{s}}$ to $R_{\mathrm{e}}, R_{\mathrm{aa}}$ to $R_{\mathrm{e}}$, and $R_{\mathrm{sG}}$ to $R_{\mathrm{e}}$, and standard errors (SE). $\mathrm{n}=10$.

$\mathrm{CO}_{2}$ exchange

\begin{tabular}{|c|c|c|}
\hline NEE & $-5.6 \mu \mathrm{mol} \mathrm{m} \mathrm{m}^{-2} \mathrm{~s}^{-1}$ & 1.2 \\
\hline$R_{\mathrm{e}}$ & $12.9 \mu \mathrm{mol} \mathrm{m} \mathrm{m}^{-2} \mathrm{~s}^{-1}$ & 1.0 \\
\hline$R_{\mathrm{s}}$ & $10.8 \mu \mathrm{mol} \mathrm{m} \mathrm{m}^{-2} \mathrm{~s}^{-1}$ & 0.80 \\
\hline$R_{\mathrm{SG}}$ & $10.5 \mu \mathrm{mol} \mathrm{m} \mathrm{m}^{-2} \mathrm{~s}^{-1}$ & 1.0 \\
\hline$R_{\mathrm{s}} / R_{\mathrm{e}}$ & $84 \%$ & 0.0 \\
\hline$R_{\mathrm{aa}} / R_{\mathrm{e}}$ & $16 \%$ & 0.0 \\
\hline$R_{\mathrm{sG}} / R_{\mathrm{e}}$ & $80 \%$ & 0.023 \\
\hline
\end{tabular}

SE 


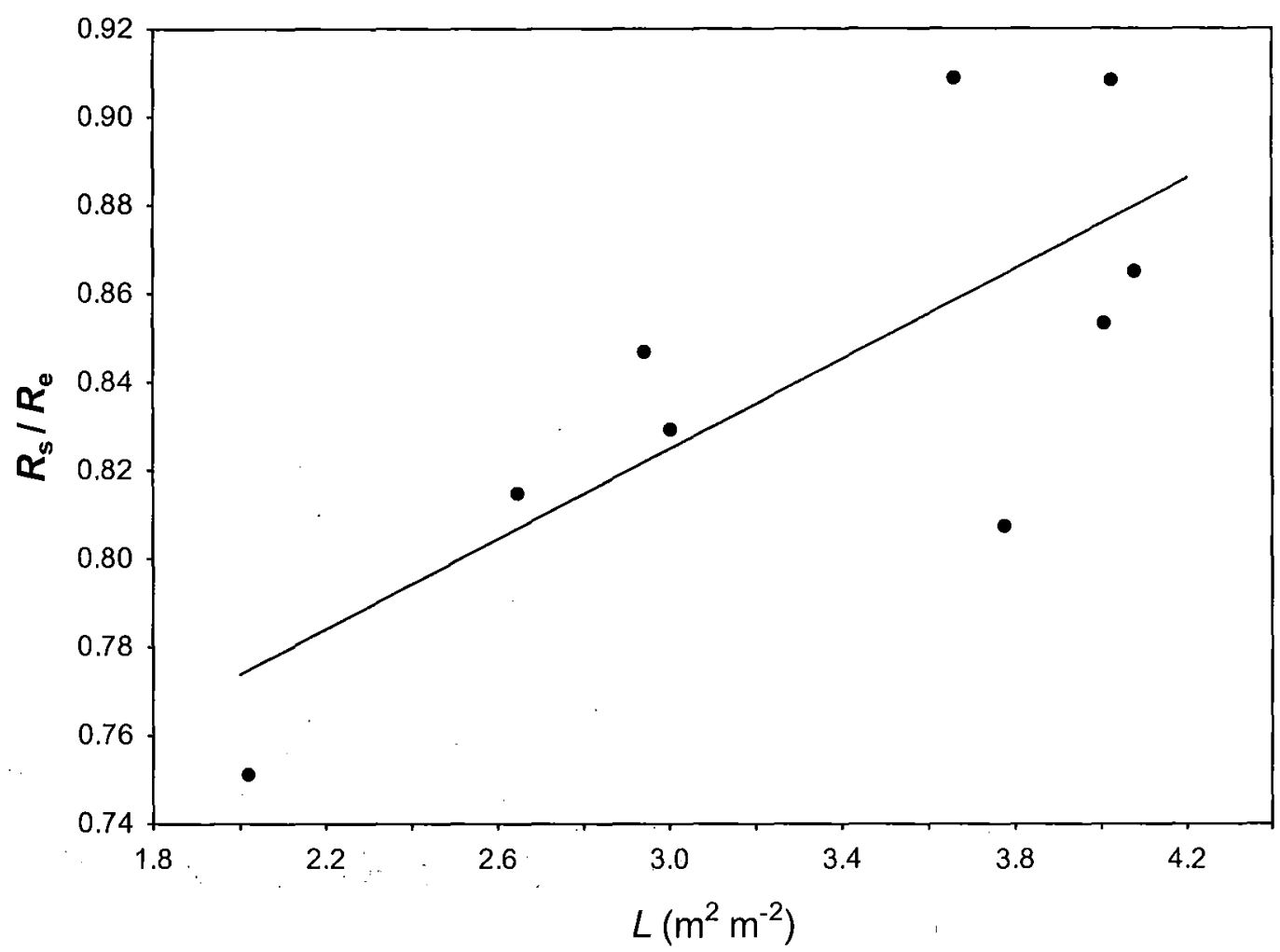

Figure 3-1 The relationship between the ratio of $R_{\mathrm{s}}$ to $R_{\mathrm{e}}$ and leaf area index $(L)$ for each of the nine replicates in the $\mathrm{CO}_{2}$ exchange partitioning exercise. $r^{2}=0.557$; $y=0.672+0.051^{*} x$.

\subsubsection{Eddy covariance nighttime respiration measurements}

There was a total of 58 nights where the nocturnal eddy covariance ecosystem respiration data met the selection criteria outlined in section 3.2.3. When the measurement period began in September 2005, the nighttime $T_{\mathrm{s}}$ was $11^{\circ} \mathrm{C}$ (Fig. 3-2). As spring progressed, $T_{\mathrm{s}}$ quickly increased to approximately $17^{\circ} \mathrm{C}$ and reached peaks of $20^{\circ} \mathrm{C}$ during mid-summer. In early autumn, $T_{\mathrm{s}}$ began to decrease to approximately $16^{\circ} \mathrm{C}$ at the end of the measurement period. Maximum $\theta$ during the measurement period was $0.49 \mathrm{~m}^{3} \mathrm{~m}^{-3}$. From spring through to the early summer period, $\theta_{\mathrm{n}}$ was between 0.9 and 1 . In mid-summer $\theta_{n}$ began to decrease but following a rainfall event it quickly returned to near field capacity. During the late summer $\theta_{\mathrm{n}}$ gradually fell and reached a low of approximately 0.57 by early autumn. 


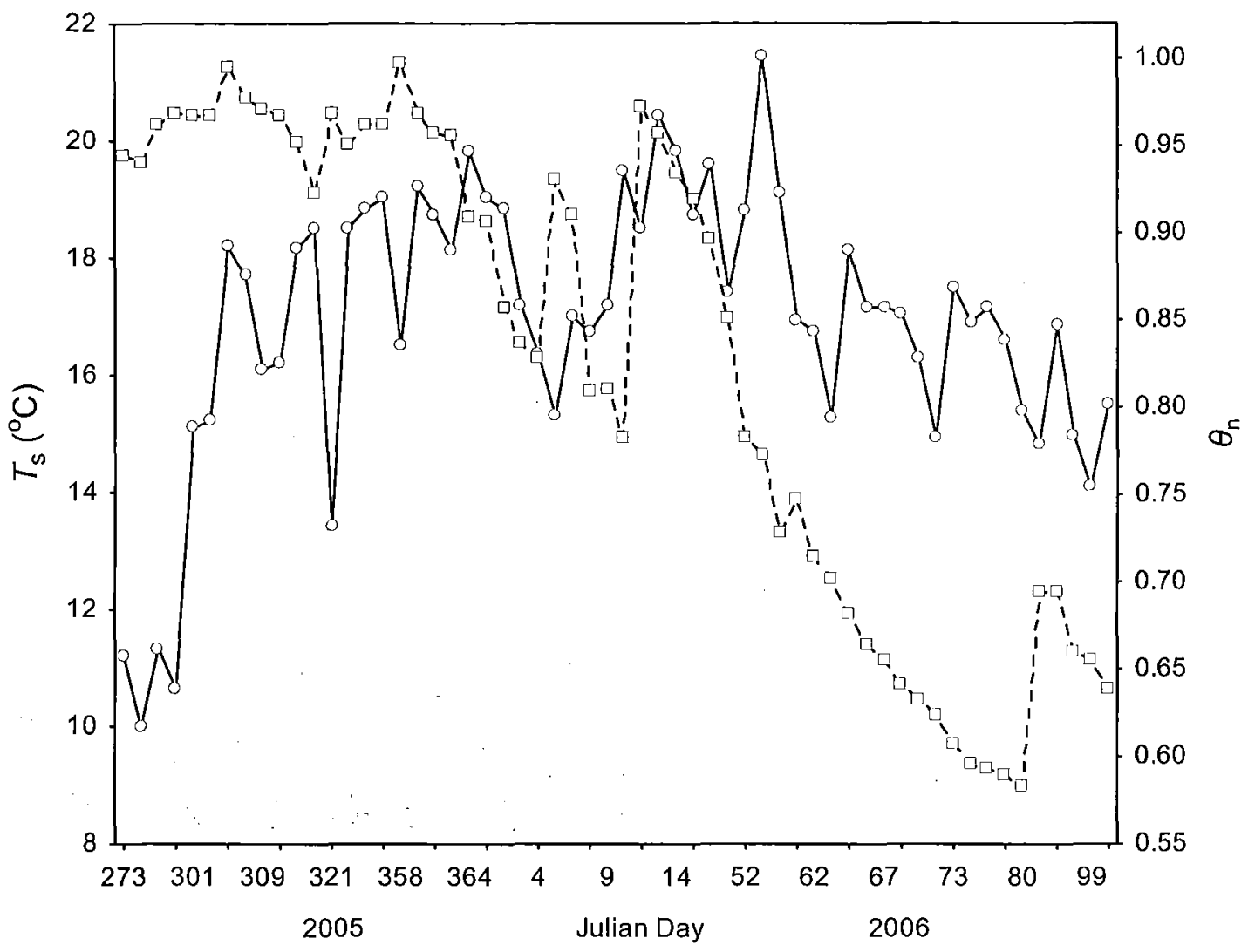

Figure 3-2 Nocturnal nighttime averages of field site soil temperature $\left(T_{\mathrm{s}}\right)$ (solid line) at $50 \mathrm{~mm}$ depth and normalised root-zone water content $\left(\theta_{\mathrm{n}}\right)$ (dashed line) over the measurement period.

The average ecosystem respiration rate for the 58 nights of valid data was $6.98 \mu \mathrm{mol} \mathrm{m} \mathrm{m}^{-2} \mathrm{~s}^{-1}$ and ranged from a high of $11.8 \mu \mathrm{mol} \mathrm{m} \mathrm{m}^{-2} \mathrm{~s}^{-1}$ in late December, 2005 to a low of $1.9 \mu \mathrm{mol} \mathrm{m} \mathrm{m}^{-2} \mathrm{~s}^{-1}$ in February, 2006 (Fig. 3-3).

Since the partitioning exercise revealed that $84 \%$ of $R_{\mathrm{e}}$ is comprised of $R_{\mathrm{s}}$, the nocturnal eddy covariance data was multiplied by this fraction to obtain eddy covariance estimates of soil-surface respiration $\left(R_{\mathrm{SE}}\right)$ (Fig. 3-3). $R_{\mathrm{SE}}$ data were compared with chamber based modelled rates of $R_{\mathrm{s}}$. $R_{\mathrm{SE}}$ rates that varied between 2.3 and $9.8 \mu \mathrm{mol}$ $\mathrm{CO}_{2} \mathrm{~m}^{-2} \mathrm{~s}^{-1}$ throughout the late spring and early summer periods. During the early autumn, $R_{S E}$ rates were relatively low, as they were limited by reductions in both $T_{\mathrm{s}}$ and 
$\theta_{n}$. Throughout the entire measurement period, the maximum and minimum $R_{S E}$ rates reached were 9.9 and $1.6 \mu \mathrm{mol} \mathrm{m} \mathrm{m}^{-2} \mathrm{~s}^{-1}$.

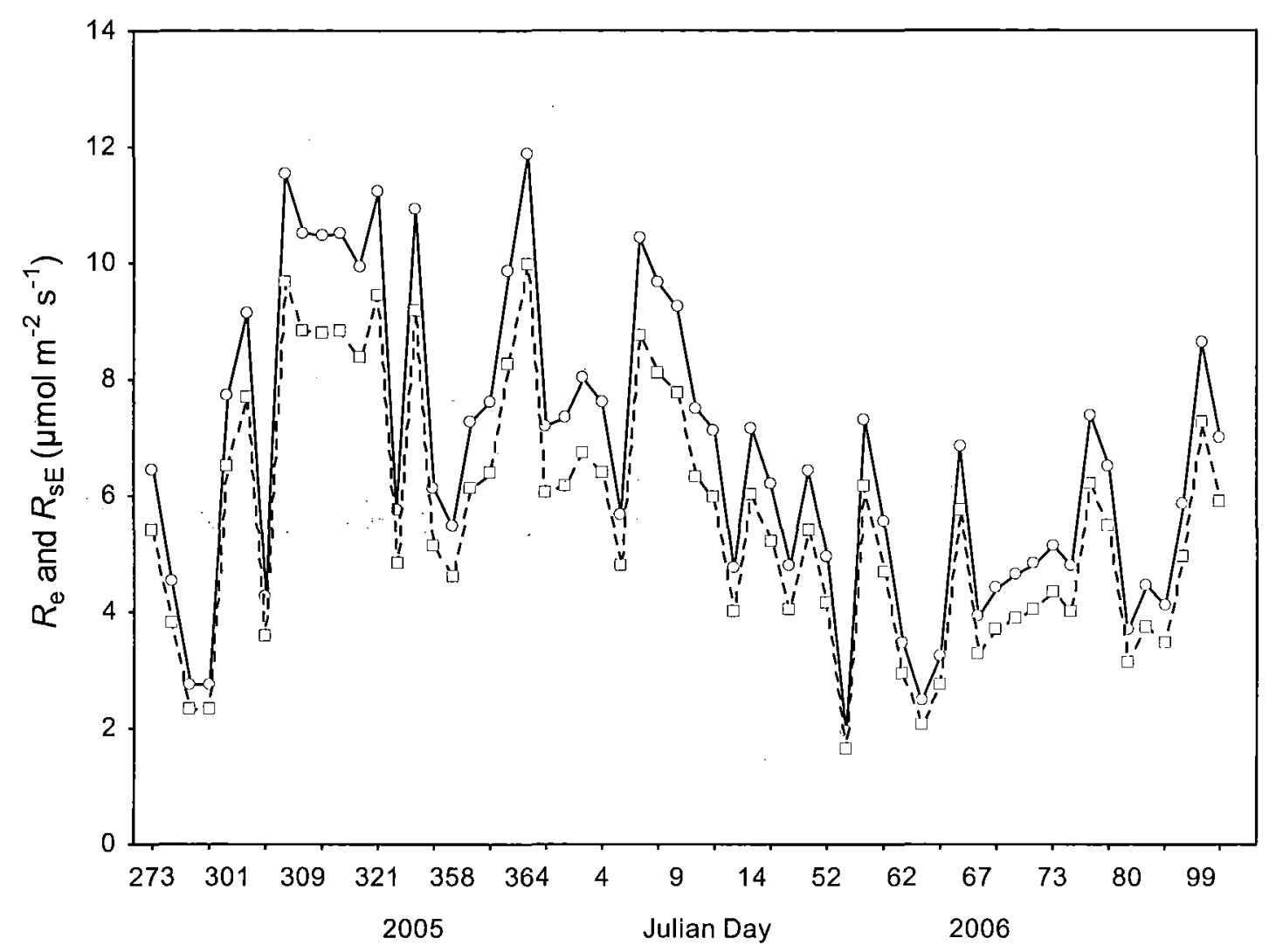

Figure 3-3 Nocturnal nighttime averages of ecosystem respiration $\left(R_{\mathrm{e}}\right)$ (solid line) and eddy covariance soil-surface respiration $\left(R_{\mathrm{SE}}\right)$ (dashed line) over the measurement period. $R_{\mathrm{SE}}$ was calculated by multiplying $R_{\mathrm{e}}$ by the fraction 0.84 , as determined in the partitioning exercise.

Any influence of $L$ on $R_{S E}$ was not able to be determined due to the large amount of overlap in the standard errors of $L$ data and normalised measurements of $R_{S E}$ (Fig. 3-4). $R_{S E}$ were normalised to $10^{\circ} \mathrm{C}$, by using equation 3.3 (with the root-zone water content term set to 1). Normalised $R_{S E}$ data were only considered for this analysis if 
measurements were made within a week of biomass collection and if the cattle did not enter the pasture to graze within that week.

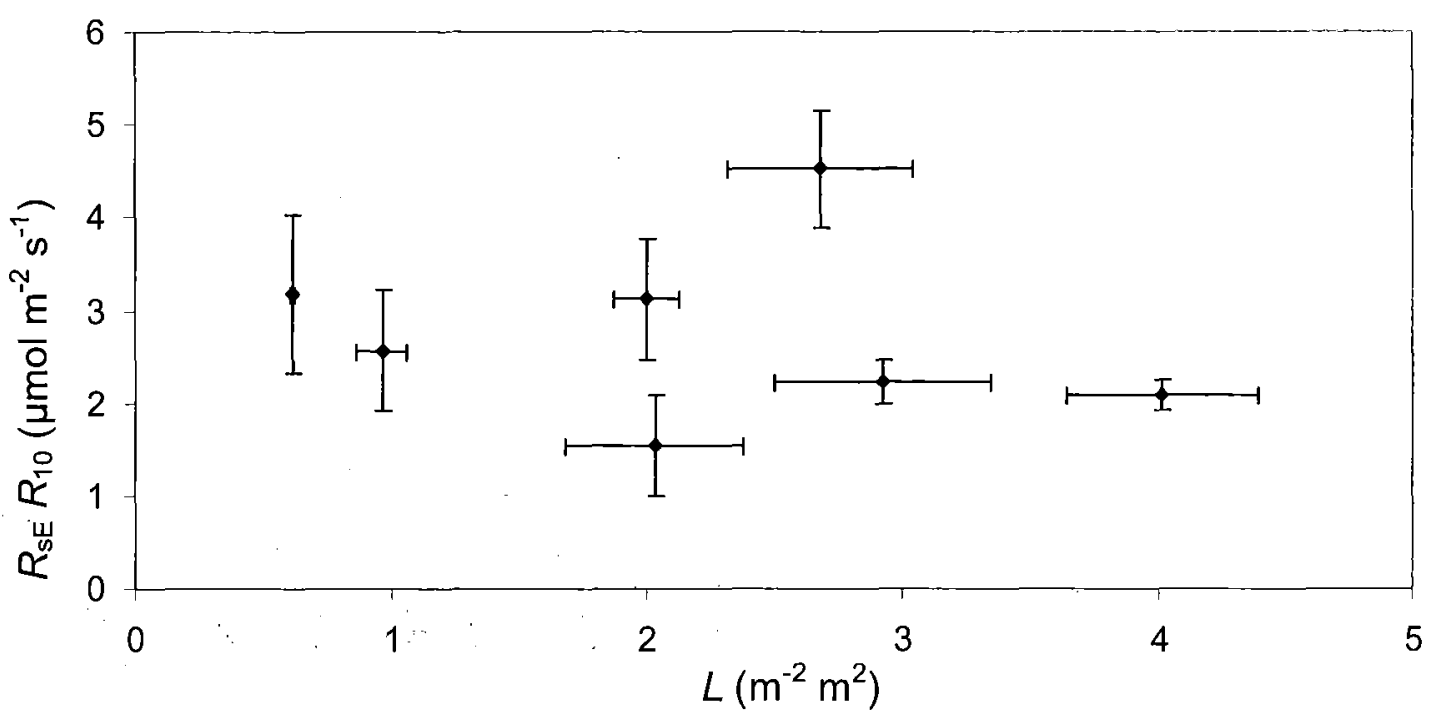

Figure 3-4 Eddy covariance estimates of soil-surface respiration $\left(R_{\mathrm{SE}}\right)$ normalised to $10^{\circ} \mathrm{C}$ and leaf area index $(L) . R_{10}$ values are averages of acceptable nights of $R_{\mathrm{SE}}$ data occurring within a week of biomass measurements (providing cattle were not grazing within that week). $L$ measurements represent the average of twenty replicate measurements. Bars show the standard errors on both axes.

\subsubsection{Modelling soil-surface respiration measurements}

In Chapter 2, a chamber-based model was developed to estimate $R_{\mathrm{s}}$ as a function of $T_{\mathrm{s}}$ and $\theta_{\mathrm{n}}$ (equation 3.3). The parameters used to run the model are presented in Table 3-3. When this model was applied to the entire period of valid nighttime eddy covariance measurements, using soil temperature and root-zone water content data collected at the site, resulting values were consistently higher than $R_{S E}$, but generally followed the same pattern (Fig. 3-5). The integrated sum for the $R_{S E}$ and modelled $R_{\mathrm{s}}$ for the total 58 nights 
of valid measurements are presented in Table 3-4. The total model $R_{\mathrm{s}}$ was greater than the total $R_{\mathrm{sE}}$ by $16 \mathrm{~mol} \mathrm{~m}^{-2}(57 \%)$ (Table $\left.3-4\right)$.

Table 3-3 Fitted parameters for the chamber based soil-surface respiration model as determined in chapter 2. $E_{0}$ is related to the energy of activation, $\theta_{c}$ is the point at which root-zone water content no longer influences respiration. The $R_{10}$ value comes from direct soil-surface respiration measurements made in the field at $10^{\circ} \mathrm{C}$ with a closed chamber.

\begin{tabular}{lll}
\hline $\boldsymbol{R}_{\mathbf{1 0}}$ & $E_{\mathrm{o}}$ & $\boldsymbol{\theta}_{\mathrm{c}}$ \\
$\left(\mu \mathrm{mol} \mathrm{m} \mathrm{s}^{-1}\right)$ & $(\mathrm{K})$ & \\
\hline 4.7 & 369.2 & 0.90 \\
\hline
\end{tabular}




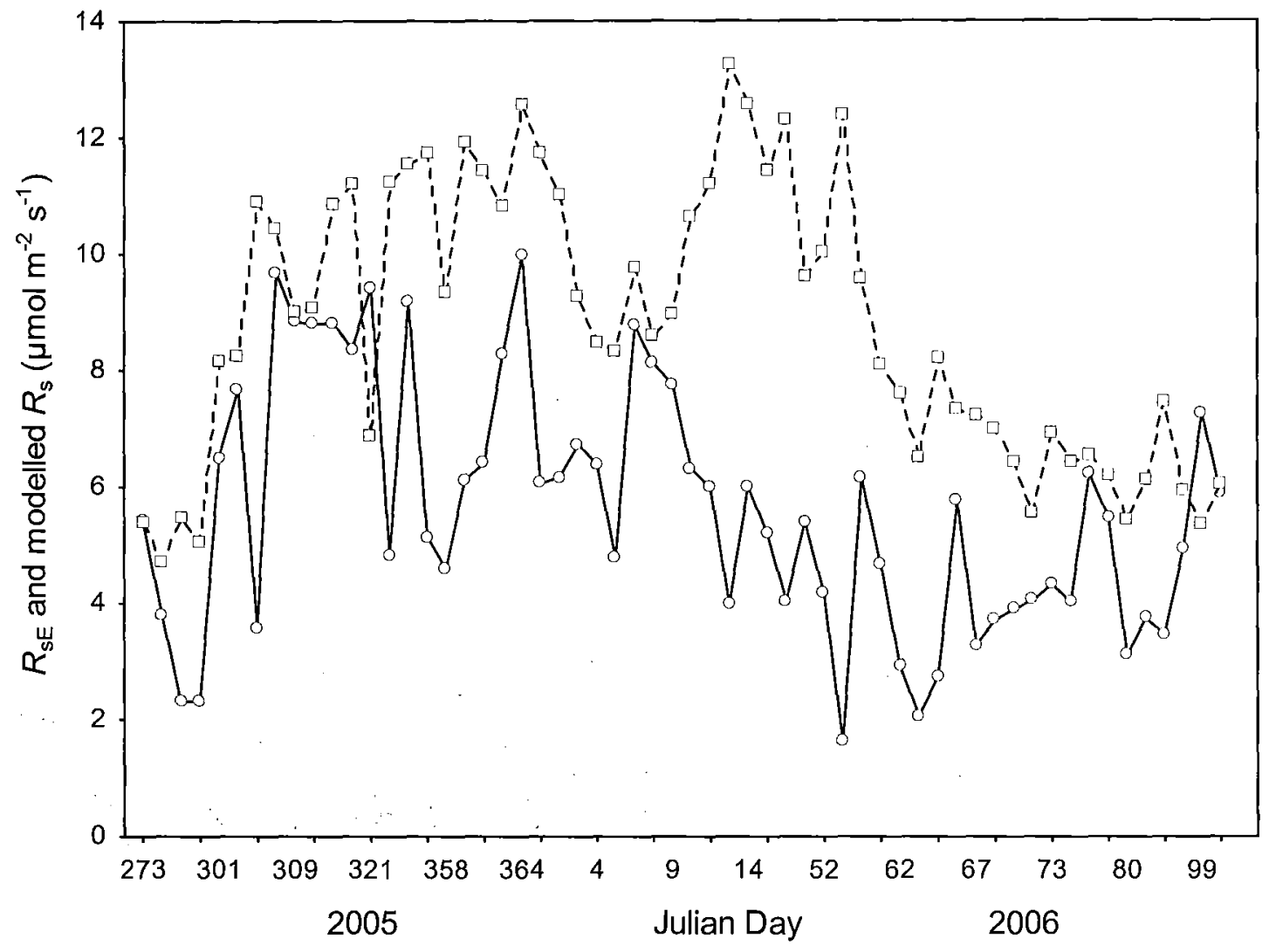

Figure 3-5 Eddy covariance soil-surface respiration $\left(R_{\mathrm{SE}}\right)$ (solid line) and modelled soil-surface respiration $\left(R_{\mathrm{s}}\right)$ (dashed line) over the measurement period. $r^{2}=0.1481$.

Table 3-4 Total eddy covariance soil-surface respiration $\left(R_{\mathrm{SE}}\right)$ and estimates using the chamber based model of $R_{\mathrm{s}}$ for the 58 nights of valid measurements.
$\boldsymbol{R}_{\mathrm{SE}}$
Modelled $\boldsymbol{R}_{\mathrm{s}}$

\begin{tabular}{llll}
\hline$\left(\mathrm{mol} \mathrm{m}^{-2}\right)$ & $\left(\mathrm{kg} \mathrm{C} \mathrm{m}^{-2}\right)$ & $\left(\mathrm{mol} \mathrm{m}^{-2}\right)$ & $\left(\mathrm{kg} \mathrm{C} \mathrm{m}^{-2}\right)$ \\
28 & 0.34 & 44 & 0.53
\end{tabular}




\subsubsection{Estimating total growing season soil-surface respiration at the field site}

The continuous field site measurements of $T_{\mathrm{s}}$ and $\theta_{\mathrm{n}}$ and the model of $R_{\mathrm{s}}$ developed in Chapter 2 were used to estimate total growing season $R_{\mathrm{S}}$ (12 August 2005 to 28 April 2006 (Fig. 3-6) (see appendix). There was a 10 day data gap from day $259-268$ due to instrumentation malfunction. The model, averaged over $24 \mathrm{~h}$ periods, ranged from a high of $13.29 \mu \mathrm{mol} \mathrm{m}^{-2} \mathrm{~s}^{-1}$ in December to a low of $2.98 \mu \mathrm{mol} \mathrm{m}^{-2} \mathrm{~s}^{-1}$ in August. Total growing season $R_{\mathrm{s}}$ is estimated to be $162 \mathrm{~mol} \mathrm{~m}^{-2}\left(1.94 \mathrm{~kg} \mathrm{C} \mathrm{m}^{-2}\right)$ for the 249 day measurement period.

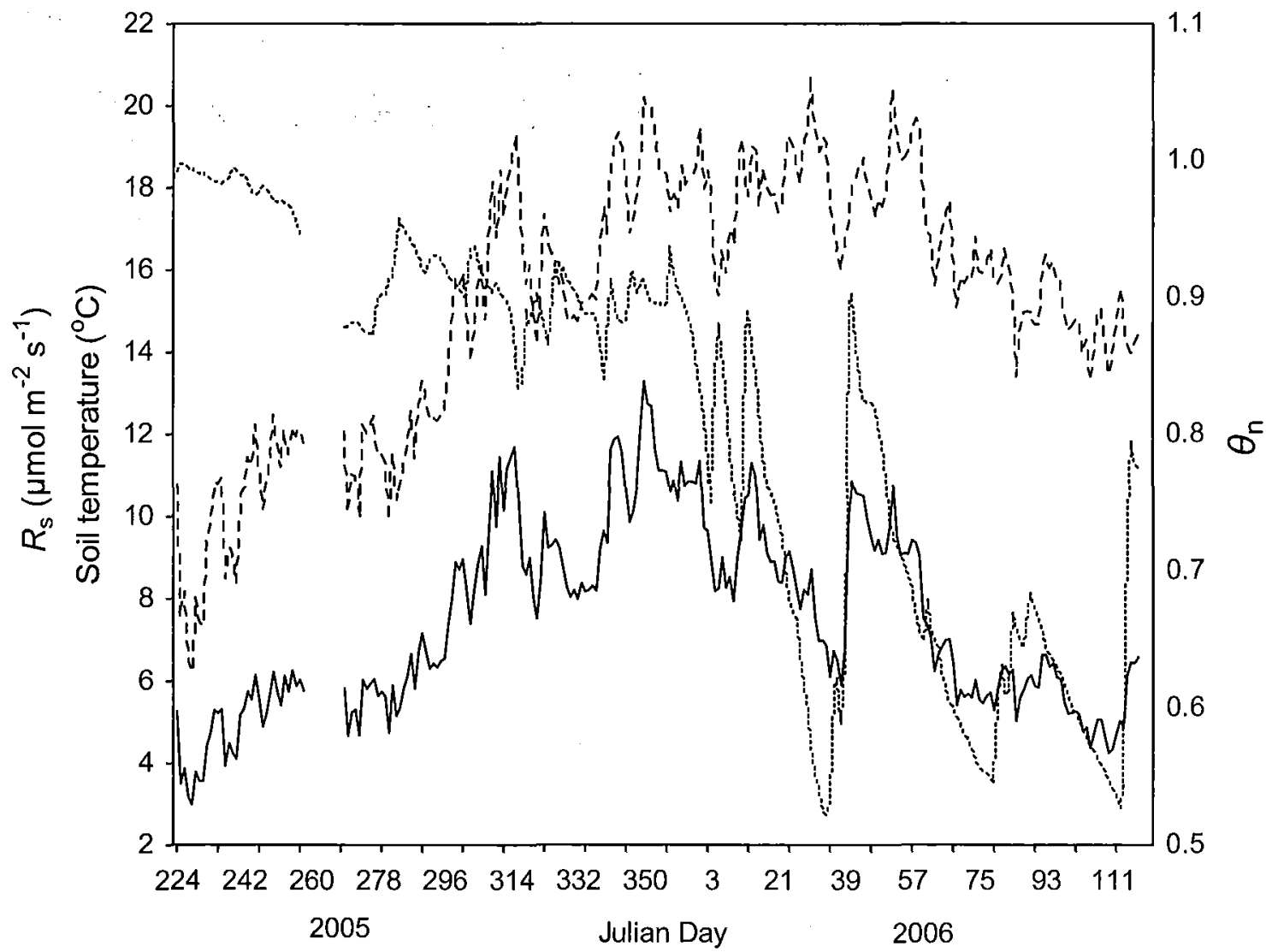

Figure 3-6 Growing season soil temperature $\left({ }^{\circ} \mathrm{C}\right.$ ) at $50 \mathrm{~mm}$ (dashed line) and modelled soil-surface respiration (black line) on the left axis, and normalised rootzone water content $\left(\theta_{n}\right)$ (dotted line) on the right axis. The gap in the data from days $259-268$ is due to equipment malfunction. 


\subsection{Discussion}

\subsubsection{Partitioning sources of respiration}

Soil-surface respiration was the dominant contributor $(84 \%)$ to $R_{\mathrm{e}}$ in this temperate pasture ecosystem. The $16 \%$ of ecosystem respiration not attributed to $R_{\mathrm{s}}$ was attributed to the respiration of above-ground grasses $\left(R_{\mathrm{aa}}\right)$. The small $4 \%$ difference between the contribution of soil-surface respiration with the grass clipped to $20 \mathrm{~mm}$ above the soil surface $\left(R_{\mathrm{s}}\right)$ and soil-surface respiration with the grass clipped right to the soil-surface $\left(R_{\mathrm{SG}}\right)$ provides support to the technique of clipping the grass to $20 \mathrm{~mm}$ above the soilsurface (used in chapter 2 ) to attain a robust measurement of soil-surface respiration.

It is possible that the contribution of $R_{\mathrm{s}}$ to $R_{\mathrm{e}}$ varies throughout the year, as $R_{\mathrm{aa}}$ and $R_{\mathrm{s}}$ could respond differently to variations in $T_{\mathrm{s}}$ and $\theta_{\mathrm{n}}$ (Davidson et al. 2006b). However, the limited data sets obtained in this study were not able to answer this question. In a study in a mountain meadow in the Austrian Alps, which used the eddy covariance technique to measure $R_{\mathrm{e}}$ and a respiration chamber to measure $R_{\mathrm{s}}$, Wohlfahrt et al. (2005) reported that the contribution of $R_{\mathrm{s}}$ to $R_{\mathrm{e}}$ varied from $100 \%$ in the winter, when above-ground grasses were absent, to $40 \%$ in mid - summer. In this study, $T_{\mathrm{s}}$ rarely fell below $10^{\circ} \mathrm{C}$ and above-ground vegetation was always present and green, so such a dramatic change in the contribution of $R_{\mathrm{s}}$ to $R_{\mathrm{e}}$ would not be expected. Risch and Frank (2006) used respiration chambers to measure $R_{\mathrm{s}}$ and $R_{\mathrm{e}}$ at grazed and ungrazed sites in a temperate grassland in Yellowstone National Park, USA, and found that the contribution of $R_{\mathrm{s}}$ to $R_{\mathrm{e}}$ ranged from 50 to $77 \%$ during the growing season (May - September). Risch and Frank (2006) found that $R_{\mathrm{s}}$ did not vary much throughout the growing season, with the exception of May when all $\mathrm{CO}_{2}$ exchange rates were low (likely due to an undeveloped canopy), but $R_{\mathrm{e}}$ generally followed seasonal changes in $L$.

In this study, the finding that the contribution of $R_{\mathrm{s}}$ to $R_{\mathrm{e}}$ amongst the nine replicates was significantly related to $L$ was expected. As $L$ increased, the contribution of $R_{\mathrm{s}}$ to $R_{\mathrm{e}}$ also increased, indicating that $R_{\mathrm{s}}$ responded to changes in above-ground leaf area. This occurs because evidence suggests that below-ground autotrophic respiration (roots) is partially dependent on plant growth and development, photosynthesis and carbon allocation patterns (Flanagan and Johnson 2005). The heterotrophic respiration 
component of $R_{\mathrm{s}}$ is also partially dependent on the supply and quality of respiratory substrate provided by plants, particularly plant roots (Raich and Schlesinger 1992; Wan and Luo 2003). Thus, both $R_{\mathrm{ab}}$ and $R_{\mathrm{h}}$ decrease as $L$ decreases, resulting in a reduced contribution of $R_{\mathrm{s}}$ to total $R_{\mathrm{e}}$.

\subsubsection{Measured and modelled soil-surface respiration}

The soil-surface respiration model developed in Chapter 2, consistently estimated higher rates of $R_{\mathrm{S}}$ than $R_{\mathrm{SE}}$ measurements (Fig. 3-5). Other studies have also reported higher chamber-based estimates of respiration when compared to eddy covariance measurements (e.g. Law et al. 2001; Law et al. 1999a; Law et al. 1999b; Lavigne et al. 1997; Goulden et al. 1996). However, there is a dearth of such studies in grazed pasture systems. In a ponderosa pine forest in Oregon, USA, Law et al. (1999b), reported that eddy covariance measurements of $R_{\mathrm{e}}$ were $50 \%$ lower than chamber based models of $R_{\mathrm{e}}$ (the sum of chamber based models of $R_{\mathrm{s}}$, foliage respiration and wood respiration), with weak correlation between the measured eddy covariance respiration and modelled respiration $\left(r^{2}=0.14\right)$. Nocturnal eddy covariance measurements of $R_{\mathrm{e}}$ were on average $23 \%, 35 \%$ and $27 \%$ lower than chamber based estimates in a ponderosa pine forest, a mixed temperate forest and boreal coniferous forests (Law et al. 1999a; Goulden et al. 1996 and Lavigne et al. 1997). There was however, good agreement between eddy covariance and chamber based respiration measurements in a different ponderosa pine forest study by Law et al. (2001).

Two factors can often lead to eddy covariance measurements underestimating nocturnal respiration. One factor is low wind conditions during the nightime (Law et al. 2000a), which we attempted to avoid by only including for analysis nocturnal fluxes which occurred under relatively turbulent conditions $\left(u^{*}>0.3 \mathrm{~m} \mathrm{~s}^{-1}\right)$. The second is a possible systematic bias error due to the lack of an energy balance closure often observed in eddy covariance studies (Baldocchi 2003), i.e. the sum of latent and sensible heat measured with the eddy covariance technique often does not match independent measurements of energy available. Baldocchi (2003) notes that since tests of surface energy balance closure at some sites are $10-30 \%$ too small to close the surface energy budget, it is possible that $\mathrm{CO}_{2}$ exchange measurements are also 
$10-30 \%$ underestimated. Although this energy balance gap might be due to different eddy covariance and independent energy measurement footprints (Wilson et al. 2002), it is a possible explanation for at least some of the difference between the modelled $R_{\mathrm{s}}$ and $R_{\mathrm{SE}}$ values observed in this study. Law et al. (2000b) noted that due to the lack of agreement between chamber and eddy covariance respiration measurements, estimates of respiration with either technique remain uncertain.

Moncrieff et al (1996) demonstrated that the overall sampling error over a year long eddy covariance dataset is $\pm 1.2 \mathrm{~mol} \mathrm{~m}^{-2} \mathrm{y}^{-1}\left(53 \mathrm{~g} \mathrm{C} \mathrm{m}^{-2} \mathrm{y}^{-1}\right)$. Thus, the method of Moncrieff et al. (1996) was used to estimate the random error for the total estimate of $R_{S E}$ in this current study. This error was extremely small $(0.002 \%)$ in relation to the total estimate of $R_{S E}$.

In this study, the effect of Lon $R_{\mathrm{SE}}$ was not able to be determined, as there was too much overlap in the standard errors of the weekly average rates of $R_{\mathrm{SE}}$ (from nights of valid measurements occurring within a week of biomass collection for $L$ measurements), and $L$ measurements (Fig. 3-4). It would be expected that $R_{\mathrm{s}}$ would be partially dependent on $L$, for reasons stated in section 3.4.1 (i.e. both below ground autotrophic and heterotrophic respiration being depending on plant $\mathrm{C}$ allocation below ground).

\subsubsection{Estimating total growing season soil-surface respiration}

The total growing-season soil-surface respiration estimate of $1.95 \mathrm{~kg} \mathrm{C} \mathrm{m}^{-2}$ for this site is relatively high compared to other studies conducted in various types of grasslands. For instance, Bolstad and Vose (2005) estimated total annual $R_{\mathrm{s}}$ to be $1.09 \mathrm{~kg} \mathrm{C} \mathrm{m}^{-2} \mathrm{y}^{-1}$ at pasture sites with an average annual soil temperature of $13^{\circ} \mathrm{C}$, in the Appalachian Mountains, USA. Total growing season and annual $R_{\mathrm{s}}$ was reported to be 0.39 and 0.53 $\mathrm{kg} \mathrm{C} \mathrm{m}{ }^{-2}$ in a semi-arid grassland in Colorado, USA (Pendall et al. 2003), and Chen et al. (2003) reported total annual $R_{\mathrm{s}}$ to be $1.43 \mathrm{~kg} \mathrm{C} \mathrm{m}^{-2}$ in a northern Australian tropical savanna. These studies were done in ecosystems that experienced cold, freezing winters or in semi-arid environments, which differ considerably from this temperate, intensively managed pasture, with mild winters and evenly distributed seasonal rainfall. 
In a study conducted in a more similar environment, Byrne et al. (2005) estimated total annual $R_{\Theta}$ in new and permanent temperate grasslands in southern Ireland to be 2.0 and $2.52 \mathrm{~kg} \mathrm{C} \mathrm{m}^{-2}$, and total growing season $R_{\mathrm{e}}$ (May - September) to be 1.17 and $1.5 \mathrm{~kg} \mathrm{C} \mathrm{m}^{-2}$, which although estimated for the total ecosystem respiration, are closer to values estimated in this study. In a New Zealand grazed pasture, Nieveen et al. (2005) calculated total annual $R_{\mathrm{e}}$ to be $1.35 \mathrm{~kg} \mathrm{C} \mathrm{m}^{-2}$, although that pasture was over a drained peat soil (bulk density of $335 \mathrm{~kg} \mathrm{~m}^{-3}$ ), which is much less than the value for the soil found at this site (average bulk density $682 \mathrm{~kg} \mathrm{~m}^{-3}$ ).

The high growing season $R_{\mathrm{s}}$ in this study was probably due to the large number of days included in the growing season (249 days) and the non-limiting root-zone water content conditions which persisted at this site throughout much of the growing season. Prolonged droughts, which might act to limit $R_{\mathrm{s}}$ were also absent during the measurement period as rainfall was well distributed. As a result, at this site, $R_{\mathrm{s}}$ is largely a function of $T_{\mathrm{s}}$.

\subsubsection{Conclusions}

The partitioning exercise was able to determine the relative contribution of $R_{\mathrm{s}}$ to $R_{\mathrm{e}}$ successfully. This enabled nocturnal eddy covariance measurements of total ecosystem respiration $\left(R_{\mathrm{SE}}\right)$ to be partitioned into $R_{\mathrm{aa}}$ and $R_{\mathrm{s}}$ components. When compared against values of $R_{\mathrm{s}}$ estimated by the model developed in Chapter 2, $R_{\mathrm{SE}}$ values were consistently lower, but generally followed the same pattern. It is not known whether the $R_{\mathrm{SE}}$ values were underestimates or the modelled $R_{\mathrm{S}}$ values were overestimates of soilsurface respiration, but other studies have shown that eddy covariance measurements of respiration often underestimate respiration compared to chamber-based models. The soil-surface respiration model was successful in estimating total-growing season respiration at this pastoral site $\left(1.95 \mathrm{~kg} \mathrm{C} \mathrm{m}^{-2}\right)$, which was of a similar magnitude compared to seasonal and annual respiration estimates reported in other grassland studies. 


\section{Conclusions and future work}

\subsection{Conclusions}

Previous studies have shown that soil-surface respiration is primarily regulated by soil temperature $\left(T_{\mathrm{s}}\right)$ and root-zone water content $(\theta)$. However, relatively few studies have investigated how these two environmental variables regulate $R_{\mathrm{s}}$ in temperate grazed pastures. This thesis addressed this data-gap by investigating the regulation of $R_{\mathrm{s}}$ by either $T_{\mathrm{s}}$ or $\theta$ in a temperate grazed pasture in New Zealand. This investigation was able to achieve the objectives of this thesis, as follows,

\section{- Objective 1 Quantify rates of $R_{s}$ in a New Zealand grazed pasture}

Field rates of soil-surface respiration were successfully quantified using a variety of techniques, including field chamber measurements, laboratory chamber measurements, and partitioned nocturnal eddy covariance measurements. The soilsurface respiration rate $\left(R_{\mathrm{s}}\right)$ at $10^{\circ} \mathrm{C}$, measured in the field using a respiration chamber, was $4.7 \mu \mathrm{mol} \mathrm{m} \mathrm{m}^{-2} \mathrm{~s}^{-1}$. This was higher than reported by the very small number of other studies that have examined temperate pasture systems, probably due to the favourably long growing season at the field site.

- Objective 2 Measure seasonal variation in $R_{s}$ in relation to $T_{s}$ and $\theta$ The laboratory exercise was able to determine the individual influence of either soil temperature or root-zone water content on $R_{\mathrm{s}}$ in this pasture ecosystem. An Arrhenius-type function described the influence of $T_{\mathrm{s}}$ on $R_{\mathrm{s}}$, while a linear function described the influence of $\theta$. The value of $\theta_{\mathrm{c}}$ determined that $\theta$ had a limiting effect on $R_{\mathrm{s}}$ up until a normalised root-zone water content $\left(\theta_{n}\right)$ of 0.90 , after which point a further increase in $\theta_{n}$ no longer influenced $R_{\mathrm{s}}$. This is the first time the effects of soil temperature and root-zone water content on $R_{\mathrm{s}}$ have been reported for an intensively grazed pasture in New Zealand. 
- Objective 3 Model $R_{s}$ and validate modelled rates of respiration against field measurements

Using measurements of soil-surface respiration, soil temperature and normalised root-zone water content made in the laboratory exercise, and equations 2.5 and 2.6 , a model of $R_{\mathrm{s}}$ was constructed. To run the model, the $R_{10}$ parameter was established by using an average of field measurements of $R_{\mathrm{s}}$ made around $10^{\circ} \mathrm{C}$. A good fit was achieved between the model and the laboratory data (Fig. 2-1).

When validated against field chamber measurements of $R_{\mathrm{s}}$, the model of $R_{\mathrm{s}}$ was successfully able to predict changes in $R_{\mathrm{s}}$ based on changes in $T_{\mathrm{s}}$ and $\theta_{\mathrm{n}}$ (Fig. 2-4). Differences between modelled and measured $R_{\mathrm{s}}$ generally occurred when $\theta_{\mathrm{n}}$ began to decline to values less than $0.90\left(\theta_{c}\right)$. At these values of normalised root-zone water content the model applied a $\theta$ limitation effect, however in the field, the $\theta$ limitation was not as apparent. This may have been due to grass roots compensating for low soilsurface water content by accessing water from deeper down the soil profile.

In order to validate the model of $R_{\mathrm{s}}$ against nocturnal eddy covariance measurements of respiration, a partitioning exercise was conducted. The partitioning exercise determined the contribution of $R_{\mathrm{s}}$ to $R_{\mathrm{e}}$ was $84 \%$. This exercise also confirmed that measuring $R_{\mathrm{s}}$ with the grass clipped to $20 \mathrm{~mm}$ above the soil-surface, as conducted in the laboratory exercise and in the field, adequately removed $R_{\mathrm{aa}}$ from the $R_{\mathrm{s}}$ measurement.

Nocturnal eddy covariance soil-surface respiration $\left(R_{\mathrm{SE}}\right)$ measurements were consistently less than modelled rates of $R_{\mathrm{s}}$. It is not known why this was the case. It is possible the lack of energy balance closure often observed in eddy covariance studies (Baldocchi 2003) led to an underestimation of $R_{\mathrm{SE}}$ (see section 3.4.2).

- Objective 4 Estimate total growing-season $R_{s}$

By using the model of $R_{\mathrm{s}}$ and continuous field measurements of $T_{\mathrm{s}}$ and $\theta$, this investigation was able to estimate a total growing season $R_{\mathrm{s}}$ of $1.94 \mathrm{~kg} \mathrm{C} \mathrm{m}^{-2}$. 


\subsection{Future work}

Based on the results from this thesis there is clearly a need for more extensive research to be undertaken on the regulation of $R_{\mathrm{s}}$ in this ecosystem. Since all field measurements were conducted over just a single growing season, there were certain limitations to this investigation. For instance, the $\mathrm{CO}_{2}$ exchange partitioning exercise was only performed during the spring/summer period. However, the contribution of $R_{\mathrm{s}}$ to $R_{\mathrm{e}}$ could vary throughout the year, as found in other studies (e.g. Davidson et al. 2006b), thus it would be useful to perform the partitioning exercise seasonally.

Throughout the field measurement period, root-zone water content conditions were relatively wet, which meant that the model of $R_{\mathrm{s}}$ could not be fully tested over a wide range of wet to dry soil conditions. Performing this study over multiple growing seasons, might allow the model to be more fully tested over a broader range of environmental conditions, including drought, which might not occur annually in this pasture.

A variety of techniques was used to measure and model $R_{\mathrm{s}}$ in this study. The laboratory exercise provided a very successful means of determining how soil temperature and root-zone water content regulate $R_{\mathrm{s}}$ across a broad range of $T_{\mathrm{s}}$ and $\theta$. This would be highly difficult to replicate in the field, where other factors, such as variations in radiation, vegetation development and precipitation (Risch and Frank 2006; Trumbore 2006: Salimon et al. 2004), which can be kept relatively constant in a growth cabinet, could confound the individual influences of $T_{\mathrm{s}}$ and $\theta$. Also, during the growing season that this study was conducted over, the ranges of $T_{\mathrm{s}}$ and $\theta$ were much narrower than the ranges allowed for in the laboratory exercise.

The eddy covariance technique has an advantage over respiration chambers of being able to measure $\mathrm{CO}_{2}$ exchange continuously at the ecosystem level (Hutley et al. 2005). Thus, nocturnal eddy covariance measurements of ecosystem respiration incorporate spatial variations in respiration throughout the field site, not necessarily captured with chamber measurements. Nocturnal eddy covariance respiration rates were lower than modelled rates of $R_{\mathrm{s}}$, which were based on laboratory measurements, 
but generally followed changes in $T_{\mathrm{s}}$ and $\theta$. It would be useful to examine the differences between eddy covariance respiration measurements and chamber based modelled rates of $R_{\mathrm{s}}$. For instance, chamber measurements of $R_{\mathrm{s}}$ could be made nocturnally, thus allowing measurements to be directly comparable to eddy covariance nighttime values.

Soil-surface respiration was measured after removing above-ground autotrophic respiration by clipping the grass to $20 \mathrm{~mm}$ above the soil surface, both in the field and in the laboratory. This level was chosen because if clipped any shorter, the grass might have died. It is not known how this clipping might have influenced $R_{\mathrm{s}}$, although previous studies by Wan and Luo (2003) and Bremer et al. (1998) showed that clipping significantly reduced rates of $R_{\mathrm{s}}$ (see section 2.2.3). Also, the specific effects of grazing on $R_{\mathrm{s}}$ in the field site were not able to be determined, although the partitioning exercise demonstrated that as leaf area index $(L)$ increased, the contribution of $R_{\mathrm{s}}$ to $R_{\mathrm{e}}$ also increased. Future work, which involved the measuring of $R_{\mathrm{s}}$ immediately before, and after grazing or clipping events, might more clearly indicate the effects of grazing, above-ground biomass and $L$ have on $R_{\mathrm{s}}$.

In this thesis, the regulation of total $R_{\mathrm{s}}$ by $T_{\mathrm{s}}$ and $\theta$ in a temperate pasture was determined. However, it is possible that below-ground autotrophic respiration $\left(R_{\mathrm{ab}}\right)$ and heterotrophic respiration $\left(R_{\mathrm{h}}\right)$ respond differently to changes in $T_{\mathrm{s}}$ and $\theta$. A more extensive investigation could determine the individual responses of $R_{\mathrm{ab}}$ and $R_{\mathrm{h}}$ to $T_{\mathrm{s}}$ and $\theta$. Such an investigation requires additional techniques and tools, such as stable isotopes, to enable $R_{\mathrm{s}}$ to be partitioned into below-ground autotrophic and heterotrophic components (Yakir and Sternberg 2000). 


\section{References}

Melillo
Aber, J. D. \& J. M!
Publishing. ${ }^{\circ} \cdot(1991)$. Terrestrial Ecosystems. Philadelphia, Saunders College

Anthoni, P. M., M. H. Unsworth, B. E. Law, J. Irvine, D. D. Baldocchi, S. Van Tuyl and D. Moore (2002). "Seasonal differences in carbon and water vapor exchange in young and old-growth ponderosa pine ecosystems." Agricultural and Forest Meteorology 111(3): 203-222.

Aubinet, M., A. Grelle, A. Ibrom, U. Rannik, J. Moncrieff, T. Foken, A. S. Kowalski, P. H. Martin, P. Berbigier, C. Bernhofer, R. Clement, J. Elbers, A. Granier, T. Grunwald, K. Morgenstern, K. Pilegaard, C. Rebmann, W. Snijders, R. Valentini and T. Vesala (2000). Estimates of the annual net carbon and water exchange of forests: The EUROFLUX methodology. Advances in Ecological Research, Vol 30. 30: 113-175.

Baldocchi, D., E. Falge, L. Gu, R. Olson, D. Hollinger, S. Running, P. Anthoni, C. Bernhofer, K. Davis, R. Evans, J. Fuentes, A. Goldstein, G. Katul, B. Law, X. Lee, Y. Malhi, T. Meyers, W. Munger, W. Oechel, U. K. T. Paw, K. Pilegaard, H. P. Schmid, R. Valentini, S. Verma, T. Vesala, K. Wilson and S. Wofsy (2001). "FLUXNET: A New Tool to Study the Temporal and Spatial Variability of Ecosystem-Scale Carbon Dioxide, Water Vapor, and Energy Flux Densities." Bulletin of the American Meteorological Society 82(11): 2415-2434.

Baldocchi, D. D. (2003). "Assessing the eddy covariance technique for evaluating carbon dioxide exchange rates of ecosystems: Past, present and future." Global Change Biology 9(4): 479-492.

Bolstad, P. V. and J. M. Vose (2005). "Forest and pasture carbon pools and soil respiration in the southern Appalachian Mountains." Forest Science 51(4): 372383.

Borken, W., K. Savage, E. A. Davidson and S. E. Trumbore (2006). "Effects of experimental drought on soil respiration and radiocarbon efflux from a temperate forest soil." Global Change Biology 12(2): 177-193.

Bremer, D. J., J. M. Ham, C. E. Owensby and A. K. Knapp (1998). "Responses of soil respiration to clipping and grazing in a tallgrass prairie." Journal of Environmental Quality 27(6): 1539-1548.

Byrne, K. A., G. Kiely and P. Leahy (2005). " $\mathrm{CO}_{2}$ fluxes in adjacent new and permanent temperate grasslands." Agricultural and Forest Meteorology 135(1-4): 82-92.

Chambers, J. Q., E. S. Tribuzy, L. C. Toledo, B. F. Crispim, N. Higuchi, J. dos Santos, A. C. Araujo, B. Kruijt, A. D. Nobre and S. E. Trumbore (2004). "Respiration from a 
tropical forest ecosystem: Partitioning of sources and low carbon use efficiency." Ecological Applications 14(4): S72-S88.

Chapin, S., Mooney HA, Matson PA (2002). Principles of terrestrial ecosystem ecology. NY, Springer-Verlag.

Chen, X. Y., D. Eamus and L. B. Hutley (2002). "Seasonal patterns of soil carbon dioxide efflux from a wet-dry tropical savanna of northern Australia (vol 50, pg 43, 2002)." Australian Journal of Botany 50(3): 373-U20.

Chen, X. Y., L. B. Hutley and D. Eamus (2003). "Carbon balance of a tropical savanna of northern Australia." Oecologia 137(3): 405-416.

Clough, T. J., R. R. Sherlock and F. M. Kelliher (2003). "Can liming mitigate $\mathrm{N}_{2} \mathrm{O}$ fluxes from a urine-amended soil?" Australian Journal of Soil Research 41(3): 439-457.

Conant, R. T., P. Dalla-Betta, C. C. Klopatek and J. A. Klopatek (2004). "Controls on soil respiration in semiarid soils." Soil Biology \& Biochemistry 36(6): 945-951.

Cramer, W., Bondeau A, Woodward I, Prentice C, Betts RA, Brovkin V, Cox P, Fisher V, Foley JA, Friend AD, Kucharik; Lomas MR, Ramankutty N, Sitch S, Smith B, White A, Young-Molling C (2001). "Global response of terrestrial ecosystem structure and function to $\mathrm{CO}_{2}$ and climate change: results from six dynamic global vegetation models." Global Change Biology 7: 357-373.

Crider, F. J. (1955). Root growth stopage resulting from defoliation of grass. Technical Bulletin Number 1102, U.S. Department of Agriculture.

Davidson, E. A., E. Belk and R. D. Boone (1998). "Soil water content and temperature as independent or confounded factors controlling soil respiration in a temperate mixed hardwood forest." Global Change Biology 4(2): 217-227.

Davidson, E. A., F. Y. Ishida and D. C. Nepstad (2004). "Effects of an experimental drought on soil emissions of carbon dioxide, methane, nitrous oxide, and nitric oxide in a moist tropical forest." Global Change Biology 10(5): 718-730.

Davidson, E. A. and I. A. Janssens (2006). "Temperature sensitivity of soil carbon decomposition and feedbacks to climate change." Nature 440(7081): 165-173.

Davidson, E. A., I. A. Janssens and Y. Lou (2006a). "On the variability of respiration in terrestrial ecosystems: Moving beyond $Q_{10}$." Global Change Biology 12(2): 154164.

Davidson, E. A., A. D. Richardson, K. E. Savage and D. Y. Hollinger (2006b). "A distinct seasonal pattern of the ratio of soil respiration to total ecosystem respiration in a spruce-dominated forest." Global Change Biology 12(2): 230-239.

Davidson, E. A., L. V. Verchot, J. H. Cattanio, I. L. Ackerman and J. E. M. Carvalho (2000). "Effects of soil water content on soil respiration in forests and cattle 
pastures of eastern Amazonia." Biogeochemistry 48(1): 53-69.

Fang, C. and J. B. Moncrieff (2001). "The dependence of soil $\mathrm{CO}_{2}$ efflux on temperature." Soil Biology \& Biochemistry 33(2): 155-165.

Flanagan, L. B. and B. G. Johnson (2005). "Interacting effects of temperature, soil moisture and plant biomass production on ecosystem respiration in a northern temperate grassland." Agricultural and Forest Meteorology 130(3-4): 237-253.

Franzluebbers, K., A. J. Franzluebbers and M. D. Jawson (2002). "Environmental controls on soil and whole-ecosystem respiration from a tallgrass prairie." Soil Science Society of America Journal 66(1): 254-262.

Garcia, F. O. (1992). Carbon and nitrogen dynamics and microbial ecology in tallgrass prairie. Dissertation. Manhattan, Kansas, USA, Kansas State University.

Goulden, M. L., J. W. Munger, S. M. Fan; B. C. Daube and S. C. Wofsy (1996). "Measurements of carbon sequestration by long-term eddy covariance: Methods and a critical evaluation of accuracy." Global Change Biology 2(3): 169-182.

Grace, J. (2004). "Understanding and managing the global carbon cycle." Journal of Ecology 92(2): 189-202.

Grace, J. and M. Rayment (2000). "Respiration in the balance." Nature 404(6780): 819820.

Hansen, J. E. (2005). "A slippery slope: How much global warming constitutes "dangerous anthropogenic interference"?" Climatic Change 68(3): 269-279.

Hanson, P. J., N. T. Edwards, C. T. Garten and J. A. Andrews (2000). "Separating root and soil microbial contributions to soil respiration: A review of methods and observations." Biogeochemistry 48(1): 115-146.

Hewitt, A. E., Ed. (1998). New Zealand Soil Classification. Landcare Research Science Series No. 1. Lincoln, NZ, Manaaki Whenua Press.

Houghton, J. (2004). Global Warming: The Complete Briefing. Cambridge, UK, Cambridge University Press.

Houghton, J. T., Ding,Y., Griggs, D. J., Noguer, and v. d. L. M., P. J., Dai, X., Maskell, K., and Johnson, C. A. (2001). Intergovernmental Panel on Climate Change: 2001. Climate Change 2001:The Scientific Basis. Cambridge, U.K., Cambridge University Press.

Houghton, R. A. (2003). The contemporary carbon cycle. Treatise on Geochemistry. W. H. Schlesinger. Oxford, U.K, Elsevier-Pergamon. Vol. 8: 473-508.

Hunt, J. E., F. M. Kelliher, T. M. McSeveny and J. N. Byers (2002). "Evaporation and carbon dioxide exchange between the atmosphere and a tussock grassland 
during a summer drought." Agricultural and Forest Meteorology 111(1): 65-82.

Hunt, J. E., F. M. Kelliher, T. M. McSeveny, D. J. Ross and D. Whitehead (2004). "Longterm carbon exchange in a sparse, seasonally dry tussock grassland." Global Change Biology 10(10): 1785-1800.

Hutley, L. B., R. Leuning, J. Beringer and H. A. Cleugh (2005). "The utility of the eddy covariance techniques as a tool in carbon accounting: tropical savanna as a case study." Australian Journal of Botany 53(7): 663-675.

Jacobson, M., Charlson RJ, Rodhe H, Orians GH (2000). Earth system science: From biogeochemical cycles to global changes. Sydney, Academic Press.

Jones, M. B. and A. Donnelly (2004). "Carbon sequestration in temperate grassland ecosystems and the influence of management, climate and elevated $\mathrm{CO}_{2}$." $\mathrm{New}$ Phytologist 164(3): 423-439.

Kelliher, F. M., J. R. Sedcole, R. F. Minchin, Y. Wan, L. M. Condron, T. J. Clough and R. Bol (2005). "Soil microbial respiration responses to repeated urea applications in three grasslands." Australian Journal of Soil Research 43(8): 905-913.

Kennedy, D. and B. Hanson (2006). "Ice and history." Science 311(5768): 1673-1673.

Lavigne, M. B., M. G. Ryan, D. E. Anderson, D. D. Baldocchi, P. M. Crill, D. R. Fitzjarrald, M. L. Goulden, S. T. Gower, J. M. Massheder, J. H. McCaughey, M. Rayment and R. G. Striegl (1997). "Comparing nocturnal eddy covariance measurements to estimates of ecosystem respiration made by scaling chamber measurements at six coniferous boreal sites." Journal of Geophysical ResearchAtmospheres 102(D24): 28977-28985.

Law, B. E., D. D. Baldocchi and P. M. Anthoni (1999a). "Below-canopy and soil $\mathrm{CO}_{2}$ fluxes in a ponderosa pine forest." Agricultural and Forest Meteorology 94(3-4): $171-188$.

Law, B. E., M. G. Ryan and P. M. Anthoni (1999b). "Seasonal and annual respiration of a ponderosa pine ecosystem." Global Change Biology 5(2): 169-182.

Law, B. E., P. E. Thornton, J. Irvine, P. M. Anthoni and S. Van Tuyl (2001). "Carbon storage and fluxes in ponderosa pine forests at different developmental stages." Global Change Biology 7(7): 755-777.

Law, B. E., R. H. Waring, P. M. Anthoni and J. D. Aber (2000a). "Measurements of gross and net ecosystem productivity and water vapour exchange of a Pinus ponderosa ecosystem, and an evaluation of two generalized models." Global Change Biology 6(2): 155-168. 
Law, B. E., M. Williams, P. M. Anthoni, D. D. Baldocchi and M. H. Unsworth (2000b). "Measuring and modelling seasonal variation of carbon dioxide and water vapour exchange of a Pinus ponderosa forest subject to soil water deficit." Global Change Biology 6(6): 613-630.

Lecain, D. R., J. A. Morgan, G. E. Schuman, J. D. Reeder and R. H. Hart (2000). "Carbon exchange rates in grazed and ungrazed pastures of Wyoming." Journal of Range Management 53(2): 199-206.

Lin, L. I - K (1989). "A concordance correlation coefficient to evaluate reproducibility." Biometrics 45: 255-268.

Linn, D. M. and J. W. Doran (1984). "Effect of Water-Filled Pore-Space on CarbonDioxide and Nitrous-Oxide Production in Tilled and Nontilled Soils." Soil Science Society of America Journal 48(6): 1267-1272.

Lloyd, J. and J. A. Taylor (1994). "On the Temperature-Dependence of Soil Respiration." Functional Ecology 8(3): 315-323.

Melillo, J. M., P. A. Steudler, J. D. Aber, K. Newkirk, H. Lux, F. P. Bowles, C. Catricala, A. Magill, T. Ahrens and S. Morrisseau (2002). "Soil warming and carbon-cycle feedbacks to the climate system." Science 298(5601): 2173-2176.

Moncrieff, J. B., Y. Malhi and R. Leuning (1996). "The propagation of errors in long-term measurements of land-atmosphere fluxes of carbon and water." Global Change Biology 2(3): 231-240.

Moncrieff, J. B., J. M. Massheder, H. deBruin, J. Elbers, T. Friborg, B. Heusinkveld, P. Kabat, S. Scott, H. Soegaard and A. Verhoef (1997). "A system to measure surface fluxes of momentum, sensible heat, water vapour and carbon dioxide." Journal of Hydrology 189(1-4): 589-611.

Nieveen, J. P., D. I. Campbell, L. A. Schipper and I. J. Blair (2005). "Carbon exchange of grazed pasture on a drained peat soil." Global Change Biology 11(4): 607-618.

Norby, R. J. and Y. Q. Luo (2004). "Evaluating ecosystem responses to rising atmospheric $\mathrm{CO}_{2}$ and global warming in a multi-factor world." New Phytologist 162(2): 281-293.

Oren, R., D. S. Ellsworth, K. H. Johnsen, N. Phillips, B. E. Ewers, C. Maier, K. V. R. Schafer, H. McCarthy, G. Hendrey, S. G. McNulty and G. G. Katul (2001). "Soil fertility limits carbon sequestration by forest ecosystems in a $\mathrm{CO}_{2}$-enriched atmosphere." Nature 411(6836): 469-472.

Overpeck, J. T., B. L. Otto-Bliesner, G. H. Miller, D. R. Muhs, R. B. Alley and J. T. Kiehl (2006). "Paleoclimatic evidence for future ice-sheet instability and rapid sea-level rise." Science 311(5768): 1747-1750.

Pendall, E., S. Del Grosso, J. Y. King, D. R. LeCain, D. G. Milchunas, J. A. Morgan, A. 
R. Mosier, D. S. Ojima, W. A. Parton, P. P. Tans and J. W. C. White (2003). "Elevated atmospheric $\mathrm{CO}_{2}$ effects and soil water feedbacks on soil respiration components in a Colorado grassland." Global Biogeochemical Cycles 17(2).

Pinheiro, J. C. and D. M. Bates (2000). Mixed-Effects Models in S and S-PLUS. New York, NY, Springer-Verlag.

Powlson, D. (2005). "Climatology - Will soil amplify climate change?" Nature 433(7023): 204-205.

Raich, J. W., C. S. Potter and D. Bhagawati (2002). "Interannual variability in global soil respiration, 1980-94." Global Change Biology 8(8): 800-812.

Raich, J. W. and W. H. Schlesinger (1992). "The Global Carbon-Dioxide Flux in Soil Respiration and Its Relationship to Vegetation and Climate." Tellus Series BChemical and Physical Meteorology 44(2): 81-99.

Rayment, M. B. and P. G. Jarvis (2000). "Temporal and spatial variation of soil $\mathrm{CO}_{2}$ efflux in a Canadian boreal forest." Soil Biology \& Biochemistry 32(1): 35-45.

Reichstein, M., F. Bednorz, G. Broll and T. Kätterer (2000). "Temperature dependence of carbon mineralisation: Conclusions from a long-term incubation of subalpine soil samples." Soil Biology and Biochemistry 32(7): 947-958.

Reichstein, M., A. Rey, A. Freibauer, J. Tenhunen, R. Valentini, J. Banza, P. Casals, Y. F. Cheng, J. M. Grunzweig, J. Irvine, R. Joffre, B. E. Law, D. Loustau, F. Miglietta, W. Oechel, J. M. Ourcival, J. S. Pereira, A. Peressotti, F. Ponti, Y. Qi, S. Rambal, M. Rayment, J. Romanya, F. Rossi, V. Tedeschi, G. Tirone, M. Xu and D. Yakir (2003). "Modeling temporal and large-scale spatial variability of soil respiration from soil water availability, temperature and vegetation productivity indices." Global Biogeochemical Cycles 17(4).

Reichstein, M., J. A. Subke, A. C. Angeli and J. D. Tenhunen (2005). "Does the temperature sensitivity of decomposition of soil organic matter depend upon water content, soil horizon, or incubation time?" Global Change Biology 11(10): $1754-1767$.

Reth, S., M. Reichstein and E. Falge (2005). "The effect of soil water content, soil temperature, soil $\mathrm{pH}$-value and the root mass on soil $\mathrm{CO}_{2}$ efflux - $\mathrm{A}$ modified model." Plant and Soil 268(1): 21-33.

Rey, A., E. Pegoraro, V. Tedeschi, I. De Parri, P. G. Jarvis and R. Valentini (2002). "Annual variation in soil respiration and its components in a coppice oak forest in Central Italy." Global Change Biology 8(9): 851-866.

Risch, A. and D. Frank (2006). "Carbon dioxide fluxes in a spatially and temporally heterogeneous temperate grassland." Oecologia 147(2): 291-302.

Rochette, P., B. Ellert, E. G. Gregorich, R. L. Desjardins, E. Pattey, R. Lessard and B. 
G. Johnson (1997). "Description of a dynamic closed chamber for measuring soil respiration and its comparison with other techniques." Canadian Journal of Soil Science 77(2): 195-203.

Ryan, M. G. and B. E. Law (2005). "Interpreting, measuring, and modeling soil respiration." Biogeochemistry 73(1): 3-27.

Salimon, C. I., E. A. Davidson, R. L. Victoria and A. W. F. Melo (2004). " $\mathrm{CO}_{2}$ flux from soil in pastures and forests in southwestern Amazonia." Global Change Biology 10(5): 833-843.

Schimel, D. S., J. I. House, K. A. Hibbard, P. Bousquet, P. Ciais, P. Peylin, B. H. Braswell, M. J. Apps, D. Baker, A. Bondeau, J. Canadell, G. Churkina, W. Cramer, A. S. Denning, C. B. Field, P. Friedlingstein, C. Goodale, M. Heimann, R. A. Houghton, J. M. Melillo, B. Moore, D. Murdiyarso, I. Noble, S. W. Pacala, I. C. Prentice, M. R. Raupach, P. J. Rayner, R. J. Scholes, W. L. Steffen and C. Wirth (2001). "Recent patterns and mechanisms of carbon exchange by terrestrial ecosystems." Nature 414(6860): 169-172.

Steffen, W., P. Tyson, J. Jager, P. Matson, B. Moore, F. Oldfield, K. Richardson, J. Schellnhuber, B. Turner and R. Wasson (2001). "Earth system science - An integrated approach." Environment 43(8): 21-27.

Tang, J. and D. D. Baldocchi (2005). "Spatial-temporal variation in soil respiration in an oak-grass savanna ecosystem in California and its partitioning into autotrophic and heterotrophic components." Biogeochemistry 73(1): 183-207.

Trotter, C. M., K R Tate, S Saggar, N A Scott, and M A Sutherland (2004). A multi-scale analysis of a national terrestrial carbon budget: Uncertainty reduction and the effects of land-use change. Global Environmental Change in the Ocean and on Land. H. K. M Shiyomi, H. Koizumi, A Tsuda, and Y Awaya. Tokyo, Terrapub: 311-342.

Trumbore, S. (2006). "Carbon respired by terrestrial ecosystems - recent progress and challenges." Global Change Biology 12(2): 141-153.

Verburg, P. S. J., J. Larsen, D. W. Johnson, D. E. Schorran and J. A. Arnone (2005). "Impacts of an anomalously warm year on soil $\mathrm{CO}_{2}$ efflux in experimentally manipulated tallgrass prairie ecosystems." Global Change Biology 11(10): 17201732.

Wan, S. Q. and Y. Q. Luo (2003). "Substrate regulation of soil respiration in a tallgrass prairie: Results of a clipping and shading experiment." Global Biogeochemical Cycles 17(2).

White, A., M. G. R. Cannell and A. D. Friend (2000). " $\mathrm{CO}_{2}$ stabilization, climate change and the terrestrial carbon sink." Global Change Biology 6(7): 817-833. 
Wilson, K. B., D. D. Baldocchi, M. Aubinet, P. Berbigier, C. Bernhofer, H. Dolman, E. Falge, C. Field, A. Goldstein, A. Granier, A. Grelle, T. Halldor, D. Hollinger, G. Katul, B. E. Law, A. Lindroth, T. Meyers, J. Moncrieff, R. Monson, W. Oechel, J. Tenhunen, R. Valentini, S. Verma, T. Vesala and S. Wofsy (2002). "Energy partitioning between latent and sensible heat flux during the warm season at FLUXNET sites." Water Resources Research 38(12).

Wohlfahrt, G., C. Anfang, M. Bahn, A. Haslwanter, C. Newesely, M. Schmitt, M. Drosler, J. Pfadenhauer and A. Cernusca (2005). "Quantifying nighttime ecosystem respiration of a meadow using eddy covariance, chambers and modelling." Agricultural and Forest Meteorology 128(3-4): 141-162.

Xu, L. K., D. D. Baldocchi and J. W. Tang (2004). "How soil moisture, rain pulses, and growth alter the response of ecosystem respiration to temperature." Global Biogeochemical Cycles 18(4).

Yakir, D. and L. D. L. Sternberg (2000). "The use of stable isotopes to study ecosystem gas exchange." Oecologia 123(3): 297-311. 